\title{
Cochrane
}

Library

Cochrane Database of Systematic Reviews

\section{Bupropion for attention deficit hyperactivity disorder (ADHD) in adults (Review)}

Verbeeck W, Bekkering GE, Van den Noortgate W, Kramers C

Verbeeck W, Bekkering GE, Van den Noortgate W, Kramers C.

Bupropion for attention deficit hyperactivity disorder (ADHD) in adults.

Cochrane Database of Systematic Reviews 2017, Issue 10. Art. No.: CD009504.

DOI: 10.1002/14651858.CD009504.pub2.

www.cochranelibrary.com 
TABLE OF CONTENTS

HEADER 1

ABSTRACT

PLAIN LANGUAGE SUMMARY

SUMMARY OF FINDINGS

BACKGROUND

OBJECTIVES

METHODS

RESULTS

Figure 1.

Figure 2.

Figure 3.

Figure 4.

Figure 5.

Figure 6.

DISCUSSION

AUTHORS' CONCLUSIONS

ACKNOWLEDGEMENTS

REFERENCES

CHARACTERISTICS OF STUDIES

DATA AND ANALYSES

Analysis 1.1. Comparison 1 Bupropion versus placebo, Outcome 1 Severity of ADHD (at study completion).

Analysis 1.2. Comparison 1 Bupropion versus placebo, Outcome 2 Achievement of significant clinical improvement (\% participants).

Analysis 1.3. Comparison 1 Bupropion versus placebo, Outcome 3 Clinical Global Impression (CGI) - Improvement scale (\% participants achieving at least one or two on CGI).

Analysis 1.4. Comparison 1 Bupropion versus placebo, Outcome 4 Number of participants withdrawn due to adverse events. .. Analysis 1.5. Comparison 1 Bupropion versus placebo, Outcome 5 Depressive symptoms (change from baseline to study completion).

Analysis 1.6. Comparison 1 Bupropion versus placebo, Outcome 6 Anxiety symptoms (change from baseline to study completion).

Analysis 1.7. Comparison 1 Bupropion versus placebo, Outcome 7 Retention rate (number of patients completing study). ..... Analysis 1.8. Comparison 1 Bupropion versus placebo, Outcome 8 Number of participants that lowered their dose due to adverse events.

Analysis 1.9. Comparison 1 Bupropion versus placebo, Outcome 9 Number of participants with at least one adverse event. .... Analysis 2.1. Comparison 2 Bupropion versus placebo (sensitivity analyses), Outcome 1 Severity of ADHD (at study completion) - clinician rated.

Analysis 2.2. Comparison 2 Bupropion versus placebo (sensitivity analyses), Outcome 2 Severity if ADHD (at study completion) - studies that exclude psychiatric comorbidity.

Analysis 2.3. Comparison 2 Bupropion versus placebo (sensitivity analyses), Outcome 3 Achievement of significant clinical improvement (\% participants) - studies that exclude psychiatric comorbidity.

Analysis 2.4. Comparison 2 Bupropion versus placebo (sensitivity analyses), Outcome 4 CGI - Improvement (\% participants achieving at least one or two on $\mathrm{CGI}$ ) - studies that exclude psychiatric comorbidity.

Analysis 2.5. Comparison 2 Bupropion versus placebo (sensitivity analyses), Outcome 5 Number of participants withdrawn due to adverse events - studies that exclude psychiatric comorbidity.

ADDITIONAL TABLES

APPENDICES

CONTRIBUTIONS OF AUTHORS

DECLARATIONS OF INTEREST

SOURCES OF SUPPORT

DIFFERENCES BETWEEN PROTOCOL AND REVIEW

INDEX TERMS 
[Intervention Review]

\section{Bupropion for attention deficit hyperactivity disorder (ADHD) in adults}

Wim Verbeeck ${ }^{1}$, Geertruida E Bekkering 2 , Wim Van den Noortgate ${ }^{3}$, Cornelis Kramers ${ }^{4}$

${ }^{1}$ Centrum ADHD/ASS, GGZ Vincent van Gogh Instituut Venray, Venray, Netherlands. ${ }^{2}$ Belgian Centre for Evidence-Based Medicine Cochrane Belgium, Leuven, Belgium. ${ }^{3}$ Faculty of Psychology and Educational Sciences, Katholieke Universiteit Leuven, Leuven, Belgium. ${ }^{4}$ Pharmacology - Toxicology, Radbound University Nijmegen Medical Center, Nijmegen, Netherlands

Contact address: Wim Verbeeck, Centrum ADHD/ASS, GGZ Vincent van Gogh Instituut Venray, Noordsingel 39, Venray, 5801 GJ, Netherlands.WVerbeeck@vvgi.nl,shrink65@yahoo.com.

Editorial group: Cochrane Developmental, Psychosocial and Learning Problems Group. Publication status and date: New, published in Issue 10, 2017.

Citation: Verbeeck W, Bekkering GE, Van den Noortgate W, Kramers C. Bupropion for attention deficit hyperactivity disorder (ADHD) in adults. Cochrane Database of Systematic Reviews 2017, Issue 10. Art. No.: CD009504. DOI: 10.1002/14651858.CD009504.pub2.

Copyright @ 2017 The Cochrane Collaboration. Published by John Wiley \& Sons, Ltd.

\section{A B S T R A C T}

\section{Background}

Attention deficit hyperactivity disorder (ADHD) is a prevalent neurobiological condition, characterised by behavioral and cognitive symptoms such as inattention, impulsivity and/or excessive activity. The syndrome is commonly accompanied by psychiatric comorbidities and is associated with educational and occupational underachievement.

Although psychostimulant medications are the mainstay of treatment for ADHD, not all adults respond optimally to, or can tolerate, these medicines. Thus, alternative non-stimulant treatment approaches for ADHD have been explored. One of these alternatives is bupropion, an aminoketone antidepressant and non-competitive antagonism of nicotinic acetylcholine receptors. Bupropion is registered for the treatment of depression and smoking cessation, but is also used off-label to treat ADHD.

\section{Objectives}

To assess the effects and safety of bupropion for the treatment of adults with ADHD.

\section{Search methods}

We searched the Cochrane Central Register of Controlled Trials (CENTRAL), MEDLINE, Embase, and seven other databases in February 2017. We also searched three trials registers and three online theses portals. In addition, we checked references of included studies and contacted study authors to identify potentially relevant studies that were missed by our search.

\section{Selection criteria}

We included all randomised controlled trials (RCTs) that evaluated the effects (including adverse effects) of bupropion compared to placebo in adults with ADHD.

\section{Data collection and analysis}

Two review authors (WV, GB) independently screened records and extracted data using a data extraction sheet that we tested in a pilot study. We extracted all relevant data on study characteristics and results. We assessed risks of bias using the Cochrane 'Risk of bias' tool, and assessed the overall quality of evidence using the GRADE approach. We used a fixed-effect model to pool the results across studies.

\section{Main results}

We included six studies with a total of 438 participants. Five studies were conducted in the USA, and one in Iran. All studies evaluated a long-acting version of bupropion, with the dosage ranging from $150 \mathrm{mg}$ up to $450 \mathrm{mg}$ daily. Study intervention length varied from six to 10 weeks. Four studies explicitly excluded participants with psychiatric comorbidity and one study included only participants with opioid 
dependency. Four studies were funded by industry, but the impact of this on study results is unknown. Two studies were publicly funded and in one of these studies, the lead author was a consultant for several pharmaceutical companies and also received investigator-driven funding from two companies, however none of these companies manufacture bupropion. We judged none of the studies to be free of bias because for most risk of bias domains the study reports failed to provide sufficient details. Using the GRADE approach, we rated the overall quality of evidence as low. We downgraded the quality of the evidence because of serious risk of bias and serious imprecision due to small sample sizes.

We found low-quality evidence that bupropion decreased the severity of ADHD symptoms (standardised mean difference $-0.50,95 \%$ confidence interval $(\mathrm{Cl})-0.86$ to -0.15 , 3 studies, 129 participants), and increased the proportion of participants achieving clinical improvement (risk ratio (RR) $1.50,95 \% \mathrm{Cl} 1.13$ to 1.99 , 4 studies, 315 participants), and reporting an improvement on the Clinical Global Impression - Improvement scale (RR $1.78,95 \% \mathrm{Cl} 1.27$ to $2.50,5$ studies, 337 participants). There was low-quality evidence that the proportion of participants who withdrew due to any adverse effect was similar in the bupropion and placebo groups (RR $1.20,95 \% \mathrm{Cl} 0.35$ to $4.10,3$ studies, 253 participants). The results were very similar when using a random-effects model and when we analysed only studies that excluded participants with a psychiatric comorbidity.

\section{Authors' conclusions}

The findings of this review, which compared bupropion to placebo for adult ADHD, indicate a possible benefit of bupropion. We found low-quality evidence that bupropion decreased the severity of ADHD symptoms and moderately increased the proportion of participants achieving a significant clinical improvement in ADHD symptoms. Furthermore, we found low-quality evidence that the tolerability of bupropion is similar to that of placebo. In the pharmacological treatment of adults with ADHD, extended- or sustained-release bupropion may be an alternative to stimulants. The low-quality evidence indicates uncertainty with respect to the pooled effect estimates. Further research is very likely to change these estimates. More research is needed to reach more definite conclusions as well as clarifying the optimal target population for this medicine. Treatment response remains to be reported in a DSM5-diagnosed population. There is also a lack of knowledge on long-term outcomes.

\section{PLAIN LANGUAGE SUMMARY}

\section{Bupropion for attention deficit hyperactivity disorder (ADHD) in adults}

\section{Review question}

We reviewed the evidence on the effects of the drug bupropion in adults with ADHD. We also reviewed adverse effects (side effects experienced as a result of taking the drug).

\section{Background}

ADHD is a brain disorder marked by an ongoing pattern of inattention, impulsivity and/or excessive activity, which interferes with functioning or development. Some people with ADHD only have problems with one of the behaviors, while others have a combination. Bupropion is a drug that is registered for the treatment of depression and for stopping smoking, but is also used to treat ADHD. People with $A D H D$ are usually prescribed stimulant drugs such as methylphenidate and amphetamines. However, not everyone responds well to stimulants. Some people cannot tolerate stimulants because of side effects. Others have medical conditions such as psychiatric conditions or tic disorders that make it not possible to use stimulants. Other people may not want to use stimulants, as these are controlled substances. Nonstimulants such as bupropion are therefore sometimes used instead. Its effectiveness in treating ADHD is not yet known.

\section{Search date}

The evidence is current to February 2017.

\section{Study characteristics}

We included six randomised controlled trials (RCTs), that is, studies in which participants are randomly allocated to one of two or more treatment groups. Five of the studies took place in the USA, and the sixth in Iran. The studies included 438 people with ADHD. All evaluated a long-acting version of bupropion, that is to say, a version of the drug is absorbed slowly, and can therefore be taken just once a day. This simple dosage suits people with ADHD, as the illness may make it difficult for them to remember to take their medication.

The duration of the studies varied between six and 10 weeks. All participants were diagnosed with ADHD, and often had other mental health problems. In one study, all participants had ADHD and were addicted to opioids (a drug that relieves pain).

\section{Study funding sources}

Four studies were funded by industry and two studies were publicly funded. In one of the publicly-funded studies, the lead author was paid by industry (although not by the manufacturers of buproprion) for research activities.

\section{Key results}


Bupropion may lead to a small improvement in ADHD and it may also decrease symptoms related to ADHD. The drug does not have more adverse effects than treatment with placebo. Bupropion may be an alternative treatment for adults with ADHD who cannot or will not take stimulant drugs.

\section{Quality of the evidence}

The quality of the evidence in this review is low, because we found very few studies; five of the six studies were small, and all were poorly conducted. The effect of bupropion on various aspects of daily functioning was not investigated. Also, no studies assessed the long-term effects of this drug. Further studies are needed, to assess whether bupropion is effective in specific ADHD subgroups or in people who have additional disorders. 


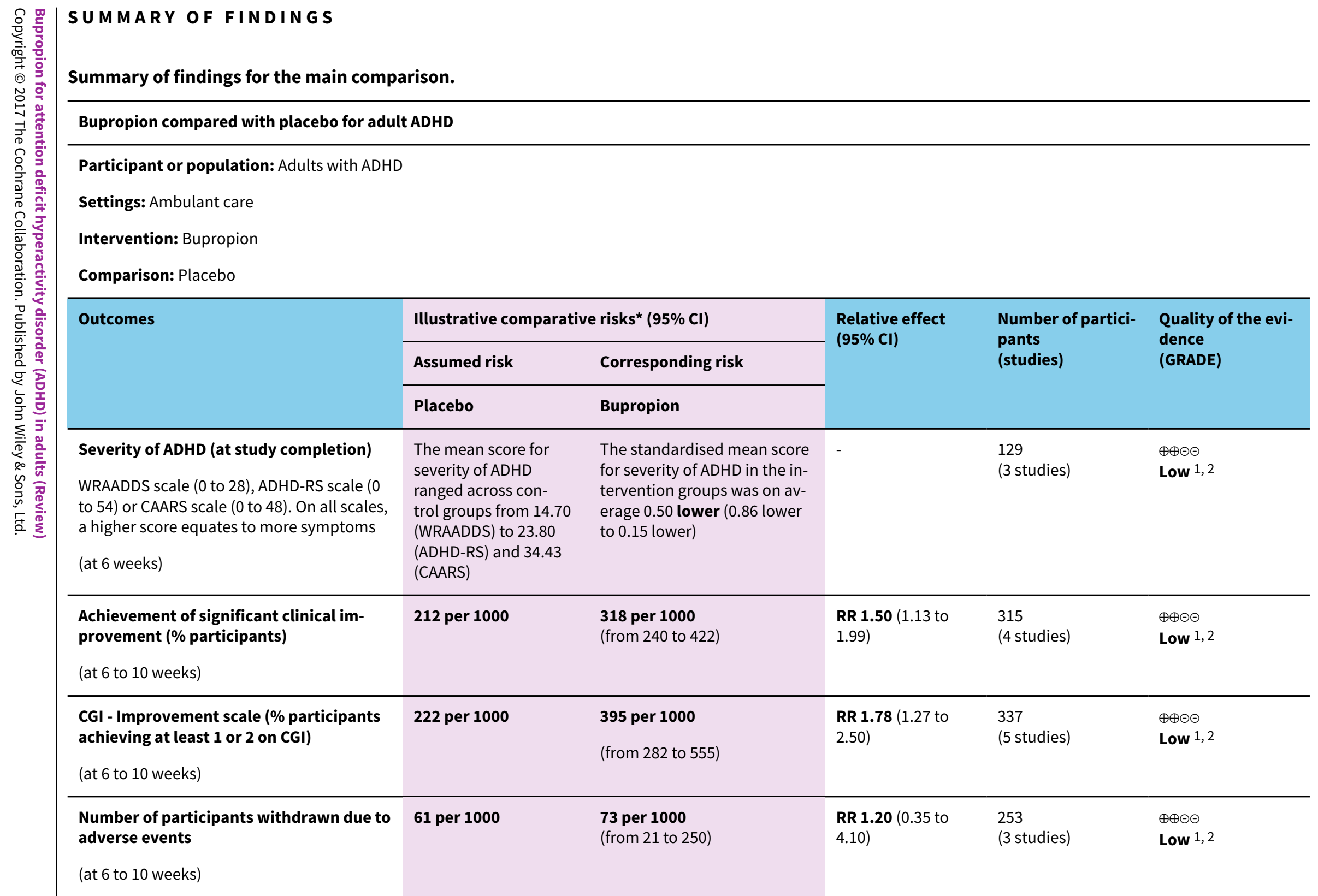

*The basis for the assumed risk was the median control group risk across studies. The corresponding risk (and its $95 \% \mathrm{Cl}$ ) is based on the assumed risk in the comparison group and the relative effect of the intervention (and its $95 \% \mathrm{Cl}$ ). 


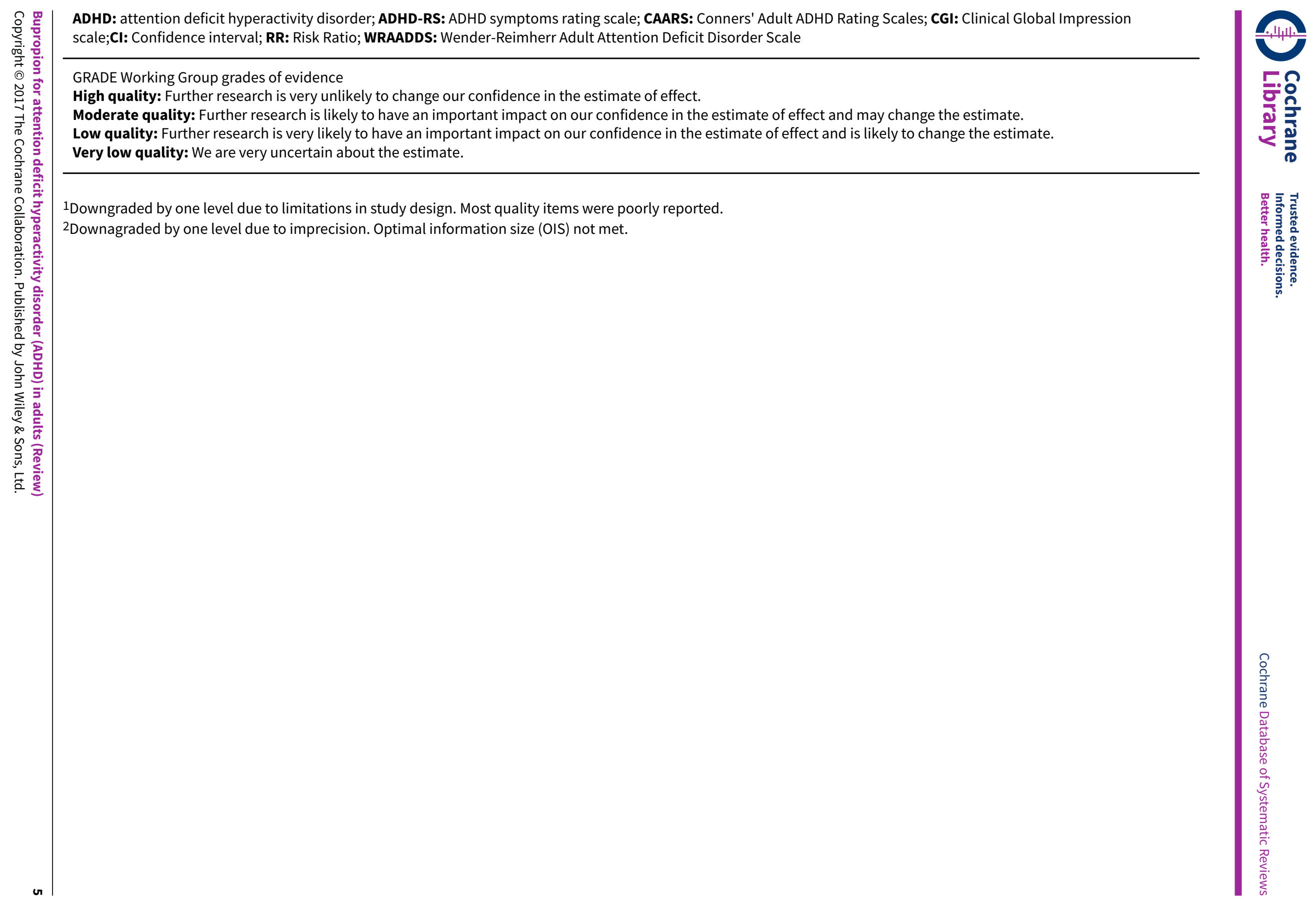




\section{B A C K G R O U N D}

\section{Description of the condition}

Attention deficit hyperactivity disorder (ADHD) is a prevalent neurobiological condition, which persists throughout the lifespan, affecting an estimated 6\% of adolescents and 3\% to $4 \%$ of adults (Fayyad 2007). ADHD is characterised by problems of inattention, impulsivity and/or excessive activity, and is commonly associated with emotional instability, sleep problems, risk-taking behaviour, accident proneness, delinquency, poor self-esteem and co-occurring mental illnesses such as mood, personality and substance use disorders (Asherson 2005). This kaleidoscopic scale of symptoms can culminate in substantial academic underachievement, as well as occupational, social and relational impairment (Vaughan 2008). The revision of the fourth edition of the Diagnostic and Statistical Manual of Mental Disorders (DSMIV-TR; APA 2000) defines the most widely used criteria and includes three ADHD subtypes: (1) predominantly inattentive, (2) predominantly hyperactive/impulsive and (3) combined. In 2013, the fifth edition of the DSM (DSM-5; APA 2013) was implemented, resulting in some changes in the diagnostic criteria for ADHD. For example, using DSM-5, several of the individual's ADHD symptoms must be present prior to age 12 years, compared to seven years as the age of onset in theDSM-IV. Also, in the DSM-5 several symptoms need to be present in more than one setting rather than just some impairment in more than one setting. Finally, only five symptoms are needed instead of the six required for younger children, lowering the threshold of symptoms for a reliable diagnosis (APA 2013; CDC 2015).

Evidence from genetic, neuroimaging and neuropsychological studies suggest that a number of biological and environmental factors (Biederman 2005; Dopheide 2009; Voeller 2004), each of small individual effect, interact to produce the condition, which is characterised by cognitive and behavioural deficits (Sonuga-Barke 2005). Putative environmental risk factors related to ADHD can be categorised as biological factors (e.g. fetal exposure to toxins or smoking) or adverse psychosocial factors (e.g. low socioeconomic status, marital discord), but it is unclear which mechanisms underlie these relations (Banerjee 2007).

Neurobiological studies highlight that dysregulation of largely dopaminergic (Wang 2004) and noradrenergic systems of the frontostriatal circuit appear operant in ADHD (Ashton 2006; Bush 2005; Wilens 2006), leading to its key manifestations. However, even a dopamine/noradrenaline hypothesis of ADHD may be oversimplified, since we may merely be observing the correlates of a process and not the cause. At a clinical, genetic, neuroanatomical and neuropsychological level, marked disparities have been found between subgroups, indicating that ADHD is best conceptualised as a heterogeneous disorder with a complex aetiology (Nutt 2007; Steinhausen 2009).

Despite the rapidly expanding body of preclinical research on the neurobiological underpinnings of ADHD, the exact aetiological processes are complex and not fully understood. As with most psychiatric disorders, there is no single test that can diagnose ADHD in adulthood. It therefore remains a clinical diagnosis, based on a comprehensive, multifaceted assessment of history and current symptoms and impairments using clinical examination, rating scales, screening instruments, semi-structured diagnostic interviews and other tools, as indicated (Kooij 2010).

\section{Description of the intervention}

Most of the effective pharmacological treatments for ADHD facilitate catecholamine transmission, either as agonists or as reuptake inhibitors (Berridge 2006; Faraone 1998; Faraone 2006; Nutt 2007; Wender 2001; Young 2006). They can be divided into psychostimulants and nonstimulants.

\section{Psychostimulants}

Despite the fact that psychostimulant medications are the mainstay of treatment, with a solid track record of safety and efficacy (Faraone 2004; Spencer 2005), they are either not effective, or tolerated, in approximately $30 \%$ to $50 \%$ of all adults with ADHD (Biederman 2006). Acute dose-related psychiatric side effects include nervousness, insomnia, psychosis and agitation; somatic side effects include anorexia, weight loss, nausea, headaches and elevated blood pressure and heart rate (Ashton 2006). Their reinforcing or euphorigenic effects mean there is a potential for abuse and diversion (Leonard 2004; Swanson 2003; Volkow 1995; Volkow 2003; Wolraich 2004). A recent Cochrane Review on the beneficial or harmful effects of methylphenidate for the treatment of ADHD in children and adolescents concluded that the magnitude of effect is uncertain, with some evidence that methylphenidate increases the risk of non-serious adverse events, such as disturbed sleep and reduced appetite, and no evidence that it increases the risk of serious adverse events (Storebø 2015).

Psychostimulants are contraindicated in patients who use monoamine oxidase (MAO) inhibitors, who have a history of illicit drug use or abuse, or who suffer from "glaucoma, symptomatic cardiovascular diseases, hyperthyroidism and hypertension" (Greenhill 2002). In addition to various medical contraindications, such as untreated bipolar illness, psychosis, anorexia, anxiety disorders and severe depression, the presence of one or more comorbid psychiatric conditions may represent a relative contraindication to using stimulants (Newcorn 2008a). Although children with ADHD demonstrate a higher rate of emotional dysregulation, which may be exacerbated through the use of stimulants, this has not been systematically demonstrated in adults (Findling 2010; Sarampote 2004). Finally, some patients simply will not accept treatment with a psychostimulant (Himpel 2005).

\section{Nonstimulants}

As stimulant medications are not effective or are poorly tolerated in a subset of patients with ADHD, efforts have been made to to expand the current pharmacopoeia to alternative approaches for ADHD (Pliszka 2003). The majority of nonstimulant compounds target noradrenaline, although there may also be primary and secondary effects on dopamine and other neurotransmitters and neuromodulators (Newcorn 2008a). In addition to these catecholaminergic agents, the nonstimulants also harbour a variety of investigational drugs that have an effect on various other neurotransmitter systems, including cholinomimetics, histaminergic agonists, modafinil and ampakines, the latter affecting the glutamatergic system. Dopamine and adrenaline reuptake inhibitors (DARI) constitute the focus of this review, amongst which bupropion is the only agent that is clinically available. Bupropion is registered as an antidepressant and it is used as an aid to stop smoking. Given its impact on the catecholaminergic system, bupropion has been used off-label to treat ADHD (Wilens 2005). Two studies have reported a therapeutic 
effect after several weeks (Wilens 2001; Wilens 2005), with the largest improvement occurring up to the six-week endpoint, suggesting a delayed onset of action in adults with ADHD. Reimherr 2005 also recommends a six-week duration for "short-term, doubleblind studies with bupropion".

Although nonstimulants like bupropion, structurally related to amphetamines, are claimed to have a lower potential for abuse, and therefore may be considered for people at risk for substance use, misuse or diversion of stimulants, several cases of recreational use via nasal insufflation and intravenous administration have been reported. In contrast to extensive first-pass metabolism (FPM) after oral use, nasal insufflation and intravenous use bypass the FPM, resulting in more rapid, higher plasma concentrations (Baribeau 2013; Hilliard 2013; Oppek 2014).

Pharmacological treatment for ADHD should be provided as part of a multimodal treatment plan, as recommended in international guidelines (Bolea-Alamañac 2014; CADDRA 2011; NICE 2008). As opposed to ADHD treatment guidelines in children, current UK guidelines recommend adults with ADHD be given pharmacological interventions as first-line therapy, unless psychological treatments are preferred (NICE 2008). This recommendation is, in part, based on a paucity of evidence for the efficacy of using non-drug interventions alone (Bolea-Alamañac 2014).

Several systematic reviews have evaluated the effects of different types of medication for adult ADHD. Peterson 2008 compared the benefits and harms of short-acting stimulants, long-acting stimulants and nonstimulants (three studies of bupropion) using an indirect comparison meta-analysis. The relative effects of short-acting stimulants were superior to those of bupropion (risk ratio (RR) 2.24, 95\% confidence interval $(\mathrm{Cl}) 1.23$ to 4.08 ) and of long-acting stimulants ( $R R 3.26,95 \% \mathrm{Cl} 2.03$ to 5.22 ). Faraone 2010 estimated effect sizes of medications and found that both stimulants and nonstimulants appeared to be effective. Stimulants showed larger effects, as illustrated by the number needed to treat for an additional beneficial outcome (NNTB). For bupropion, the NNTB approached five, while for stimulants the NNTB was nearer two. Maneeton 2014 compared bupropion versus methylphenidate. Based on four small studies, they found no difference in effects and tolerability between the two drugs. Moriyama 2013 systematically reviewed meta-analyses on pharmacological interventions for adults with ADHD, including the Faraone 2010 and Peterson 2008 reviews. The review authors concluded that bupropion was inferior to stimulants. Two previous reviews compared bupropion to placebo: Faraone 2010 compared effect sizes while Maneeton 2011 compared both effects and safety. Both concluded that bupropion was superior to placebo.

\section{How the intervention might work}

Bupropion is an aminoketone antidepressant and non-competitive antagonism of nicotinic acetylcholine receptors (Gobbi 2003). Its mechanism of action most likely involves reuptake inhibition of the catecholamines, dopamine and noradrenaline, a profile similar to the presumed action of psychostimulants. The powerful influence that catecholamines have on brain circuits, which appear to be altered in ADHD, are mediated through stimulation of dopamine 1 (D1) and noradrenergic 2a receptors, respectively (Arnsten 2005). A study published almost 30 years ago on the biochemical effects of bupropion in depressed people concluded that the rise in plasma homovanillic acid (HVA) level in bupropion nonresponders may represent a perturbation of dopaminergic systems (Golden 1988a). Whole-body noradrenaline turn-over in depressed people was reduced without altering plasma levels of noradrenaline at rest and following an orthostatic challenge. The effect of bupropion on cerebrospinal fluid (CSF) monoamine metabolite concentrations lacked significance, but may have been due to an alpha error (Golden 1988a). The major metabolites of bupropion have substantially longer half-lives than the parent compound. The half-lives of hydroxybupropion (HB), erythrohydrobupropion and threohydrobupropion were 27,43 and 50 hours, respectively. Thus, the longer half-lives of these active metabolites should be taken into consideration when calculating when steady state has been reached in people receiving bupropion (Golden 1988b). Higher plasma metabolite concentrations were associated with poor clinical outcome. This relationship was most striking with HB, and may suggest a curvilinear dose-response relationship, similar to that seen with nortriptyline, for the bupropion metabolites.

Studies have demonstrated similar bioavailability for immediate-, sustained- and extended-release bupropion, but information about their efficacy and the occurrence of adverse effects is scarce. The spontaneous seizure rate reported in the general population is approximately $0.1 \%$ (Pisani 2002), whereby the incidence of a convulsion rises significantly at dosages higher than $450 \mathrm{mg}$ per day, the highest recommended dose (Spencer 2004). Also, some people taking the drug have developed anxiety, some have developed headaches (Rostain 2008), and others have reported exacerbation of tic disorders (Popper 1997). The potential increase in blood pressure is usually small and only of concern in those with marginal or high blood pressure. Bupropion shows little impact on weight and sexual function (Demyttenaere 2008; Wilens 2004). Dose-related side effects are mediated via the catecholamines transmitters. The mechanism of idiosyncratic side effects is unknown.

Bupropion appears to be effective in adolescents with ADHD and comorbid drug misuse and mood disorders (Solhkhah 2005). There are few data regarding the most effective formulation and dosing of bupropion. There is also a lack of clarity about whether there is a differential response rate to bupropion according to the patient's ADHD subtype. Depression is often comorbid with ADHD and can influence ADHD symptoms, suggesting that bupropion, which is an antidepressant, may reduce ADHD symptoms only in the presence of depression. Although there is some evidence that bupropion may be useful in treating adolescents with ADHD and comorbid depression (Daviss 2001), no studies of good quality have addressed the issue in adults.

Both bupropion and methylphenidate are dopamine and noradrenaline re-uptake inhibitors at the presynapse. However, the re-uptake inhibition is less strong for bupropion, as reflected by the half maximal inhibitory concentration $\left(\mathrm{IC}_{50}\right)$, which is a measure of the effectiveness of a compound.

Four positron emission tomography (PET) studies have been conducted in healthy and depressed individuals to gain information about the contribution of dopamine transporter (DAT-) inhibition to the pharmacological mechanism of action of bupropion (Argyelán 2005; Egerton 2010; Learned-Coughlin 2003; Meyer 2002). All of these studies showed a DAT occupancy of approximately $20 \%$ during exposure to bupropion (and its metabolites). This raises the question of whether these low DAToccupancy rates are therapeutic or whether bupropion derives 
its efficacy from another mechanism. In contrast, weight-adjusted doses of methylphenidate used therapeutically are likely to occupy more than $50 \%$ of the dopamine transporters (Volkow 1998; Volkow 2002).

The tolerability profile of bupropion is well documented, with thousands of participants in clinical trials and over 40 million clinical-use exposures for all uses. The most common adverse effects (incidence higher than 10\%) found to be associated with the use of bupropion are headache (27\% for bupropion versus $23 \%$ for placebo), dry mouth (16\% for bupropion versus $7 \%$ for placebo; $\mathrm{P}<0.05$ ), nausea (13\% for bupropion versus $8 \%$ for placebo; $\mathrm{P}<$ 0.05 ), and insomnia (11\% for bupropion versus $7 \%$ for placebo; $P<$ 0.05 ) (Jefferson 2005). In addition, there is an elevated risk of druginduced seizures with bupropion $(0.1 \%$ at doses up to $300 \mathrm{mg}$ a day with a sustained-release formulation and $0.4 \%$ at doses up to $450 \mathrm{mg}$ a day with an immediate-release formulation). To minimise the risk for seizure, patients should be screened for predisposing factors, clinical situations, and concomitant medications that may decrease seizure threshold (Jefferson 2005).

Bupropion hydrochloride, a noradrenergic/dopaminergic antidepressant, is available as immediate-release (given three times a day), sustained-release (given twice a day), and extendedrelease (given once a day) oral formulations. The mean elimination half-life of bupropion is 21 hours, which is similar to that of hydroxy-bupropion (20 hours). The elimination half-life values of erythrohydrobupropion and threohydrobupropion are longer ( 33 and 37 hours, respectively). Seven to 10 days are therefore required for bupropion and its metabolites to reach steady state. Sustained-release and extended-release bupropion have been found to be bioequivalent to the immediate-release formulation and to each other. Bioequivalence criteria included demonstration of equivalent delivery of the drug via the respective formulations when multiple doses were administered until steady state was achieved. Patients being converted from one formulation to another should be given the same daily dose that they are currently receiving (Dhillon 2008).

\section{Why it is important to do this review}

The high ADHD prevalence rate, incomplete response and/or adverse drug reactions to stimulants, as well as the risk of stimulant abuse mean that pharmacotherapeutic alternatives to stimulants, such as bupropion, should be explored.

Although buproprion is widely used as a treatment for ADHD, data from randomised controlled trials regarding its effectiveness are lacking (Reimherr 2005). It is of both clinical and research interest to document the efficacy of buproprion for ADHD, as it might generate new avenues of research that inform us of the aetiology of ADHD (Reimherr 2005). It is likely that there is a differential response to stimulant and nonstimulant drugs in adults with ADHD. Patients may prefer one treatment to the other (Newcorn 2008b). A major challenge for the future is to develop strategies to identify a priori those people who will prefer a stimulant over a nonstimulant drug. At present, there are a lack of empirical data to guide such treatment selection.

A nonscheduled agent such as bupropion does not produce euphoria and so may be used in patients who have a history of illicit drug use and abuse (Young 2006). Differing patterns of comorbidity and symptom heterogeneity pose different treatment challenges.
As psychostimulants are relatively contraindicated in people with ADHD and comorbid conditions, such as depression, anxiety and substance misuse, it is vital to explore nonstimulant treatment options.

When proper symptom control and functional improvement cannot be met by licensed medicines, clinicians resort to off-label use (Nutt 2007). This is the case with bupropion for adults with ADHD. It is important that the effectiveness and safety of such off-label use of bupropion is assessed, which is the purpose of this review. A systematic review may reduce the uncertainty that remains about recommended optimum prescribing hierarchies that vary between different guideline committees. Our review updates two previously published systematic reviews on bupropion (Faraone 2010; Maneeton 2011), while using the latest rigorous systematic review methodology to come to a trustworthy answer to our clinical question.

\section{O B JECT IVES}

To assess the effects and safety of bupropion for the treatment of adults with ADHD.

\section{METHOD S}

\section{Criteria for considering studies for this review}

\section{Types of studies}

Randomised controlled trials (RCTs), including acute studies (less than 24 hours), as well as short-term (less than six weeks), mediumterm (six weeks to six months), and long-term studies (more than six months).

\section{Types of participants}

Adults aged 18 years or older, diagnosed with ADHD according to formal, standardised diagnostic criteria (Wender Utah criteria (Ward 1993); Diagnostic and Statistical Manual of Mental Disorders, Fourth Edition, Text Revision (DSM IV-TR; APA 2000); International Classification of Diseases, 10th Revision (ICD 10; WHO 2011)). We included all ADHD subtypes. We did not exclude comorbid psychiatric conditions.

\section{Types of interventions}

Any formulation of bupropion (bupropion, extended-release bupropion, sustained-release bupropion), at any dose, compared with placebo. We did not exclude studies with adjuvant interventions if they were provided to both arms of the study.

\section{Types of outcome measures}

\section{Primary outcomes}

1. Efficacy outcomes.

a. Change in severity of ADHD symptoms from baseline, as assessed by a standardised instrument (participantor investigator-rated) such as the Wender-Reimherr Adult Attention Deficit Disorder Scale (WRAADS; Marchant 2013), ADHD Rating Scale (ADHD-RS; DuPaul 1990) or the Adult ADHD Rating Scale (AARS; Murphy 1996).

b. Proportion of participants achieving a significant clinical improvement. Significant improvement is defined as a reduction of at least $30 \%$ in the severity of ADHD symptoms or 
a score of one or two on the Clinical Global Impression (CGI)Improvement scale (NIMH 1984).

2. Any adverse effects.

a. Proportion of participants withdrawn due to any adverse effect (somatic or psychiatric).

\section{Secondary outcomes}

1. Efficacy outcomes.

a. Clinical impression, as measured by the CGI-Severity of illness scale (Guy 1976).

b. Global level of functioning, as measured by the Global Assessment of Functioning (GAF) scale (Goldman 1992).

c. Social adjustment, as measured by a social adjustment scale such as the Social Adjustment Scale - Self-report (SAS-SR; Weissman 1999).

d. Depressive symptoms, as assessed by standardised instruments such as the Hamilton Depression Rating Scale (HAM-D; Hamilton 1960).

e. Anxiety, as assessed by standardised instruments such as the Hamilton Anxiety Rating Scale (HAM-A; Maier 1988).

2. Somatic or psychiatric adverse effects.

a. Proportion of participants withdrawn due to any somatic adverse effect such as headache or nausea.

b. Proportion of participants withdrawn due to any psychiatric adverse effect such as agitation, insomnia or problems with concentration.

All primary outcomes are included in Summary of findings for the main comparison. Although we anticipated classifying outcomes of all studies based on time of measurement from randomisation (see Table 1), none of the studies reported outcomes at multiple time points.

\section{Search methods for identification of studies}

\section{Electronic searches}

We ran the first searches for this review in January 2012. We updated the searches in September 2014, November 2015 and February 2017. We did not limit the searches by date or language.

1. Cochrane Central Register of Controlled Trials (CENTRAL; 2017, Issue 1); in the Cochrane LIbrary, which includes the Cochrane Developmental, Psychosocial and Learning Problems Specialised Register (searched 20 February 2017).

2. MEDLINE Ovid (1946 to February Week 5 2017).

3. MEDLINE Ovid In-Process \& Other Non-Indexed Citations (17 February 2017).

4. MEDLINE Ovid Epub Ahead of Print (17 February 2017).

5. Embase Ovid (1980 to 2017 Week 8).

6. PsycINFO Ovid (1806 to November Week 2 2017).

7. Cumulative Index to Nursing and Allied Health Literature (CINAHL Plus EBSCOhost; 1937 to 21 February 2017).

8. Science Citation Index - EXPANDED Web of Science (SCIEXPANDED; 1970 to 20 February 2017).

9. Social Sciences Citation Index Web of Science (SSCl; 1970 to 20 February 2017).

10.Conference Proceedings Citation Index - Science Web of Science (CPCl-S; 1990 to 20 February 2017).
11.Conference Proceedings Citation Index - Social Science \& Humanities Web of Science (CPCI-SS\&H; 1990 to 20 February 2017).

12.Latin American and Caribbean Health Science Information (LILACS) database; bases.bireme.br; searched 21 February 2017).

13.WorldCat (limited to theses) (worldcat.org; searched 21 February 2017).

14.metaRegister of Controlled Trials ( $m R C T$; isrctn.com/page/mrct; last searched 2 October 2014. Service is currently under review).

15. World Health Organization International Clinical Trials Registry Platform (WHO ICTRP; apps.who.int/trialsearch/Default.aspx; searched 21 February 2017).

16. ClinicalTrials.gov (clinicaltrials.gov; searched 21 February 2017).

17.Netherlands Trials Register (trialregister.nl/trialreg/index.asp; searched 21 February 2017).

18. Networked Digital Library of Theses and Dissertations (ndltd.org, searched 21 February 2017).

19.DART - Europe E-theses Portal (dart-europe.eu, searched 21 February 2017).

The search strategies and search dates for each source are reported in Appendix 1.

\section{Searching other resources}

We searched the reference lists of all relevant reports for further studies. We also contacted colleagues, experts and pharmaceutical companies in the field, to ascertain if there were any ongoing or unpublished studies.

\section{Data collection and analysis}

\section{Selection of studies}

Two review authors (WV, GB) screened titles and abstracts of all identified studies for relevance. The same two review authors screened the full texts of studies that we deemed potentially relevant or for which we needed more information. We resolved any disagreements by consensus. We reported our study selection process in a PRISMA study flow diagram (Moher 2009).

\section{Data extraction and management}

Two review authors (WV, GB), working independently, extracted data using a data extraction sheet that we tested in a pilot study. Appendix 2 provides an overview of the data that we extracted, resolving any disagreements by consensus. In case of missing information with respect to study quality (all studies) or with respect to study results (Hamedi 2014; Kuperman 2001; Wilens 2001; Wilens 2005), we emailed the respective study authors to request this information. We considered data as 'missing' if the study authors could not provide the information or if they did not respond.

\section{Assessment of risk of bias in included studies}

Two reviewers (WV and GB) independently assessed the risks of bias of each included study using the Cochrane 'Risk of bias' tool (Higgins 2011). This tool consists of six domains. For each domain, we judged the risk of bias to be 'low', 'high' or 'unclear', using criteria outlined by the tool. The criteria are explained below. 


\section{Random sequence generation}

We rated studies that used adequate methods to generate the random sequence, such as computer-generated randomisation lists, as being at low risk of bias. We rated studies that used inadequate methods, such as date of admission or allocation by the clinician, at high risk of bias. We judged studies that did not provide details on the method of sequence generation to be at unclear risk of bias.

\section{Allocation concealment}

We rated studies that used adequate methods to conceal the randomisation, such as central allocation or sequentiallynumbered and identical-looking drug containers, as having low risk of bias for this domain. Inadequate methods of concealment referred to methods by which clinicians or participants were able to foresee which group they were assigned to, such as using an open allocation schedule, and we judged them to be at high risk of bias. We rated studies that did not provide details on the method of concealment at unclear risk of bias.

\section{Blinding of participants, clinicians and outcome assessors}

Blinding of participants, clinicians and outcome assessors were each assessed separately.

With regard to participant blinding, we judged adequate blinding to have been achieved if the study reported that the placebo tablets were identical in appearance, and rated them at low risk of bias. We judged studies that reported that placebo tablets were not identical to bupropion, or unblinded studies, to be at high risk of bias. Where blinding was not reported, we rated the studies at unclear risk of bias.

We judged adequate blinding for clinicians and outcome assessors to have been achieved if the study explicitly reported that these persons were blinded, and rated them at low risk of bias on the separate blinding domains. We judged unblinded studies to be at high risk of bias. Where this was not reported, we rated studies at unclear risk of bias for these domains.

\section{Incomplete outcome data}

For this domain, we assessed the completeness of outcome data. We judged studies to be at low risk of bias if attrition was clearly reported, if it was balanced between the groups, and if it was judged not to be related to the study outcome. We also rated the study at low risk of bias if all participants that were randomised were included in the analysis. We accepted imputations in case of missing values. We assigned a high risk of bias for studies where we judged the reason for missing data to be related to the study outcome. This also applied to studies that analysed a subset of randomised participants; for example, only those participants that took at least one dose of medication or only those that attended the first follow-up appointment. We considered imputation by last observation carried forward (LOCF) to be at high risk of bias, as it fails to acknowledge uncertainty in the imputed values and results; typically confidence intervals (Cls) are too narrow (Higgins 2011). We rated studies that did not provide sufficient details on attrition, exclusions or methods of imputing missing values to permit judgement as being at unclear risk of bias.

\section{Selective reporting}

We rated studies for which a protocol was available, and from which it was clear that the published reports contained all expected outcomes, at low risk of bias for this domain. We judged studies with unexplained differences in reported outcomes between protocol and study report to be at high risk of bias. Where we could not locate the protocol, we could make no assessment and judged the risk of bias to be unclear.

\section{Other bias}

No other potential sources of bias were assessed. However, for each study, we noted whether or not the study was funded by the pharmaceutical industry. This information is reported in the Characteristics of included studies tables.

\section{Measures of treatment effect}

\section{Continuous outcomes}

For continuous outcomes (e.g. change in severity of ADHD symptoms) measured identically across studies, we summarised data by calculating a mean difference (MD) and 95\% confidence interval $(\mathrm{Cl})$. If the same continuous outcome was measured differently across studies, we calculated an overall standardised mean difference (SMD) and 95\% Cl, using Hedge's $g$ (Deeks 2011).

\section{Dichotomous outcomes}

For dichotomous outcomes (e.g. the proportion of participants achieving a significant clinical improvement), we summarised data by calculating the risk ratio (RR) with a $95 \% \mathrm{Cl}$.

\section{Unit of analysis issues}

\section{Multiple-arm trials}

We performed pair-wise comparisons, selecting 'placebo' versus 'bupropion' as being relevant to this systematic review.

Additional methods described in the protocol (Verbeeck 2011), but not used in this review are summarised in additional Table 1.

\section{Dealing with missing data}

In the first instance, we contacted authors with a request to supply data missing from included studies. If authors were not able or willing to supply the data, we imputed missing standard deviations by replacement values. The replacement value was the mean of the standard deviations of other studies in the analysis that used the same dependent variable, provided that the outcomes were measured identically. We anticipated conducting a Sensitivity analysis to assess how sensitive our conclusions were to these replacements. We did not impute missing mean values.

\section{Assessment of heterogeneity}

We assessed clinical heterogeneity by comparing the distribution of important participant factors between studies (such as treatment type, co-interventions, participant characteristics, ADHD subtype), and discussed the impact of this on the findings. We did not assess methodological heterogeneity in this review, due to poor reporting of methodology.

We assessed statistical heterogeneity by examining the 12 statistic (Deeks 2011; Higgins 2003), a measure which describes approximately the proportion of variation in point estimates that is 
due to heterogeneity rather than sampling error. We also employed a Chi' ${ }^{2}$ test of homogeneity to determine the strength of evidence that heterogeneity was genuine.

\section{Assessment of reporting biases}

We did not identify sufficient studies to conduct an assessment of reporting bias. Our plans for such assessment are reported in the protocol (Verbeeck 2011), and described in additional Table 1.

\section{Data synthesis}

We conducted meta-analyses when at least two studies reported on similar interventions in respect of dosage, frequency and duration, and when suitable data were presented. We expected fewer than 10 studies in the analyses. We used a fixed-effect model to pool the results because when there are few studies between-study variance estimates may be very unreliable, and statistical inferences based on random-effects models may be more flawed than estimates based on a fixed-effect model (Van den Noortgate 2003). We used the inverse variance method to pool data from continuous outcomes, and the Mantel-Haenszel method to pool data from dichotomous outcomes, as this method has been shown to have better statistical properties when data are sparse (Deeks 2011), as is the case in this review. Where meta-analysis was not possible, we provided a narrative description of the results and conclusions.

\section{'Summary of findings' table}

We produced Summary of findings for the main comparison in which we report all Primary outcomes. This table presents an overview of both the results and the quality of evidence. The basis for the assumed risk was the median control group risk across studies. We based the corresponding risk (and its $95 \% \mathrm{Cl}$ ) on the assumed risk in the comparison group and the relative effect of the intervention (and its $95 \% \mathrm{Cl}$ ). We assessed the quality of the evidence using the GRADE approach and associated criteria (Guyatt 2011a). In this approach, RCTs start as high-quality evidence but are downgraded by one, two or three levels (to moderate-, lowand very low-quality evidence), depending on the presence of the following five factors.

1. Study limitations. We assessed important study design limitations, such as failure to conceal allocation, failure to blind, loss to follow-up and failure to appropriately consider the intention to-treat principle, using the Cochrane 'Risk of bias' tool (Higgins 2011).

2. Imprecision. We judged precision as adequate if the $95 \%$ $\mathrm{Cl}$ excluded a RR of 1.00 , and the total number of events or participants exceeded the optimal information size (OIS) criterion. We rated precision as inadequate if the $95 \% \mathrm{Cl}$ included appreciable benefit or harm (we used an RR of under 0.75 or over 1.25 ), even if the OIS criterion was met (Guyatt 2011b).

3. Inconsistency of results. We assessed inconsistency of results using four criteria (1) point estimates varied widely across studies; (2) Cls showed minimal or no overlap; (3) the statistical test for heterogeneity, which tests the null hypothesis that all studies in a meta-analysis have the same underlying magnitude of effect, showed a low P value; and (4) the $\mathrm{I}^{2}$ was large (Guyatt 2011c).
4. Indirectness of evidence. We assessed whether the studies directly compared the intervention of interest delivered to the populations in which we were interested and measured the outcomes important to participants (Guyatt 2011d).

5. Publication bias. There were too few studies in the review to be able to assess small-study effects statistically.

We report the ratings for the overall quality of evidence for each outcome and the reasons for downgrading in Summary of findings for the main comparison.

\section{Subgroup analysis and investigation of heterogeneity}

We did not conduct subgroup analyses on the type of drug-release formulation, because all studies assessed a long-acting version of bupropion, or on dose of study drug, because the actual study dose was not reported. We describe these analyses, which have been archived for use in future updates of this review, in Table 1 and in our protocol (Verbeeck 2011).

\section{Sensitivity analysis}

We performed the following three sensitivity analyses on our Primary outcomes.

1. The impact of including studies of participants with potential comorbid disorders, by analysing only those studies where the presence of a comorbid disorder was an exclusion criterion.

2. The impact of combining self-rated and clinician-rated ADHD scales, by analysing only those studies that used clinician-rated ADHD scales.

3. The impact of using fixed-effect meta-analyses, by comparing the results of fixed-effect versus random-effects models. See Differences between protocol and review.

In Table 1, we summarise additional sensitivity analyses that we had planned to perform, to assess whether findings would be sensitive to restricting the analyses to studies judged to be at low risk of bias (Verbeeck 2011). However, we were unable to conduct these analyses because we considered none of the studies at low risk of bias for some characteristics (based on assessment sequence generation and allocation concealment, financial support and affiliations with industry), and we considered all studies to be at low risk of bias for other characteristics (i.e. data imputation and unstandardised instruments were not used in any of the studies).

\section{RES U L T S}

\section{Description of studies}

\section{Results of the search}

The database searches yielded 2235 records. After de-duplication, we screened the titles and abstracts of 1645 records and discarded 1633 as irrelevant. We obtained the full-text reports of the 12 remaining records and assessed these against our inclusion criteria (Criteria for considering studies for this review). We excluded four irrelevant reports, and formally excluded one report with a reason (Excluded studies). We included six studies (from seven reports) in this review (Included studies). See Figure 1. 
Figure 1. Study flow diagram.

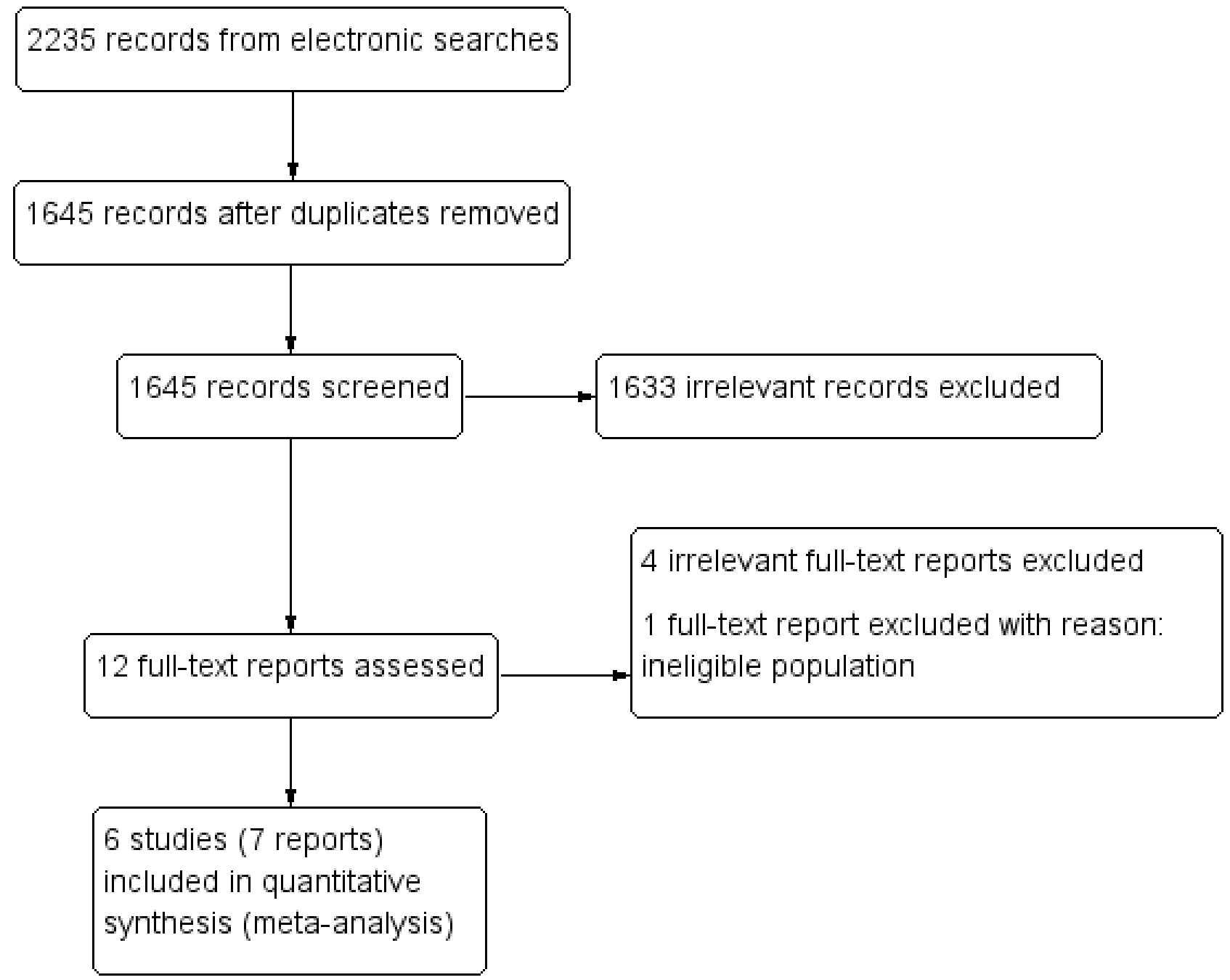

\section{Included studies}

Please see the Characteristics of included studies tables for more details.

\section{Setting and location}

Five studies were conducted in the USA (Kuperman 2001; Levin 2006; Reimherr 2005; Wilens 2001; Wilens 2005) and one in Iran (Hamedi 2014). Four studies recruited cases from one location or treatment centre (Hamedi 2014; Kuperman 2001; Reimherr 2005; Wilens 2001), and two studies recruited cases from multiple centres (Levin 2006; Wilens 2005).

\section{Study design}

All included studies were RCTs.

\section{Participants}

The six included studies randomised 438 participants (Hamedi 2014; Kuperman 2001; Levin 2006; Reimherr 2005; Wilens 2001; Wilens 2005). Of these, 270 (62\%) were men. The mean age of the groups ranged between 32.2 years (Kuperman 2001) and 41.4 years (Wilens 2005).
Three of the six studies reported race distribution (Hamedi 2014; Levin 2006; Wilens 2005). Levin 2006 included mainly white (39\% and $42 \%$ for the two groups) and Hispanic participants (39\% for the two groups) and a smaller proportion of black participants ( $21 \%$ and $18 \%)$. The study population of Wilens 2005 consisted of $88 \%$ white, $6 \%$ black and $4 \%$ American-Hispanic participants. One study was performed in a Persian population (Hamedi 2014). Although these studies reported the ethnic origin of the included participant sample, the influence of race on responsiveness to pharmacotherapy was not further explored.

Two studies reported ADHD subtype (Wilens 2001; Wilens 2005). The main subtype in the Wilens 2001 study was the inattentive subtype (58\% of the total) and the main subtype in the Wilens 2005 study was the combined subtype (68\% and $58 \%$ for the two treatment groups).

Four studies excluded participants with psychiatric comorbidity (Hamedi 2014; Reimherr 2005; Wilens 2005; Wilens 2001), one study was unclear about this (Kuperman 2001), and another study included participants with opioid dependency (Levin 2006).

For a detailed description of participant characteristics, see Characteristics of included studies. 


\section{Intervention}

All studies compared a long-acting version of bupropion with placebo. Two studies also included a comparison with an active intervention (methylphenidate) (Kuperman 2001; Levin 2006). Five studied doses of bupropion ranging from up to $300 \mathrm{mg}$ to up to 450 mg per day; the average dose in the Hamedi 2014 study was $150 \mathrm{mg}$ per day. Study intervention length varied from six to 10 weeks, with a mean of 7.2 weeks.

\section{Outcomes and outcome measures}

Five of the six studies reported scores on the severity of ADHD, but the outcome measures differed between studies (Hamedi 2014; Kuperman 2001; Reimherr 2005; Wilens 2001; Wilens 2005). Reimherr 2005 reported the Wender-Reimherr Adult Attention Deficit Disorder Scale (WRAADS; Marchant 2013), a clinician-rated scale with scores ranging from 0 to 28 . The two Wilens studies used the clinician-rated ADHD Symptom Checklist (DuPaul 1990), with scores ranging from 0 to 54 (Wilens 2001; Wilens 2005). Kuperman 2001 used the participant-rated ADHD Symptom Checklist - Severity Scale (Barkley 1990), with scores ranging between 0 and 42 . Hamedi 2014 used the self-report screening form from the Conners' Adult ADHD Rating Scales (CAARS) scales (Conners 2003). Based on the mean scores in the two groups, we assumed that the short version was used, with scores ranging between 0 and 48 .

All scales are scored in the same direction, with a higher score indicating more symptoms.

Five studies reported the proportion of participants achieving a significant clinical improvement (Kuperman 2001; Levin 2006; Reimherr 2005; Wilens 2001; Wilens 2005), defined as a score of one or two on the Clinical Global Impression-Improvement (CGI-I) scale (NIMH 1984). Four studies also reported this outcome using a reduction of at least $30 \%$ in the severity of ADHD symptoms.

Three studies reported the number of participants withdrawn due to any event (Kuperman 2001; Levin 2006; Wilens 2005). One study reported that "there was no evidence of adverse effects leading to study withdrawal" (Reimherr 2005), and another study reported adverse events using another outcome (Wilens 2001), i.e. the number of participants with adverse effects and the number of participants that lowered the dose of their medication due to adverse effects.

\section{Attrition}

Five studies reported retention rates (Kuperman 2001; Levin 2006; Reimherr 2005; Wilens 2001; Wilens 2005). The retention rates in the bupropion groups varied from $69.7 \%$ (Levin 2006) to $90.5 \%$ (Wilens 2001). The retention rates of the placebo groups varied between $75.0 \%$ (Reimherr 2005) and 100\% (Wilens 2001). Hamedi 2014 was unclear about the number of participants that were dropped during the trial,

\section{Compliance}

Compliance was measured and reported in various ways. Levin 2006 gave self-reported compliance rates of 0.83 for placebo and 0.91 for bupropion. Compliance rates in the Wilens 2005 study were 0.989 and 0.998 for bupropion and placebo groups, respectively. Kuperman 2001 reported all participants to be compliant based on medication logs and pill counts. Wilens 2001 measured compliance using pill-counting but no results were reported. The remaining studies were unclear whether compliance was measured (Hamedi 2014; Reimherr 2005)

\section{Study funding}

Four studies were funded by industry (Kuperman 2001; Reimherr 2005; Wilens 2001; Wilens 2005), and two studies were publicly funded (Hamedi 2014; Levin 2006). In one of the publicly-funded studies (Levin 2006), the first author was a consultant for several pharmaceutical companies and also received investigator-driven funding from two companies, however none of these companies manufacture bupropion.

\section{Excluded studies}

We excluded one study from the review because it was performed in a non-adult population (See Characteristics of excluded studies; Excluded studies).

\section{Risk of bias in included studies}

We present a comprehensive description of the risk of bias of each included study in the 'Risk of bias' tables, beneath the Characteristics of included studies tables, with information summarised in Figure 2. We rated approximately $75 \%$ of all 'Risk of bias' items as unclear, reflecting poor reporting of methodology and outcomes of trials on the effectiveness of bupropion. 
Figure 2. Risk of bias summary: review authors' judgements about each risk of bias item for each included study

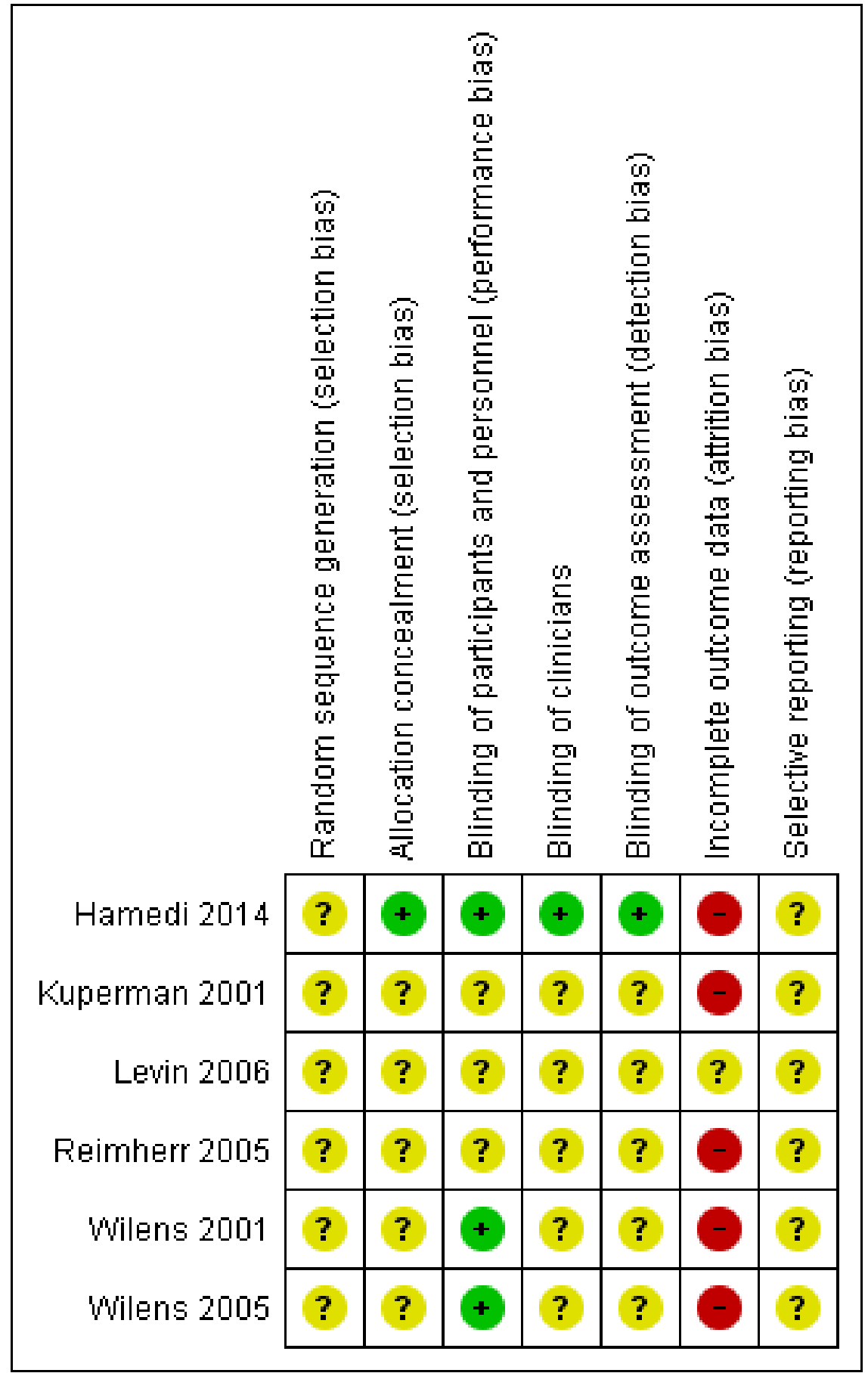

\section{Allocation}

\section{Random sequence generation}

None of the included studies reported details on how the random sequence was generated, so we scored all studies as being at unclear risk of bias for this domain (Hamedi 2014; Kuperman 2001; Levin 2006; Reimherr 2005; Wilens 2001; Wilens 2005).

\section{Allocation concealment}

Only one study (Hamedi 2014) reported an adequate method of allocation concealment leading to a judgement of low risk of bias. We score the remaining studies as being at unclear risk of bias for this domain (Kuperman 2001; Levin 2006; Reimherr 2005; Wilens 2001; Wilens 2005).

\section{Blinding}

We judged blinding of participants to be adequately addressed in three studies; two because these studies stated that placebo tablets 
were identical in appearance to bupropion tablets (Wilens 2001; Wilens 2005), and one because it stated that all people involved in the study were blinded (Hamedi 2014). We judged blinding as unclear for the remaining three studies, as no details on blinding were given (Kuperman 2001; Levin 2006; Reimherr 2005).

Blinding of clinicians and assessors was not discussed in five studies and hence we rated these studies at unclear risk of bias (Kuperman 2001; Levin 2006; Reimherr 2005; Wilens 2001; Wilens 2005). We rated one study (Hamedi 2014) at low risk of bias, as it stated that all people involved in the study were blind to assignments.

\section{Incomplete outcome data}

We rated five studies as having a high risk of bias for this domain; four because they did not perform intention-to-treat analyses (Kuperman 2001; Reimherr 2005; Wilens 2001; Wilens 2005), and one because they reported that some participants were dropped because they could not tolerate the drug, without reporting the number of dropouts (Hamedi 2014). The remaining study reported both the numbers of dropouts in each group as well as the reasons for dropout (Levin 2006). However, we judged this study to be at unclear risk of bias because of the high numbers of participants that dropped out (10/33 in the bupropion group and $8 / 33$ in the placebo group).

\section{Selective reporting}

We rated all studies at unclear risk of reporting bias, as we were unable to ascertain whether all measured outcomes were reported (Hamedi 2014; Kuperman 2001; Levin 2006; Reimherr 2005; Wilens 2001; Wilens 2005).

\section{Effects of interventions}

See: Summary of findings for the main comparison

\section{Comparison: Bupropion versus placebo}

Primary outcomes

\section{Efficacy outcomes}

\section{A. Changes in the severity of ADHD symptoms from baseline}

Five studies reported the severity of ADHD symptoms (Hamedi 2014; Kuperman 2001; Reimherr 2005; Wilens 2001; Wilens 2005).

Three studies (129 participants) reported severity of ADHD at study completion (Hamedi 2014; Reimherr 2005; Wilens 2001). The pooled, fixed-effect SMD between bupropion and placebo was -0.50 (95\% confidence interval $(\mathrm{Cl})-0.86$ to $-0.15, \mathrm{I}^{2}=0 \%$, see Analysis 1.1 ; Figure 3).

\section{Figure 3. Forest plot of comparison: 1 Bupropion versus placebo, outcome: 1.1 Severity of ADHD (at study} completion).

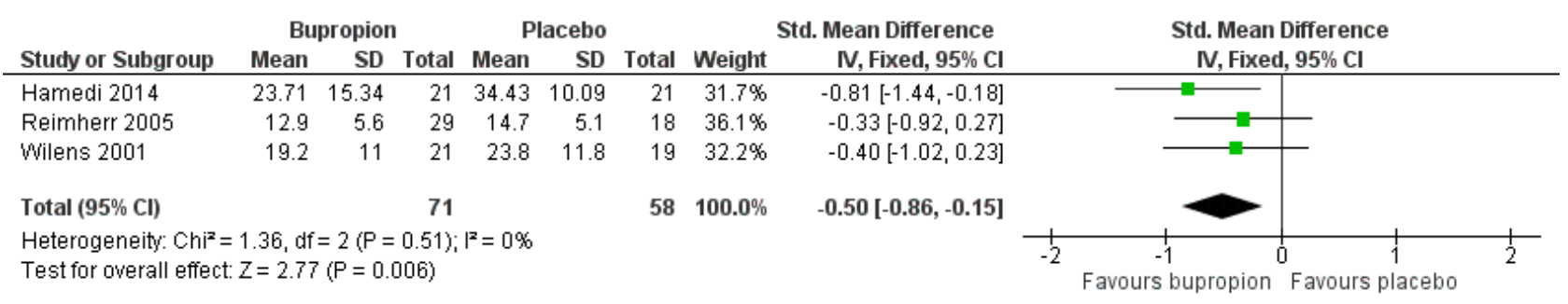

Two other studies reported mean change from baseline to study completion (Kuperman 2001; Wilens 2005). However, in the Wilens 2005 study, standard deviations were missing. We did not impute these standard deviations using the Kuperman 2001 study, as the outcomes were not measured in an identical way. Wilens 2005 reported better results for the bupropion group, while Kuperman 2001 found no difference between the groups. The results of these studies are reported in Table 2.

\section{B. Proportion of participants achieving a significant clinical improvement}

Four studies (315 participants) reported the proportion of participants achieving a significant clinical improvement (Levin 2006; Reimherr 2005; Wilens 2001; Wilens 2005), using either the WRAADDS (Marchant 2013), the ADHD Symptom Checklist (DuPaul 1990) or a participant-rated scale (Adult ADHD Rating Scale (AARS); Murphy 1996). The pooled, fixed-effect RR for achieving significant clinical improvement (\% of participants) was 1.50 (95\% Cl 1.13 to $1.99, \mathrm{I}^{2}=27 \%$, see Analysis 1.2; Figure 4). 
Figure 4. Forest plot of comparison: 1 Bupropion vs placebo, outcome: 1.1 Achievement of significant clinical improvement (\% participants).

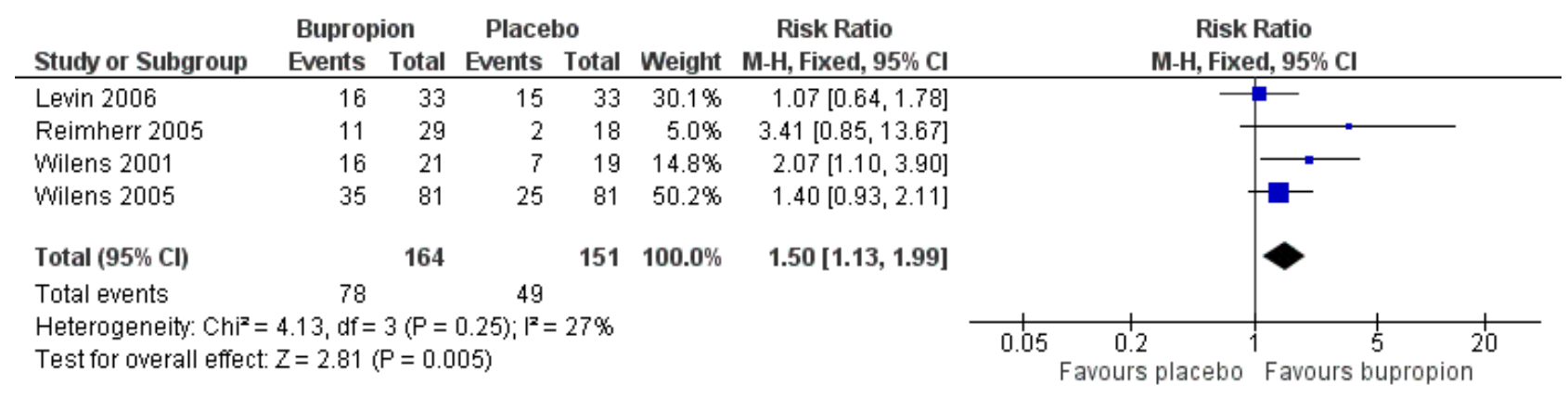

Five studies (337 participants) assessed the effect of bupropion versus placebo by means of the CGI (at least one or two points on the CGI) (NIMH 1984). The pooled, fixed-effect RR for achieving significant clinical improvement (\% of participants) was 1.78 (95\% $\mathrm{Cl} 1.27$ to $2.50, \mathrm{I}^{2}=54 \%$, see Analysis 1.3; Figure 5).

Figure 5. Forest plot of comparison: 1 Bupropion vs placebo, outcome: 1.3 Clinical Global Impression (CGI) improvement scale (\% participants achieving at least 1 or 2 on CGI).

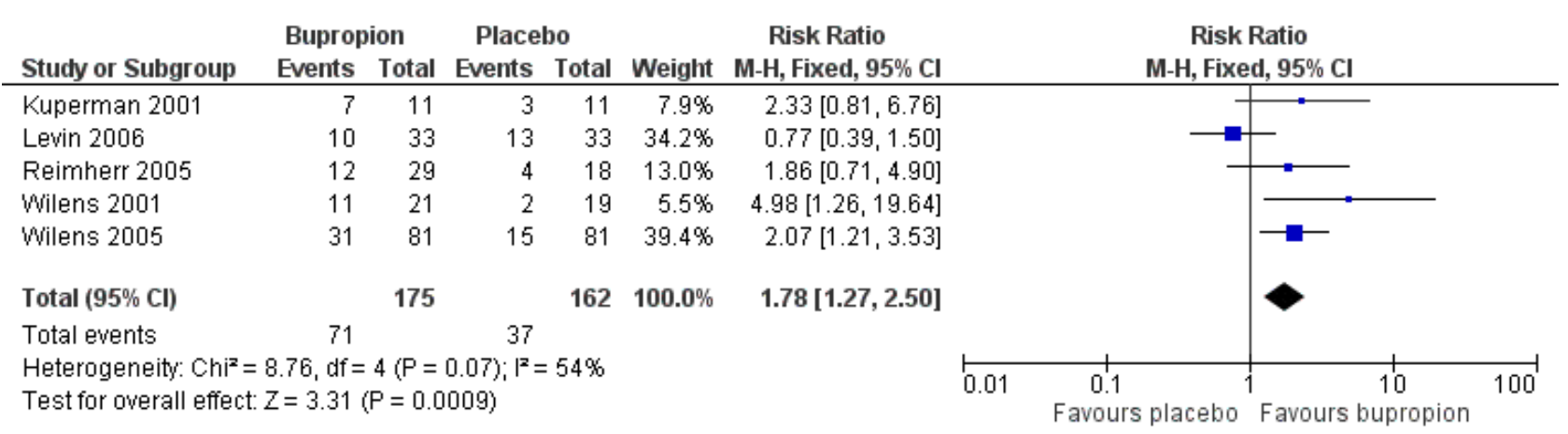

2. Adverse events: Proportion of participants withdrawn due to any adverse event (somatic or psychiatric)
2001; Levin 2006; Wilens 2005). The pooled, fixed-effect RR was 1.20 (95\% $\mathrm{Cl} 0.35$ to $4.10, \mathrm{I}^{2}=49 \%$, see Analysis 1.4; Figure 6).

Three studies (253 participants) reported the number of participants who withdrew due to any adverse events (Kuperman

Figure 6. Forest plot of comparison: 1 Bupropion versus placebo, outcome: 1.4 Number of participants withdrawn due to adverse events.

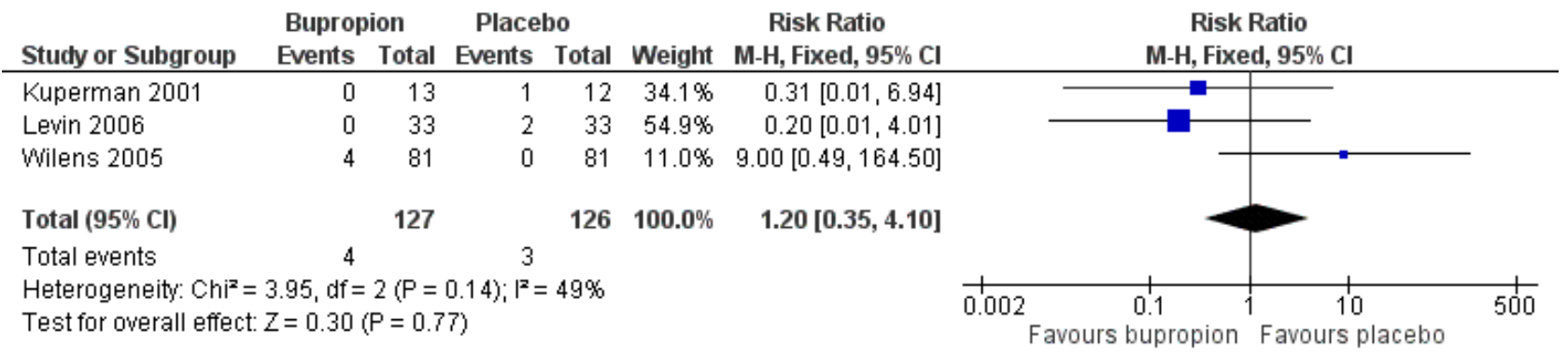

One study (Hamedi 2014) reported that the maximum dose in their study was $150 \mathrm{mg}$ a day, due to adverse events. Some cases were dropped due to side effects but the exact numbers were not reported.

\section{Secondary outcomes}

\section{Efficacy outcomes}

A. Clinical impression

No studies reported data on this outcome. 


\section{B Global level of functioning}

Two studies (Reimherr 2005; Wilens 2005) used the Global Assessment of Functioning (GAF) scale (Goldman 1992). These were not pooled as Reimherr 2005 reported only the mean final values (at study completion), while Wilens 2005 reported mean change from baseline scores. Reimherr 2005 found no differences while Wilens 2005 reported an increased change from baseline in the group that received bupropion. The results of these studies are reported in Table 2.

\section{Social adjustment}

No studies reported data on this outcome.

\section{Depressive symptoms}

Two studies (184 participants) reported the mean change from baseline for depressive symptoms using the Hamilton Depression Rating Scale (HAM-D; Hamilton 1960) (Kuperman 2001; Wilens 2005). The pooled, fixed-effect MD between bupropion and placebo was $0.52(95 \% \mathrm{Cl}-0.46$ to $1.51, \mathrm{I} 2=0 \%$; see Analysis 1.5$)$.

Wilens 2001 did not quantify results for depression but only reported that they found no significant treatment effect of bupropion on this outcome variable.

\section{E. Anxiety}

Two studies (184 participants) reported the mean change from baseline for anxiety using Hamiliton Anxiety Rating Scale (HAM-A; Maier 1988) (Kuperman 2001; Wilens 2005). The pooled, fixed-effect MD between bupropion and placebo was $0.36\left(-0.72\right.$ to $1.43,1^{2}=0 \%$; see Analysis 1.6).

Wilens 2001 did not quantify results for anxiety but only reported that they found no significant treatment effect of bupropion on this outcome variable.

\section{Adverse events}

\section{A. Proportion of participants withdrawn due to any somatic adverse event}

The reasons for withdrawal were typically not reported and therefore it was not possible to analyse the number of participants who withdrew due to somatic adverse events.

\section{B. Proportion of participants withdrawn due to any psychiatric adverse event}

The reasons for withdrawal were typically not reported and therefore it was not possible to analyse the number of participants who withdrew due to psychiatric adverse events.

\section{Other adverse effect outcomes}

As adverse effects were sparsely reported in the studies, we added analyses on related outcomes that were reported, which were: the retention rate, the number of participants that lowered their dose due to adverse effects, and the number of participants with at least one adverse effect (see Differences between protocol and review).

Five studies (352 participants) reported retention rates (number of participants completing the study). The pooled, fixed-effect RR for completing the treatment was $0.96\left(95 \% \mathrm{Cl} 0.87\right.$ to $1.06, \mathrm{I}^{2}=0 \%$; see Analysis 1.7).
Two studies (104 participants) reported on the number of participants that lowered their dose due to adverse effects (Levin 2006; Wilens 2001). The pooled, fixed-effect RR was $1.86(95 \% \mathrm{Cl}$ 0.57 to $6.10, \mathrm{I}^{2}=0 \%$; see Analysis 1.8 ), indicating that participants on bupropion were more likely to lower their dose compared to those on placebo.

Three studies (227 participants) reported on the number of participants with at least one adverse effect (Kuperman 2001; Wilens 2001; Wilens 2005). The pooled, fixed-effect RR was 1.14 (95\% Cl 0.95 to $1.37, \mathrm{~L} 2=0 \%$, see Analysis 1.9).

It was not possible to evaluate the impact of adverse effects. Such details were reported sparsely and used different terminology. Wilens 2001 and Wilens 2005 stated that no serious adverse effects occurred. Kuperman 2001 noted only mild and moderate adverse effects, and Reimherr 2005 reported that "there were no significant adverse effects".

\section{Sensitivity analyses}

The severity of ADHD was assessed by the clinician in three studies (Reimherr 2005; Wilens 2001; Wilens 2005). We pooled in a metaanalysis data from two studies (Reimherr 2005; Wilens 2001), both of which reported final severity scores (see Analysis 2.1; 87 participants). This sensitivity analysis showed a non-significant result for the severity of ADHD when pooling only studies using clinician-rated scales (see also Table 3).

We were unable to pool the data from two studies, which assessed the severity of ADHD using patient-rated scales, as one reported final values (Hamedi 2014) and the other reported mean change from baseline (Kuperman 2001).

We performed sensitivity analyses on studies that excluded participants with psychiatric comorbidity (Hamedi 2014; Kuperman 2001; Reimherr 2005; Wilens 2005); see Analysis 2.2, Analysis 2.3, Analysis 2.4; Analysis 2.5. The results, which are very similar to our overall results, are presented in Table 3 for ease of comparison.

Finally, we performed sensitivity analyses using random-effects models. The results were similar to those obtained when using fixed-effect models. Table 3 presents the results of both models.

\section{DISCUSSION}

\section{Summary of main results}

Efficacy of pharmacotherapy in treating ADHD symptoms has generally been considerable, with at least three-quarters of individuals reported to benefit from pharmacotherapy, typically in the form of stimulants. While stimulant medications are the primary pharmacological treatment for ADHD during a lifespan, a subset of people with ADHD do not experience any benefit from stimulants or cannot tolerate effective stimulant doses (Waxmonsky 2005). We analysed the use of a nonstimulant psychopharmacologic agent, bupropion, to treat ADHD in adults.

Overall, the results of this review suggest a possible benefit of bupropion on core ADHD symptoms. All pooled point estimates of the three primary efficacy outcomes showed benefit for bupropion when compared to placebo. Groups that received bupropion had lower severity of ADHD symptoms, and more participants achieved a significant clinical improvement or improved at least one or two 
points on the CGI scale. The evidence is of low quality, mainly due to methodological limitations, poor reporting and a lack of precision, meaning that there is uncertainty in these results.

We also found low-quality evidence that suggests that the tolerability of bupropion is similar to that of placebo. Based on three studies, there was no difference between those given bupropion and those given placebo as regards risk of withdrawal from the study due to adverse effects. Also, we found no difference between bupropion and placebo for the other tolerability outcomes (i.e. overall retention rates, and the number of participants that lowered their dose due to adverse effects).

\section{Overall completeness and applicability of evidence}

We conducted this Cochrane Review to ascertain whether bupropion is a viable alternative for adults with ADHD who do not experience symptom relief or cannot tolerate the side effects of first-line agents such as stimulants. Our findings correlate with the recommendations reflected in major international guidelines (Bolea-Alamañac 2014; NICE 2008), where the effectiveness of bupropion reaches a $\mathrm{lb}$ level and is considered a second- or thirdline medication, for use in tertiary care services. It should be noted that bupropion is an unlicensed medication for the treatment of ADHD, so its use is considered off-label.

This review found only six RCTs. Of these, five had small samples, ranging from 11 to 33 participants in each group. We therefore cannot exclude a type II error, meaning that we cannot conclude that bupropion is not effective. Only short-term outcomes, from six to 10 weeks, were reported and dose regimens were not uniform across the studies. We therefore cannot confirm that efficacy and safety outcomes apply in the long term in this patient group, where chronic exposure to medication is the rule rather than the exception. Four studies excluded participants with psychiatric comorbidity and one study (Levin 2006) included methadone-maintained participants with ADHD. The exclusion of comorbid disorders in these studies is in contrast with the very high prevalence of associated disorders encountered in realworld practice. A substantial number of participants with ADHD suffer from mood, anxiety, developmental, and substance abuse disorders. The effects on daily functioning are ambiguous in most studies. Adverse effects were not always systematically evaluated. The methodological shortcomings, as described above, limit the generalisability of the results.

The predominance of white participants limits the generalisability of the findings. Although none of the studies remarked on ethnic effects, there is some evidence that metabolism of bupropion differs across ethnic groups. In humans, bupropion is metabolised by cytochrome P450 2B6 (CYP-2B6) to its active metabolite. Hamedi 2014 administered a maximum of $150 \mathrm{mg}$ a day because of side effects in their study population, which is a low dose compared to other trials. They hypothesised that genetic polymorphism across different ethnic groups with regard to CYP-2B6 activity may explain the differential response or vulnerability to side effects amongst different ethnic populations. Striking differences among different ethnic groups were observed, whereby CYP2B6 activity was 3.6- and five-fold higher in Hispanic women than in white or African-American women (Lamba 2003). Evidence of dependence of CYP2B6 activity on ethnicity or genotype-by-ethnicity interactions was not detected in women. These results suggest that the CYP2B6 genotype is the most important variable for predicting the level of
CYP2B6 activity in women, when measured by the metabolism of bupropion (Ilic 2013).

Sensitivity analyses suggested that the person who completes the scale on the severity of ADHD influences this outcome. We found no difference between bupropion and placebo measured using clinician-rated scales. In contrast, we observed a small difference between the two groups when pooling clinician-rated and selfrated scales. There is ample knowledge on the difference between self-rated and clinician-rated scales for ADHD. Adler 2008 found suggestive evidence that clinician-rated ADHD scores better predict the treatment effect. This does not match our results. However, our pooled result was based on only three small studies. Future studies should examine this topic in more detail.

This review identified studies up to February 2017. ADHD criteria have changed markedly over this period, and, in particular, the prevalence and comorbidity profile of this population has shifted significantly with the adoption of the DSM-5 in 2013. The DSM-5 changes have the potential for increases in ADHD prevalence and concomitant psychostimulant treatment. For example, raising the age of onset, combined with the requirement to show only symptoms in the past (rather than impairment), may increase levels of diagnosis (Sibley 2013). Close analysis shows that the changes in the DSM-5 are more than just a tweak in terminology. The result is likely to be a growth in levels of diagnosis and increased demands on clinical, health and education professionals (Prosser 2013). The consequences of recent changes in diagnostic practice arising from the use of $D S M-5$ and the effects of these on the generalisability of our findings are largely unknown. Future studies testing the effect of this criterion change in large population samples are therefore needed (Matte 2015).

People with ADHD are at risk for comorbidities such as depression. Bupropion is an anti-depressant and, if the drug is shown to be effective, we do not know the working mechanism in people with ADHD. Although some evidence suggests that bupropion may be useful in adolescents with a dual diagnosis of ADHD and depression (Daviss 2001), no studies of good quality have addressed the issue whether bupropion alleviates ADHD symptoms directly or whether it works indirectly through its antidepressant effects.

Another limitation of the studies has been the focus on ADHD symptoms as a measure of efficacy, as the effects of medication in ADHD is typically assessed using symptoms scales. However, cognitive benefits may be more important to patients than symptoms scales. The effects of bupropion on cognition in people with ADHD have yet to assessed directly. Several stimulants trials have demonstrate that when used at low and clinically-relevant doses, psychostimulants improve prefrontal cortex (PFC)-dependent behavioural or cognitive processes in people with and without ADHD (Mehta 2000; Rapoport 2002). One study found that bupropion improved attention, as measured by the CPT( Continuous performance Test), in people with schizophrenia (Evins 2005), while another found that bupropion partially improved visual memory and mental processing speed performance in people with a major depressive disorder (Bidwell 2011; Herrera-Guzmán 2008). Future studies should incorporate more measures of functional impairment.

Based on expert opinion, guidelines recommend consideration of the use of bupropion, if the risk of stimulant abuse is high (BoleaAlamañac 2014). Whether there is a therapeutic niche for bupropion 
as a first-line treatment for ADHD and comorbid substance abuse cannot be extrapolated from this review. Drug dependence is frequent in people with ADHD. A systematic review by Cunill 2015 showed that pharmacological nterventions (including bupropion) improved ADHD symptoms, but noted no beneficial effect on drug abstinence or on treatment discontinuation. The strength of the recommendation of pharmacological treatment for co-occurring ADHD and substance use disorder was therefore regarded as modest.

\section{Quality of the evidence}

We judged the overall quality of evidence in this review to be low. Reasons for downgrading were serious risk of bias and serious imprecision.

We considered the included studies to have serious risks of bias. The main reason was poor reporting, which meant that it was not possible to judge whether studies were free of important biases. All included studies were RCTs but none described the procedures used for sequence generation and only one for allocation concealment. All studies were reported as doubleblinded, but the methods for blinding were poorly described by study authors. Only two studies reported that they used identicallooking placebo tablets, which would imply that participants were blinded. Only one study reported that outcome assessors were blinded. Blinding is important to prevent bias for subjective outcomes such as the CGI scale (NIMH 1984), and adverse effects. As all outcomes in this review are subjective, lack of blinding could have affected the results of the studies. We judged none of the studies to be free of selective reporting, as the protocol was not available for most of them. Finally, none of the studies used a true intention-to-treat analysis. Typically, the numbers of participants analysed were not reported or a modified intentionto-treat analysis was used, including a subset of all randomised participants. Participants who are randomised but not included in analyses are likely to differ from those who are included in an analysis, and this may potentially lead to bias. The limitations in study design were one of the reasons to downgrade the level of evidence (see Summary of findings for the main comparison).

We judged results for all outcomes to be imprecise. Of our six included studies, five had a sample size of fewer than 50 . There were fewer than 300 events for all dichotomous outcomes, which does not meet the OIS criterion as suggested by the GRADE Handbook (Schünemann 2013). This imprecision due to the small number of events is a major limitation that hampers the generalisability of these results. We found no limitations with respect to the consistency of effect or indirectness. For each outcome, we judged the results to be consistent and direct.

Four of the six studies were sponsored by industry, but the effects of funding on study results were not clear. For example, there may be a difference between trials that were performed by industry versus trials that were performed by an investigator. From personal correspondence, we know that two studies were investigatordriven (Kuperman 2001; Reimherr 2005); this is unclear for all other studies. The two remaining studies were publicly funded, though the lead author in one of these studies was a consultant for several pharmaceutical companies and also received investigator-driven funding from two companies, however none of these companies manufacture bupropion. We therefore cannot make assumptions on the effects of funding on the conclusions of the review.

\section{Potential biases in the review process}

We conducted a comprehensive search of the literature and did not apply any restrictions by language or publication status. However, we cannot be sure that we found all relevant studies. We were not able to statistically assess the risk of publication bias due to the small number of studies, however some characteristics of this review may indicate a potential risk of publication bias. For example, four studies were sponsored by pharmaceutical companies that produce bupropion, and the lead author of one of the two publicly-funded studies was paid by industry (although not by the manufacturers of bupropion) for research activities. Lexchin 2003 investigated whether the quality of the methods in studies funded by pharmaceutical companies differs from that in other studies and concluded that "studies sponsored by pharmaceutical companies were more likely to have outcomes favouring the sponsor than were studies with other sponsors". One of the explanations that they provided for these results was publication bias. We are not able to confirm or refute this conclusion, as the majority of our included studies were sponsored by industry. Another indication of publication bias was the lack of studies with negative results, which may be due to sampling variance even if there is in general a positive effect. Hopewell 2009 found that studies with positive results are more likely to be published than studies with negative results.

The included studies in this review do not provide an adequate basis for the assessment of adverse effects. The results of this review, with respect to the adverse effects, may therefore underestimate the adverse effects in real life. The duration of trials was six to 10 weeks, and provided no information on longer-term effects. The studies do not provide a clear picture of the severity of the adverse effects. We anticipated analysing the proportion of participants that withdrew due to psychiatric or somatic adverse effects, but causes of withdrawal were not reported. During data extraction, we noted two trials reporting on 'the number of participants that lowered their dose due to adverse events'. This outcome implies an impact or severity of adverse effects because participants will lower their dose when adverse effects outweigh the benefits gained from bupropion. Consequently, we added this outcome to this review post hoc (see Differences between protocol and review). Future reviews should try to capture the impact or severity of adverse effects of bupropion on the participant.

\section{Agreements and disagreements with other studies or reviews}

Two previous systematic reviews have assessed the effects of bupropion for adult ADHD. Faraone 2010 estimated effect sizes of different medications for adult ADHD. They included doubleblinded, placebo-controlled studies of ADHD in adults that presented the means and SDs of either change or endpoint scores for intervention and placebo groups. Out of 18 records, they found three studies that evaluated bupropion versus placebo (Reimherr 2005; Wilens 2001; Wilens 2005). Whilst they did not provide an estimate of effects for the thee studies of bupropion, they estimated the number needed to treat for an additional beneficial outcome (NNTB) to be approximately 4.5 for bupropion.

Maneeton 2011 aimed to systematically review the efficacy, acceptability, and tolerability of bupropion compared to placebo for adults with ADHD. They included five trials also included in our review and reached similar conclusions. There are some differences 
between their review and ours in the way that results are included in the analysis. For example, we set higher standards for methodological quality, concluding that for most items reporting was incomplete to make a robust assessment, whereas Maneeton 2011 judged all studies to be at low risk of bias. The authors concluded that evidence suggests that bupropion is effective and safe for adults with ADHD. Although the conclusions are similar to our review, their review lacks any caution with respect to their conclusion due to small studies sizes and poor reporting of study quality.

\section{AUTHORS' CONCLUSIONS}

\section{Implications for practice}

This review found suggestive evidence on the effectiveness of bupropion. Tolerability of bupropion appears similar to that of placebo. The quality was low, indicating uncertainty. Currently, guidance for practice can only be based on these data, which are limited in amount and in quality. Extended- or sustained-release bupropion may be an alternative compound to stimulants in the pharmacological treatment of adults with ADHD. However, based on the evidence, prescribers may wish to exercise caution in the prolonged use of bupropion in ADHD, given the lack of studies that have assessed long-term outcomes. Due to the limited number of studies, we can offer no guidance on sequential use after or instead of methylphenidate, or preferred use in participants with comorbid depression. In future, Research Domain Critera (RDoC; see below) may provide a means of reclassifying this population in ways that could prospectively differentiate bupropion responders from nonresponders, based on parameters that are not employed in clinical practice using current ADHD criteria.

\section{Implications for research}

First, a better understanding of the underlying pathophysiology of ADHD is necessary. A deeper insight into the different molecular subtypes of ADHD would inform us as to which group of medications would match a particular individual. Also, the underlying neurochemistry of ADHD and comorbid conditions, such as mood disorders, is very limited and warrants further preclinical research.

Second, a new approach should be explored, aiming to reduce heterogeneity between studies of ADHD. Currently, inclusion in studies is typically based on behavioural criteria (top-down paradigms). In 2013, the National Institute of Mental Health (NIMH) suggested re-orienting away from the DSMs symptombased categories. They embarked on a new approach to psychiatric classification aimed at reflecting functional dimensions based on translational research on gene circuits and behaviour. The new framework is called RDoC, with broader research categories incorporating behavioural and neuroscience evidence (bottomup paradigm). The goal of $\mathrm{RDoC}$ is to relate fundamental domains of behavioural functioning to underlying neurobiological components, conceptualised as disorders in brain circuitry; the critical change is to a more empirically-based system rather than grounded in symptom-based diagnostic categories, which only constitute conventions between psychiatrists. According to First 2013, the RDoC approach represents a true paradigm shift in the classification of mental disorders, moving away from defining disorders based on descriptive phenomenology, to a focus on neural circuitry as the fundamental classificatory principle. He points out that RDoC's impact on future clinical classification in psychiatry will depend on how well the included molecular and neurobiological parameters predict prognosis and treatment response.

In the meantime, the quality of trials could be improved by emphasising effectiveness outcomes, in contrast to efficacy outcomes. Also, future studies should assess potential cognitive benefits. Current clinical trials have strict exclusion criteria, and the extent to which these results apply to patients who, in routine practice, would have been excluded from participation in those trials is unclear. Trials could therefore include more 'naturalistic' participants with comorbid disorders that are highly prevalent amongst adults with ADHD, such as mood disorders and substance use disorders. Furthermore, more long-term effectiveness studies are warranted, assessing the impact on the quality of life and ability to function in occupational, social and leisure spheres. They should include sufficient sample sizes, and make use of validated outcome measures. In addition, long-term assessments of the safety of this drug are needed, because the pharmacological treatment of ADHD is usually chronic in nature. Finally, future head-to-head studies comparing efficacy and safety with approved agents, such as stimulants and atomoxetine, will benefit practice recommendations in this field.

\section{ACKNOWLEDGEMENTS}

We acknowledge, with gratitude, the comments of Professor Geraldine Macdonald, Co-ordinating Editor of the Cochrane Developmental, Psychosocial and Learning Problems Group (CDPLPG), and the assistance of Laura MacDonald (former Managing Editor), Margaret Anderson (Information Specialist), Dr Joanne Wilson (Managing Editor), and Gemma O'Loughlin (Assistant Managing Editor) in the development of this review. 


\section{RE F E R E N C E S}

\section{References to studies included in this review}

Hamedi 2014 \{published data only\}

Hamedi M, Mohammadi M, Ghaleiha A, Keshavarzi Z, Jafarinia M, Keramatfar R, et al. Bupropion in adults with attention-deficit/hyperactivity disorder: a randomized doubleblinded study. Acta Medica Iranica 2014;52(9):675-80. [PUBMED: 25325205]

\section{Kuperman 2001 \{published data only\}}

Kuperman S [pers comm]. Reply to: Cochrane review [personal communication]. Email to: W Verbeeck 07 June 2016.

* Kuperman S, Perry PJ, Gaffney GR, Lund BC, Bever-Stille KA, Arndt S, et al. Bupropion SR vs. methylphenidate vs. placebo for attention deficit hyperactivity disorder in adults. Annals of Clinical Psychiatry 2001;13(3):129-34. [PUBMED: 11791949]

Verbeeck W [pers comm]. Cochrane review [personal communication]. Email to: S Kuperman 05 June 2016.

\section{Levin 2006 \{published data only\}}

Levin FR, Evans SM, Brooks DJ, Kalbag AS, Garawi F, Nunes EV. Treatment of methadone-maintained patients with adult ADHD: double-blind comparison of methylphenidate, bupropion and placebo. Drug and Alcohol Dependence 2006;81(2):137-48. [DOI: 10.1016/j.drugalcdep.2005.06.012; PUBMED: 16102908]

\section{Reimherr 2005 \{published data only\}}

Reimherr F [pers comm]. Reply to: Cochrane review [personal communication]. Email to: W Verbeeck 06 June 2016.

* Reimherr FW, Hedges DW, Strong RE, Marchant BK, Williams ED. Bupropion SR in adults with ADHD: a shortterm, placebo-controlled trial. Neuropsychiatric Disease and Treatment 2005;1(3):245-51. [PMC2416755; PUBMED: 18568102]

Verbeeck W [pers comm]. Cochrane review [personal communication]. Email to: F Reimherr 05 June 2016.

\section{Wilens 2001 \{published data only\}}

Wilens TE, Spencer TJ, Biederman J, Girard K, Doyle R, Prince J, et al. A controlled clinical trial of bupropion for attention deficit hyperactivity disorder in adults. American Journal of Psychiatry 2001;158(2):282-8. [DOI: 10.1176/appi.ajp.158.2.282; PUBMED: $11156812]$

\section{Wilens 2005 \{published data only\}}

Hudziak JJ, Wilens TE, Connor DF, Haight BR, Horrigan JP, Hampton KD, et al. A controlled trial of extendedrelease bupropion in adult ADHD. Biological Psychiatry 2004;8(Suppl):135S.

* Wilens TE, Haight BR, Horrigan JP, Hudziak JJ, Rosenthal NE, Connor DF, et al. Bupropion XL in adults with attention-deficit/ hyperactivity disorder: a randomized, placebo-controlled study. Biological Psychiatry 2005;57(7):793-801. [DOI: 10.1016/ j.biopsych.2005.01.027; PUBMED: 15820237]

\section{References to studies excluded from this review}

Clay 1988 \{published data only\}

Clay TH, Gualtieri CT, Evans RW, Gullion CM. Clinical and neuropsychological effects of the novel antidepressant bupropion. Psychopharmacology Bulletin 1988;24(1):143-8. [PUBMED: 3133717]

\section{Additional references}

\section{Adler 2008}

Adler LA, Faraone SV, Spencer TJ, Michelson D, Reimherr FW, Glatt SJ, et al. The reliability and validity of self- and investigator ratings of $A D H D$ in adults. Journal of Attention Disorders 2008;11(6):711-9. [DOI: 10.1177/1087054707308503; PUBMED: 18025250]

\section{APA 2000}

American Psychiatric Association. Diagnostic and Statistical Manual of Mental Disorders. 4th Edition. Washington (DC): APA, 2000.

\section{APA 2013}

American Psychiatric Association. Diagnostic and Statistical Manual of Mental Disorders (DSM-5 ${ }^{\circledR}$ ), Fifth Edition. Arlington (VA): American Psychiatric Publishing, 2013.

\section{Argyelán 2005}

Argyelán M, Szabó Z, Kanyó B, Tanács A, Kovács Z, Janka Z, et al. Dopamine transporter availability in medication free and in bupropion treated depression: a 99mTc-TRODAT-1 SPECT study. Journal of Affective Disorders 2005;89(1-3):115-23. [DOI: 10.1016/ j.jad.2005.08.016; PUBMED: 16213028]

\section{Arnsten 2005}

Arnsten AF, Li BM. Neurobiology of executive functions: catecholamine influences on prefrontal cortical functions. Biological Psychiatry 2005;57(11):1377-84. [DOI: 10.1016/ j.biopsych.2004.08.019; PUBMED: 15950011]

\section{Asherson 2005}

Asherson P. Clinical assessment and treatment of attention deficit hyperactivity disorder in adults. Expert Review of Neurotherapeutics 2005;5(4):525-39. [DOI: 10.1586/14737175.5.4.525; PUBMED: 16026236]

\section{Ashton 2006}

Ashton H, Gallagher P, Moore B. The adult psychiatrist's dilemma: psychostimulant use in attention deficit/hyperactivity disorder. Journal of Psychopharmacology 2006;20(5):602-10. [DOI: 10.1177/0269881106061710; PUBMED: 16478756]

\section{Banerjee 2007}

Banerjee TD, Middleton F, Faraone SV. Environmental risk factors for attention-deficit hyperactivity disorder. Acta Paediatrica 2007;96(9):1269-74. [DOI: 10.1111/ j.1651-2227.2007.00430.x; PUBMED: 17718779] 


\section{Baribeau 2013}

Baribeau D, Araki KF. Intravenous bupropion: a previously undocumented method of abuse of a commonly prescribed antidepressant agent. Journal of Addiction Medicine 2013;7(3):216-7. [DOI: 10.1097/ADM.0b013e3182824863; PUBMED: 23519045]

\section{Barkley 1990}

Barkley RA. Attention-Deficit Hyperactivity Disorder: a Handbook for Diagnosis and Treatment. New York: Guilford Press, 1990.

\section{Berridge 2006}

Berridge CW, Devilbiss DM, Andrzejewski ME, Arnsten AF, Kelley AE, Schmeichel B, et al. Methylphenidate preferentially increases catecholamine neurotransmission within the prefrontal cortex at low doses that enhance cognitive function. Biological Psychiatry 2006;60(10):1111-20. [DOI: 10.1016/ j.biopsych.2006.04.022; PUBMED: 16806100]

\section{Bidwell 2011}

Bidwell LC, McClernon FJ, Kollins SH. Cognitive enhancers for the treatment of ADHD. Pharmacology, Biochemistry, and Behavior 2011;99(2):262-74. [DOI: 10.1016/j.pbb.2011.05.002; PMC3353150; PUBMED: 21596055]

\section{Biederman 2005}

Biederman J, Faraone SV. Attention-deficit hyperactivity disorder. Lancet 2005;366(9481):237-48. [DOI: 10.1016/ S0140-6736(05)66915-2; PUBMED: 16023516]

\section{Biederman 2006}

Biederman J. Introduction: new developments in the treatment of attention-deficit/hyperactivity disorder. Journal of Clinical Psychiatry 2006;67(Suppl 8):4-6. [PUBMED: 16961423]

\section{Bolea-Alamañac 2014}

Bolea-Alamañac B, Nutt DJ, Adamou M, Asherson P, Bazire S, Coghill D, et al. Evidence-based guidelines for the pharmacological management of attention deficit hyperactivity disorder: update on recommendations from the British Association for Psychopharmacology. Journal of Psychopharmacology 2014;28(3):179-203. [DOI: 10.1177/0269881113519509; PUBMED: 24526134]

\section{Bush 2005}

Bush G, Valera EM, Seidman LJ. Functional neuroimaging of attention-deficit/hyperactivity disorder: a review and suggested future directions. Biological Psychiatry 2005;57(11):1273-84. [DOI: 10.1016/j.biopsych.2005.01.034; PUBMED: 15949999]

\section{CADDRA 2011}

Canadian Attention Deficit Hyperactivity Disorder Resource Alliance (CADDRA). Canadian ADHD Practice Guidelines (CAPGuidlines), 3rd Edition. www.caddra.ca/practice-guidelines (accessed prior to 30 May 2017).

\section{CDC 2015}

Centers for Disease Control and Prevention (CDC). Attention Deficit/Hyperactivity Disorder (ADHD). Symptoms and diagnosis. www.cdc.gov/ncbddd/adhd/diagnosis.html (accessed 19 May 2015).

\section{Conners 2003}

DeGeorge Macey K. Book review. Conners' adult ADHD rating scales (CAARS). Archives of Clinical Neuropsychology 2003;18(4):431-7. [DOI: 10.1016/S0887-6177(03)00021-0]

\section{Cunill 2015}

Cunill R, Castells X, Tobias A, Capellà D. Pharmacological treatment of attention deficit hyperactivity disorder with comorbid drug dependence. Journal of Psychopharmacology 2015;29(1):15-23. [DOI: 10.1177/0269881114544777; PUBMED: 25142405]

\section{Daviss 2001}

Daviss WB, Bentivoglio P, Racusin R, Brown KM, Bostic JQ, Wiley L. Bupropion sustained release in adolescents with comorbid attention-deficit/hyperactivity disorder and depression. Journal of the American Academy of Child Adolescent Psychiatry 2001;40(3):307-14. [DOI: 10.1097/00004583-200103000-00010; PUBMED: 11288772]

\section{Deeks 2011}

Deeks JJ, Higgins JPT, Altman DG, editor(s). Chapter 9: Analysing data and undertaking meta-analyses. In: Higgins JP, Green S, editor(s). Cochrane Handbook for Systematic Reviews of Interventions Version 5.1.0 (updated March 2011). The Cochrane Collaboration, 2011. Available from handbook.cochrane.org.

\section{Demyttenaere 2008}

Demyttenaere K, Jaspers L. Review: bupropion and SSRIinduced side effects. Journal of Psychopharmacology 2008;22(7):792-804. [DOI: 10.1177/0269881107083798; PUBMED: 18308785]

\section{Dhillon 2008}

Dhillon S, Yang LP, Curran MP. Bupropion: a review of its use in the management of major depressive disorder. Drugs 2008;68(5):653-89. [PUBMED: 18370448]

\section{Dopheide 2009}

Dopheide JA, Pliszka SR. Attention-deficit-hyperactivity disorder: an update. Pharmacotherapy 2009;29(6):656-79. [DOI: 10.1592/phco.29.6.656; PUBMED: 19476419]

\section{DuPaul 1990}

DuPaul GJ. The ADHD Rating Scale: Normative Data, Reliability, and Validity. Worchester (MA): University of Massachusetts Medical Center, 1990.

\section{Egerton 2010}

Egerton A, Shotbolt JP, Stokes PR, Hirani E, Ahmad R, Lappin JM, et al. Acute effect of the anti-addiction drug bupropion on extracellular dopamine concentrations in the human striatum: an [11C]raclopride PET study. Neuroimage 2010;50(1):260-6. [DOI: 10.1016/j.neuroimage.2009.11.077; PMC4135078; PUBMED: 19969097] 


\section{Evins 2005}

Evins AE, Deckersbach T, Cather C, Freudenreich O, Culhane MA, Henderson DC, et al. Independent effects of tobacco abstinence and bupropion on cognitive function in schizophrenia. Journal of Clinical Psychiatry 2005;66(9):1184-90. [PUBMED: 16187778]

\section{Faraone 1998}

Faraone SV, Biederman J. Neurobiology of attention-deficit hyperactivity disorder. Biological Psychiatry 1998;44(10):951-8. [PUBMED: 9821559]

\section{Faraone 2004}

Faraone SV, Spencer T, Aleardi M, Pagano C, Biederman J. Meta-analysis of the efficacy of methylphenidate for treating adult attention-deficit/hyperactivity disorder. Journal of Clinical Psychopharmacology 2004;24(1):24-9. [DOI: 10.1097/01.jcp.0000108984.11879.95; PUBMED: 14709943]

\section{Faraone 2006}

Faraone SV, Biederman J, Spencer TJ, Aleardi M. Comparing the efficacy of medications for ADHD using meta-analysis. Medscape General Medicine 2006;8(4):4. [PUBMED: 17415287]

\section{Faraone $\mathbf{2 0 1 0}$}

Faraone SV, Glatt SJ. A comparison of the efficacy of medications for adult attention-deficit/hyperactivity disorder using meta-analysis of effect sizes. Journal of Clinical Psychiatry 2010;71(6):754-63. [DOI: 10.4088/JCP.08m04902pur; PUBMED: 20051220]

\section{Fayyad 2007}

Fayyad J, De Graaf R, Kessler R, Alonso J, Angermeyer M, Demyttenaere $\mathrm{K}$, et al. Cross-national prevalence and correlates of adult attention-deficit hyperactivity disorder. British Journal of Psychiatry 2007;190:402-9. [DOI: 10.1192/bjp.bp.106.034389; PUBMED: 17470954]

\section{Findling 2010}

Findling RL, Brams M, Childress AC, López FA, Manos MJ, Jensen PS. Changes in emotions related to medication used to treat ADHD. Part II: clinical approaches. Journal of Attention Disorders 2010;15(2):113-21. [DOI: 10.1177/1087054710381232; PUBMED: 20858786]

\section{First 2013}

First MB. Comments: The National Institute of Mental Health Research Domain Criteria (RDoC) project: moving towards a neuroscience-based diagnostic classification in psychiatry. In: Kendler KS, Parnas J editor(s). Philosophical Issues in Psychiatry II: Nosology. Oxford: Oxford University Press, 2013:12-8.

\section{Gobbi 2003}

Gobbi G, Slater S, Boucher N, Debonnel G, Blier P. Neurochemical and psychotropic effects of bupropion in healthy male subjects. Journal of Clinical Psychopharmacology 2003;23(3):233-9. [DOI: 10.1097/01.jcp.0000084023.22282.03; PUBMED: 12826985$]$

\section{Golden 1988a}

Golden RN, Rudorfer MV, Sherer MA, Linnoila M, Potter WZ. Bupropion in depression. I Biochemical effects and clinical response. Archives of General Psychiatry 1988;45(2):139-43. [PUBMED: 3122698]

\section{Golden 1988b}

Golden RN, De Vane CL, Laizure SC, Rudorfer MV, Sherer MA, Potter WZ. Bupropion in depression. II. The role of metabolites in clinical outcome. Archives of General Psychiatry 1988;45(2):145-9. [PUBMED: 3122699]

\section{Goldman 1992}

Goldman HH, Skodol AE, Lave TR. Revising axis V for DSM-IV: a review of measures of social functioning. American Journal of Psychiatry 1992;149(9):1148-56. [DOI: 10.1176/ajp.149.9.1148; PUBMED: 1386964]

\section{Greenhill 2002}

Greenhill LL, Pliszka S, Dulcan MK, Bernet W, Arnold V, Beitchman J, et al. Practice parameter for the use of stimulant medications in the treatment of children, adolescents, and adults. Journal of the American Academy of Child and Adolescent Psychiatry 2002;41(2 Suppl):26S-49S. [PUBMED: 11833633]

\section{Guy 1976}

Guy W. Clinical global impressions. In: US Department of Health, Education, WelfarePublic Health Service, Alcohol, Drug Abuse and Mental Health Administration, editor(s). ECDEU Assessment Manual for Psychopharmacology. Rockville (MD): NIMH Psychopharmacology Research Branch, 1976:218-222.

\section{Guyatt 2011a}

Guyatt GH, Oxman AD, Akl EA, Kunz R, Vist G, Brozek J, et al. GRADE guidelines: 1. Introduction-GRADE evidence profiles and summary of findings tables. Journal of Clinical Epidemiology 2011;64(4):383-94. [DOI: 10.1016/ j.jclinepi.2010.04.026; PUBMED: 21195583]

\section{Guyatt 2011b}

Guyatt GH, Oxman AD, Kunz R, Brozek J, Alonso-Coello P, Rind $D$, et al. GRADE guidelines 6 . Rating the quality of evidence - imprecision. Journal of Clinical Epidemiology 2011;64(12):1283-93. [DOI: 10.1016/j.jclinepi.2011.01.012; PUBMED: 21839614]

\section{Guyatt 2011c}

Guyatt GH, Oxman AD, Kunz R, Woodcock J, Brozek J, Helfand M, et al. GRADE guidelines: 7. Rating the quality of evidence: inconsistency. Journal of Clinical Epidemiology 2011;64(12):1294-1302. [DOI: 10.1016/j.jclinepi.2011.03.017; PUBMED: 21803546]

\section{Guyatt 2011d}

Guyatt GH, Oxman AD, Kunz R, Woodcock J, Brozek J, Helfand M, et al. GRADE guidelines: 8. Rating the quality of evidence - indirectness. Journal of Clinical Epidemiology 2011;64(12):1303-10. [DOI: 10.1016/j.jclinepi.2011.04.014; PUBMED: 21802903] 


\section{Hamilton 1960}

Hamilton M. A rating scale for depression. Journal of Neurology, Neurosurgery and Psychiatry 1960;23:56-62. [10.1136/ jnnp.23.1.56 PMID 14399272]

\section{Herrera-Guzmán 2008}

Herrera-Guzmán I, Gudayol-Ferré E, Lira-Mandujano J, Herrera-Abarca J, Herrera-Guzmán D, Montoya-Pérez K, et al. Cognitive predictors of treatment response to bupropion and cognitive effects of bupropion in patients with major depressive disorder. Psychiatry Research 2008;160(1):72-82. [DOI: 10.1016/ j.psychres.2007.04.012; PUBMED: 18501971]

\section{Higgins 2003}

Higgins JP, Thompson SG, Deeks JJ, Altman DG. Measuring inconsistency in meta-analyses. BMJ 2003;327(7414):557-60. [DOI: 10.1136/bmj.327.7414.557]

\section{Higgins 2011}

Higgins JPT, Altman DG, Sterne JAC, editor(s). Chapter 8: Assessing risk of bias in included studies. In: Higgins JP, Green $\mathrm{S}$, editor(s). Cochrane Handbook for Systematic Reviews of Interventions Version 5.1.0 (updated March 2011). The Cochrane Collaboration, 2011. Available from handbook.cochrane.org.

\section{Hilliard 2013}

Hilliard WT, Barloon L, Farley P, Penn JV, Koranek A. Bupropion diversion and misuse in the correctional facility. Journal of Correctional Health Care 2013;19(3):211-7. [DOI: 10.1177/1078345813486448; PUBMED: 23788587]

\section{Himpel 2005}

Himpel S, Banaschewski T, Heise CA, Rothenberger A. The safety of non-stimulant agents for the treatment of attentiondeficit hyperactivity disorder. Expert Opinion on Drug Safety 2005;4(2):311-21. [PUBMED: 15794722]

\section{Hopewell 2009}

Hopewell S, Loudon K, Clarke MJ, Oxman AD, Dickersin K. Publication bias in clinical trials due to statistical significance or direction of trial results. Cochrane Database of Systematic Reviews 2009, Issue 1. [DOI: 10.1002/14651858.MR000006.pub3]

\section{Ilic 2013}

Ilic K, Hawke RL, Thirumaran RK, Schuetz EG, Hull JH, Kashuba AD, et al. The influence of sex, ethnicity, and CYP2B6 genotype on bupropion metabolism as an index of hepatic CYP2B6 activity in humans. Drug Metabolism and Disposition 2013;41(3):575-81. [DOI: 10.1124/dmd.112.048108; PMC4162003]

\section{Jefferson 2005}

Jefferson JW, Pradko JF, Muir KT. Bupropion for major depressive disorder: pharmacokinetic and formulation considerations. Clinical Therapeutics 2005;27(11):1685-95. [DOI: 10.1016/j.clinthera.2005.11.011; PUBMED: 16368442]

\section{Kooij 2010}

Kooij SJ, Bejerot S, Blackwell A, Caci H, Casas-Brugué M, Carpentier PJ, et al. European consensus statement on diagnosis and treatment of adult ADHD: the European
Network Adult ADHD. BMC Psychiatry 2010;10:67. [DOI: 10.1186/1471-244X-10-67]

\section{Lamba 2003}

Lamba V, Lamba J, Yasuda K, Strom S, Davila J, Hancock ML, et al. Hepatic CYP2B6 expression: gender and ethnic differences and relationship to CYP2B6 genotype and CAR (Constitutive Androstane Receptor) expression. Journal of Pharmacology and Experimental Therapeutics 2003;307(3):906-22. [DOI: 10.1124/ jpet.103.054866; PUBMED: 14551287]

\section{Learned-Coughlin 2003}

Learned-Coughlin SM, Bergström M, Savitcheva I, Ascher J, Schmith VD, Långstrom $B$. In vivo activity of bupropion at the human dopamine transporter as measured by positron emission tomography. Biological Psychiatry 2003;54(8):800-5. [PUBMED: 14550679]

\section{Leonard 2004}

Leonard BE, McCartan D, White J, King DJ. Methylphenidate: a review of its neuropharmacological, neuropsychological and adverse clinical effects. Human Psychopharmacology 2004;19(3):151-80. [DOI: 10.1002/hup.579; PUBMED: 15079851]

\section{Lexchin 2003}

Lexchin J, Bero LA, Djulbegovic B, Clark O. Pharmaceutical industry sponsorship and research outcome and quality: $a$ systematic review. BMJ 2003;326(7400):1167-70. [DOI: 10.1136/ bmj.326.7400.1167; PMC156458; PUBMED: 12775614]

\section{Maier 1988}

Maier W, Buller R, Philipp M, Heuser I. The Hamilton Anxiety Scale: reliability, validity and sensitivity to change in anxiety and depressive disorders. Journal of Affective Disorders 1988;14(1):61-8. [PUBMED: 2963053]

\section{Maneeton 2011}

Maneeton N, Maneeton B, Srisurapanont M, Martin SD. Bupropion for adults with attention-deficit hyperactivity disorder: meta-analysis of randomized, placebo-controlled trials. Psychiatry and Clinical Neurosciences 2011;65(7):611-7. [DOI: 10.1111/j.1440-1819.2011.02264.x; PUBMED: 22176279]

\section{Maneeton 2014}

Maneeton N, Maneeton B, Intaprasert S, Woottiluk P. A systematic review of randomized controlled trials of bupropion versus methylphenidate in the treatment of attention-deficit/ hyperactivity disorder. Neuropsychiatric Disease and Treatment 2014;10:1439-49. [DOI: 10.2147/NDT.S62714; PMC4128852; PUBMED: 25120365]

\section{Marchant 2013}

Marchant, BK, Reimherr FW, Robison D, Robison RJ, Wender PH. Psychometric properties of the Wender-Reimherr Adult Attention Deficit Disorder Scale. Psychological Assessment Sept 2013;25(3):942-50. [DOI: 10.1037/a0032797; PUBMED: 23647041]

\section{Matte 2015}

Matte B, Rohde LA, Turner JB, Fisher PW, Shen S, Bau CH, et al. Reliability and validity of proposed DSM-5 ADHD symptoms in a clinical sample of adults. Journal of Neuropsychiatry 
and Clinical Neurosciences 2015;27(3):228-36. [DOI: 10.1176/ appi.neuropsych.13060137; PUBMED: 26067434]

\section{Mehta 2000}

Mehta MA, Owen AM, Sahakian BJ, Mavaddat N, Pickard JD, Robbins TW. Methylphenidate enhances working memory by modulating discrete frontal and parietal lobe regions in the human brain. Journal of Neuroscience 2000;20(6):RC65. [PUBMED: 10704519]

\section{Meyer 2002}

Meyer JH, Goulding VS, Wilson AA, Hussey D, Christensen BK, Houle S. Bupropion occupancy of the dopamine transporter is low during clinical treatment. Psychopharmacology 2002;163(1):102-5. [DOI: 10.1007/s00213-002-1166-3; PUBMED: $12185406]$

\section{Moher 2009}

Moher D, Liberati A, Tetzlaff J, Altman DG, PRISMA Group. Preferred reporting items for systematic reviews and meta-analyses: the PRISMA statement. PLoS Medicine 2009;6(7):e1000097. [DOI: 10.1371/journal.pmed.1000097; PMC2707599; PUBMED: 19621072]

\section{Moriyama 2013}

Moriyama TS, Polanczyk GV, Terzi FS, Faria KM, Rohde LA. Psychopharmacology and psychotherapy for the treatment of adults with ADHD-a systematic review of available metaanalyses. CNS Spectrums 2013;18(6):296-306. [DOI: 10.1017/ S109285291300031X; PUBMED: 23739183]

\section{Murphy 1996}

Murphy K, Barkley RA. Prevalence of DSM-IV symptoms of ADHD in adult licensed drivers: implications for clinical diagnosis. Journal of Attention Disorders 1996;1(3):147-61. [DOI: 10.1177/108705479600100303]

\section{Newcorn 2008a}

Newcorn JH. Nonstimulants and emerging treatments in adults with ADHD. CNS Spectrums 2008;13(S13):12-6. [DOI: 10.1017/ S1092852900026857]

\section{Newcorn 2008b}

Newcorn JH, Kratochvil CJ, Allen AJ, Casat CD, Ruff DD, Moore RJ, et al. Atomoxetine/Methylphenidate Comparative Study Group. Atomoxetine and osmotically released methylphenidate for the treatment of attention deficit hyperactivity disorder: acute comparison and differential response. American Journal of Psychiatry 2008;165(6):721-30. [DOI: 10.1176/appi.ajp.2007.05091676; PUBMED: 18281409]

\section{NICE 2008}

National Institute for Health and Clinical Excellence. Attention deficit hyperactivity disorder: diagnosis and management of ADHD in children, young people and adults (NICE guidelines CG72). www.nice.org.uk/guidance/cg72 (accessed 19 May 2015).

\section{NIMH 1984}

National Institute of Mental Health. CGI (Clinical Global Impression Scale). Psychopharmacology Bulletin 1985;21:839-44.

\section{Nutt 2007}

Nutt DJ, Fone K, Asherson P, Bramble D, Hill P, Matthews K, et al. British Association for Psychopharmacology. Evidence-based guidelines for management of attention-deficit/hyperactivity disorder in adolescents in transition to adult services and in adults: recommendations from the British Association for Psychopharmacology. Journal of Psychopharmacology 2007;21(1):10-41. [DOI: 10.1177/0269881106073219; PUBMED: $17092962]$

\section{Oppek 2014}

Oppek K, Koller G, Zwergal A, Pogarell O. Intravenous administration and abuse of bupropion: a case report and a review of the literature. Journal of Addiction Medicine 2014;8(4):290-3. [DOI: 10.1097/ADM.0000000000000044; PUBMED: 24950138]

\section{Peterson 2008}

Peterson K, McDonagh MS, Fu R. Comparative benefits and harms of competing medications for adults with attentiondeficit hyperactivity disorder: a systematic review and indirect comparison meta-analysis. Psychopharmacology 2008;197(1):1-11. [DOI: 10.1007/s00213-007-0996-4; PUBMED: 18026719]

\section{Pisani 2002}

Pisani F, Oteri G, Costa C, Di Raimondo G, Di Perri R. Effects of psychotropic drugs on seizure threshold. Drug Safety 2002;25(2):91-110. [PUBMED: 11888352]

\section{Pliszka 2003}

Pliszka SR. Non-stimulant treatment of attention-deficit/ hyperactivity disorder. CNS Spectrums 2003;8(4):253-8. [PUBMED: 12679740]

\section{Popper 1997}

Popper CW. Antidepressants in the treatment of ADHD. Journal of Clinical Psychiatry 1997;58(Suppl 14):14-29. [PUBMED: 9418743]

\section{Prosser 2013}

Prosser B, Reid R. The DSM- 5 changes and ADHD: more than a tweak of terms. The Australian and New Zealand Journal of Psychiatry 2013;47(12):1196-7. [DOI: 10.1177/0004867413509695; PUBMED: 24159050]

\section{Rapoport 2002}

Rapoport JL, Inoff-Germain G. Responses to methylphenidate in Attention-Deficit/Hyperactivity Disorder and normal children: update 2002. Journal of Attention Disorders 2002;6(Suppl 1):S57-60. [PUBMED: 12685519]

\section{Rostain 2008}

Rostain AL. Attention-deficit/hyperactivity disorder in adults: evidence-based recommendations for management. Postgraduate Medicine 2008;120(3):27-38. [DOI: 10.3810/ pgm.2008.09.1905; PUBMED: 18824823]

\section{Sarampote 2004}

Sarampote CS, Efron LA, Robb AS, Pearl PL, Stein MA. Can stimulant rebound mimic pediatric bipolar disorder?. Journal 
of Child and Adolescent Psychopharmacology 2004;12(1):63-7. [DOI: 10.1089/10445460252943588; PUBMED: 12014597]

\section{Schünemann 2013}

Schünemann H, Brożek J, Guyatt G, Oxman A, GRADE Working Group. GRADE handbook for grading quality of evidence and strength of recommendations. www.guidelinedevelopment.org/handbook. (accessed prior to 30 May 2017).

\section{Sibley 2013}

Sibley MH, Waxmonsky JG, Robb JA, Pelham WE. Implications of changes for the field: ADHD. Journal of Learning Disabilities 2013;46(1):34-42. [DOI: 10.1177/0022219412464350; PUBMED: 23128456]

\section{Solhkhah 2005}

Solhkhah R, Wilens TE, Daly J, Prince JB, Van Patten SL, Biederman J. Bupropion SR for the treatment of substanceabusing outpatient adolescents with attention-deficit/ hyperactivity disorder and mood disorders. Journal of Child and Adolescent Psychopharmacology 2005;15(5):777-86. [DOI: 10.1089/cap.2005.15.777; PUBMED: 16262594]

\section{Sonuga-Barke 2005}

Sonuga-Barke EJ. Causal models of attention-deficit/ hyperactivity disorder: from common simple deficits to multiple developmental pathways. Biological Psychiatry 2005;57(11):1231-8. [DOI: 10.1016/j.biopsych.2004.09.008; PUBMED: 15949993]

\section{Spencer 2004}

Spencer T, Biederman J, Wilens T. Nonstimulant treatment of adult attention-deficit/hyperactivity disorder. Psychiatric Clinics of North America 2004;27(2):373-83. [DOI: 10.1016/ j.psc.2003.12.001; PUBMED: 15064003]

\section{Spencer 2005}

Spencer T, Biederman J, Wilens T, Doyle R, Surman C, Prince J, et al. A large, double-blind, randomized clinical trial of methylphenidate in the treatment of adults with attention-deficit/hyperactivity disorder. Biological Psychiatry 2005;57(5):456-63. [DOI: 10.1016/j.biopsych.2004.11.043; PUBMED: 15737659]

\section{Steinhausen 2009}

Steinhausen HC. The heterogeneity of causes and courses of attention-deficit/hyperactivity disorder. Acta Psychiatrica Scandinavica 2009;120(5):392-9. [DOI: 10.1111/ j.1600-0447.2009.01446.x; PUBMED: 19807721]

\section{Storebø 2015}

Storebø OJ, Ramstad E, Krogh HB, Nilausen TD, Skoog M, Holmskov M, et al. Methylphenidate for children and adolescents with attention deficit hyperactivity disorder (ADHD). Cochrane Database of Systematic Reviews 2015, Issue 11. [DOI: 10.1002/14651858.CD009885.pub2]

\section{Swanson 2003}

Swanson JM, Volkow ND. Serum and brain concentrations of methylphenidate: implications for use and abuse. Neuroscience and Biobehavioral Reviews 2003;27(7):615-21. [PUBMED: 14624806]

\section{Van den Noortgate 2003}

Van den Noortgate W, Onghena P. Multilevel meta-analysis: a comparison with traditional meta-analytical procedures. Educational and Psychological Measurement 2003;63(5):765-90. [DOI: 10.1177/0013164403251027]

\section{Vaughan 2008}

Vaughan BS, Wetzel MW, Kratochvil CJ. Beyond the 'typical' patient: treating attention-deficit/hyperactivity disorder in preschoolers and adults. International Review of Psychiatry 2008;20(2):143-9. [DOI: 10.1080/09540260801887751; PUBMED: 18386204]

\section{Voeller 2004}

Voeller KK. Attention-deficit hyperactivity disorder (ADHD). Journal of Child Neurology 2004;19(10):798-814. [DOI: 10.1177/08830738040190100901; PUBMED: 15559895]

\section{Volkow 1995}

Volkow ND, Ding Y, Fowler JS, Wang GJ, Logan J, Gatley JS, et al. Is methylphenidate like cocaine? Studies on their pharmacokinetics and distribution in the human brain. Archives of General Psychiatry 1995;52(6):456-63. [PUBMED: 7771915]

\section{Volkow 1998}

Volkow ND, Wang GJ, Fowler JS, Gatley SJ, Logan J, Ding YS, et al. Dopamine transporter occupancies in the human brain induced by therapeutic doses of oral methylphenidate. American Journal of Psychiatry 1998;155(10):1325-31. [DOI: 10.1176/ajp.155.10.1325; PUBMED: 9766762]

\section{Volkow 2002}

Volkow ND, Wang GJ, Fowler JS, Logan J, Franceschi D, Maynard L, et al. Relationship between blockade of dopamine transporters by oral methylphenidate and the increases in extracellular dopamine: therapeutic implications. Synapse 2002;143(3):181-7. [DOI: 10.1002/syn.10038; PUBMED: 11793423]

\section{Volkow 2003}

Volkow ND, Swanson JM. Variables that affect the clinical use and abuse of methylphenidate in the treatment of ADHD. American Journal of Psychiatry 2003;160(11):1990-18. [DOI: 10.1176/appi.ajp.160.11.1909; PUBMED: 14594733]

\section{Wang 2004}

Wang M, Vijayraghavan S, Goldman-Rakic PS. Selective D2 receptor actions on the functional circuitry of working memory. Science 2004;303(5659):853-6. [DOI: 10.1126/science.1091162; PUBMED: 14764884$]$

\section{Ward 1993}

Ward MF, Wender PH, Reimherr FW. The Wender Utah Rating Scale (WURS): an aid in the retrospective diagnosis of childhood attention deficit hyperactivity disorder. American Journal of Psychiatry 1993;150(6):885-90. [DOI: 10.1176/ajp.150.6.885; PUBMED: 8494063] 


\section{Waxmonsky 2005}

Waxmonsky JG. Nonstimulant therapies for attention-deficit hyperactivity disorder (ADHD) in children and adults. Essential Psychopharmacology 2005;6(5):262-76. [PUBMED: 16222911]

\section{Weissman 1999}

Weissman MM. Social Adjustment Scale - Self-report Technical Manual. Toronto (OT): Multi-Health Systems, 1999.

\section{Wender 2001}

Wender PH, Wolf LE, Wasserstein J. Adults with ADHD. An overview. Annals of the New York Academy of Sciences 2001;931:1-16. [PUBMED: 11462736]

\section{WHO 2011}

World Health Organization. International Statistical Classification of Diseases and Related Health Problems (ICD-10). Vol. 10th revision, WHO, 2010.

\section{Wilens 2004}

Wilens TE, Dodson W. A clinical perspective of attention-deficit/ hyperactivity disorder into adulthood. Journal of Clinical Psychiatry 2004;65(10):1301-13. [PUBMED: 15491232]

\section{Wilens 2006}

Wilens TE. Mechanism of action of agents used in attentiondeficit/hyperactivity disorder. Journal of Clinical Psychiatry 2006;67(Suppl 8):32-8. [PUBMED: 16961428]

\section{Wolraich 2004}

Wolraich ML, Doffing MA. Pharmacokinetic considerations in the treatment of attention-deficit hyperactivity disorder with methylphenidate. CNS Drugs 2004;18(4):243-50. [PUBMED: 15015904]

\section{Young 2006}

Young JL. Treatment of adult ADHD and comorbid disorders. CNS Spectrums 2006;11(S11):10-2. [DOI: 10.1017/ S1092852900025773]

\section{References to other published versions of this review Verbeeck 2011}

Verbeeck W, Bekkering GE, Van den Noortgate W. Bupropion for Attention Deficit Hyperactivity Disorder (ADHD) in adults. Cochrane Database of Systematic Reviews 2011, Issue 12. [DOI: 10.1002/14651858.CD009504; Art. No.: CD009504]

* Indicates the major publication for the study

\section{CHARACTERISTICS OF STUDIES}

Characteristics of included studies [ordered by study ID]

Hamedi 2014

Methods $\quad$ RCT with parallel groups, 1 site

Participants

Participants: Persons with a diagnosis of ADHD based on DSM-IV; age between 20 - 60 years

Setting: Outpatients who were referred to a psychiatrist for psychiatric evaluation

Study date: January 2013 - March 2014

Type of ADHD: Not reported

Comorbid psychiatric disorders: Not reported

Number randomised: 42 (bupropion 21; placebo 21)

Sex: $64 \%$ male

Mean (SD) age: Bupropion 33.9 (4.83) years; placebo 33.19 (4.0) years

Race: $100 \%$ Persian

Employment status: Not reported

Prior ADHD treatment (\% yes): Not reported

Prior treatment with stimulants (\% yes): Not reported

Interventions $\quad 6$ weeks of bupropion versus placebo

Dose bupropion: Average dose of $150 \mathrm{mg} /$ day 
Hamedi 2014 (Continued)

Adjunctive treatments: Not reported

\begin{tabular}{ll}
\hline Outcomes & 1. ADHD severity score \\
\hline Study funded by industry & No. Study funded by grant from Teheran University. \\
\hline Country & Iran \\
\hline
\end{tabular}

Inclusion criteria

Inclusion criteria

1. Diagnosis of ADHD based on DSM-IV

2. Aged between $20-60$ years

\section{Exclusion criteria}

1. People with chronic medical disease, including seizure, cardiovascular disease, CVA and organic brain disease

2. People with substance abuse or dependence during past 6 months

3. Nursing or pregnant women

4. People with a history of tic disorder; receiving of any psychotropics drugs during past 2 weeks; mental retardation; history of suicide attempt, psychosis or aggressiveness

5. People receiving psychotropic drugs; receiving psycho-stimulants or atomoxetine during past 3 months; bipolar disorder

Notes Unclear whether compliance was measured

\section{Risk of bias}

\begin{tabular}{|c|c|c|}
\hline Bias & Authors' judgement & Support for judgement \\
\hline $\begin{array}{l}\text { Random sequence genera- } \\
\text { tion (selection bias) }\end{array}$ & Unclear risk & $\begin{array}{l}\text { Quote: "the randomization and allocation process was accomplished by prin- } \\
\text { ciple investigator". }\end{array}$ \\
\hline $\begin{array}{l}\text { Allocation concealment } \\
\text { (selection bias) }\end{array}$ & Low risk & $\begin{array}{l}\text { Quote: "the assignments were kept in sealed, opaque envelopes until random- } \\
\text { ization". }\end{array}$ \\
\hline $\begin{array}{l}\text { Blinding of participants } \\
\text { and personnel (perfor- } \\
\text { mance bias) } \\
\text { All outcomes }\end{array}$ & Low risk & $\begin{array}{l}\text { Comment: All people involved in the study - the psychiatrist, the rater and the } \\
\text { participants - were blind to assignments }\end{array}$ \\
\hline Blinding of clinicians & Low risk & $\begin{array}{l}\text { Comment: All people involved in the study - the psychiatrist, the rater and the } \\
\text { participants - were blind to assignments }\end{array}$ \\
\hline $\begin{array}{l}\text { Blinding of outcome as- } \\
\text { sessment (detection bias) } \\
\text { All outcomes }\end{array}$ & Low risk & $\begin{array}{l}\text { Comment: All people involved in the study - the psychiatrist, the rater and the } \\
\text { participants - were blind to assignments }\end{array}$ \\
\hline $\begin{array}{l}\text { Incomplete outcome data } \\
\text { (attrition bias) } \\
\text { All outcomes }\end{array}$ & High risk & $\begin{array}{l}\text { Comment: No statement on numbers recruited and excluded. Only the num- } \\
\text { ber randomised was reported. The Discussion states that "The drug was not } \\
\text { well tolerated in some patients and these cases were dropped", suggesting } \\
\text { that the reason for missing data may be related to the study outcome }\end{array}$ \\
\hline $\begin{array}{l}\text { Selective reporting (re- } \\
\text { porting bias) }\end{array}$ & Unclear risk & $\begin{array}{l}\text { Comment: Protocol in trial registry reported only } 2 \text { outcomes. Also states that } \\
\text { "patients were also assessed by a psychiatrist at baseline and after } 14 \text { day pe- } \\
\text { riods up to } 6 \text { wks" but these results are not reported, and that participants had } \\
\text { their doses adjusted, but this was not reported }\end{array}$ \\
\hline
\end{tabular}


Kuperman 2001

\begin{tabular}{|c|c|}
\hline Methods & RCT with parallel groups, 1 site \\
\hline \multirow[t]{12}{*}{ Participants } & Participants: Adults with a diagnosis of ADHD \\
\hline & Setting: Recruited from community through newspaper advertisements \\
\hline & Study date: Not reported \\
\hline & Type of ADHD: Not reported \\
\hline & Comorbid psychiatric disorders: Not reported \\
\hline & Number randomised: 37 (bupropion 13; placebo 12; methylphenidate 12) \\
\hline & Sex: $70 \%$ male \\
\hline & Mean (SD) age: Bupropion 33.2 (10.8) years, placebo 32.2 (9.8) years \\
\hline & Race: Not reported \\
\hline & Employment status: Not reported \\
\hline & Prior ADHD treatment (\% yes): Not reported \\
\hline & Prior treatment with stimulants (\% yes): Not reported \\
\hline \multirow[t]{4}{*}{ Interventions } & 7 weeks of sustained-release bupropion versus methylphenidate versus placebo \\
\hline & Dose bupropion: Up to $300 \mathrm{mg} /$ day (200 mg given once, $100 \mathrm{mg}$ given once, 1 placebo pill) \\
\hline & Dose placebo: 3 pills/day \\
\hline & Adjunctive treatment: Unclear whether participants received adjunctive psychological interventions \\
\hline \multirow[t]{7}{*}{ Outcomes } & 1. ADHD severity score \\
\hline & $\begin{array}{l}\text { 2. Clinical Global Impression - Improvement (\% of participants achieving a score of } 1 \text { or } 2 \text { at study con- } \\
\text { clusion) }\end{array}$ \\
\hline & 3. Depressive symptoms \\
\hline & 4. Anxiety symptoms \\
\hline & 5. Number of participants withdrawn due to any adverse events \\
\hline & 6. Retention (\% of participants who completed the study) \\
\hline & 7. Other outcomes: Number of participants with at least 1 adverse effect \\
\hline
\end{tabular}

\begin{tabular}{ll}
\hline Study funded by industry & Yes (Glaxo Welcome) \\
\hline Country & USA \\
\hline
\end{tabular}

\section{Inclusion criteria Inclusion criteria}

1. Participants with diagnosis of ADHD

a. The presence of full DSM-IV criteria for a diagnosis of ADHD at the time of study entry

b. The presence of a chronic course of ADHD symptoms from childhood to adulthood

c. Endorsement of moderate or severe level of impairment attributed to the ADHD symptoms

2. Females of child-bearing potential had to use a medically approved form of contraception

\section{Exclusion criteria}

1. People with "clinically unstable psychiatric symptoms" 
Kuperman 2001 (Continued)

Notes
Medication logs, pill counts and blood level samples were used to assess compliance. The authors reported "All patients were compliant based on medication logs and pill counts. Furthermore, all patients who received an active medication were found to have detectable plasma levels at endpoint"

\section{Risk of bias}

\begin{tabular}{|c|c|c|}
\hline Bias & Authors' judgement & Support for judgement \\
\hline $\begin{array}{l}\text { Random sequence genera- } \\
\text { tion (selection bias) }\end{array}$ & Unclear risk & Comment: No statement made \\
\hline $\begin{array}{l}\text { Allocation concealment } \\
\text { (selection bias) }\end{array}$ & Unclear risk & Comment: No statement made \\
\hline $\begin{array}{l}\text { Blinding of participants } \\
\text { and personnel (perfor- } \\
\text { mance bias) } \\
\text { All outcomes }\end{array}$ & Unclear risk & $\begin{array}{l}\text { Comment: Participants in the bupropion group received an additional place- } \\
\text { bo tablet to maintain blinding }\end{array}$ \\
\hline Blinding of clinicians & Unclear risk & Comment: No statement made \\
\hline $\begin{array}{l}\text { Blinding of outcome as- } \\
\text { sessment (detection bias) } \\
\text { All outcomes }\end{array}$ & Unclear risk & Comment: No statement made \\
\hline $\begin{array}{l}\text { Incomplete outcome data } \\
\text { (attrition bias) } \\
\text { All outcomes }\end{array}$ & High risk & $\begin{array}{l}\text { Quote: "Outcome data were analyzed using a last observation forward ap- } \\
\text { proach for patients completing at least } 1 \text { week of double-blind treatment". } \\
\text { Comment: } 37 \text { participants were randomised. } 7 \text { participants were not included } \\
\text { in the analyses. Reasons for dropout were not reported by group }\end{array}$ \\
\hline $\begin{array}{l}\text { Selective reporting (re- } \\
\text { porting bias) }\end{array}$ & Unclear risk & $\begin{array}{l}\text { Comment: There was insufficient information to make a judgement as we } \\
\text { could not locate the protocol }\end{array}$ \\
\hline
\end{tabular}

Levin 2006

\begin{tabular}{ll}
\hline Methods & RCT with parallel groups, 6 sites \\
\hline
\end{tabular}

\section{Participants}

Participants: Opiate-dependent adults with ADHD

Setting: Recruited from 5 community-based, local methadone treatment programmes and 1 psychiatric institute

\section{Study date: Not reported \\ Type of ADHD: Not reported \\ Comorbid psychiatric disorders \\ 1. Bupropion: $18 \%$ affective disorder $(n=6) ; 18 \%$ anxiety disorder $(n=6)$ \\ 2. Placebo: $18 \%$ affective disorder $(n=6) ; 21 \%$ anxiety disorder $(n=7)$ \\ Current substance use disorders}

1. Bupropion: $15 \%$ alcohol $(n=5) ; 24 \%$ marijuana $(n=8) ; 54 \%$ cocaine $(n=18) ; 51 \%$ opiates $(n=17)$

2. Placebo: $15 \%$ alcohol $(n=5) ; 15 \%$ marijuana $(n=5) ; 64 \%$ cocaine $(n=21) ; 61 \%$ opiates $(n=20)$

Number randomised: 98 (bupropion 33; placebo 33; methylphenidate 32) 
Levin 2006 (Continued)
Sex: $56 \%$ male
Mean (SD) age: Bupropion 39 (8) years; placebo 38 (8) years

\section{Race}

1. Bupropion: $42 \%$ white; $39 \%$ Hispanic; $18 \%$ black

2. Placebo: $39 \%$ white; $39 \%$ Hispanic; $21 \%$ black

\section{Employment status:}

1. Bupropion: $57 \%$ unemployed

2. Placebo: $11 \%$ unemployed

Prior ADHD treatment (\% yes): Not reported

Prior treatment with stimulants (\% yes): Not reported

\begin{tabular}{l} 
Interventions \\
Dose bupropion: Up to $400 \mathrm{mg} /$ day \\
Adjunctive treatment: All participants received weekly individual cognitive behavioural therapy \\
\hline Outcomes \\
$\begin{array}{l}\text { 1. Achievement of significant clinical improvement (\% of participants achieving a significant improve- } \\
\text { ment) } \\
\text { 2. Clinical Global Impression - Improvement (\% of participants achieving a score of } 1 \text { or } 2 \text { at study con- } \\
\text { clusion) } \\
\text { 3. Number of participants withdrawn due to any adverse events } \\
\text { 4. Number of participants withdrawn due to any somatic event } \\
\text { 5. Number of participants withdrawn due to any psychiatric event } \\
\text { 6. Retention (\% of participants who completed the study) } \\
\text { 7. Other outcomes: Number of participants that lowered their dose due to adverse events }\end{array}$
\end{tabular}

Study funded by industry No, but authors are affiliated with Eli Lily and Company, Shire Pharmaceutical Group, and Ortho-McNeil Pharmaceutical Inc

\begin{tabular}{ll}
\hline Country & USA \\
\hline Inclusion criteria & Inclusion criteria \\
& $\begin{array}{l}\text { 1. To meet DSM-IV criteria for opiate dependence and adult ADHD } \\
\text { 2. To be between the age of } 18 \text { and } 60 \text { years } \\
\text { 3. To be on the same dose of methadone for at least } 3 \text { weeks }\end{array}$
\end{tabular}

\section{Exclusion criteria}

1. People were excluded if they met DSM-IV criteria for current psychiatric disorder (other than ADHD and substance abuse), which required psychiatric intervention

\begin{tabular}{ll}
\hline Notes & Compliance was measured using self-report. The authors reported " compliance was good: mean self- \\
reported missed doses was about $5 \%$ for all groups." Measurement of compliance via riboflavin was \\
0.83 for placebo and 0.91 for bupropion
\end{tabular}

\section{Risk of bias}

\begin{tabular}{lll}
\hline Bias & Authors' judgement & Support for judgement \\
\hline $\begin{array}{l}\text { Random sequence genera- } \\
\text { tion (selection bias) }\end{array}$ & Unclear risk & Comment: No statement made \\
\hline
\end{tabular}


Levin 2006 (Continued)

Allocation concealment Unclear risk Comment: No statement made
(selection bias)

\begin{tabular}{|c|c|c|}
\hline $\begin{array}{l}\text { Blinding of participants } \\
\text { and personnel (perfor- } \\
\text { mance bias) } \\
\text { All outcomes }\end{array}$ & Unclear risk & $\begin{array}{l}\text { Comment: A double-dummy method was used but no details were given that } \\
\text { suggested that these were identical in appearance. Folic acid was added to all } \\
\text { placebo capsules to improve the blind but no explanation was given on how } \\
\text { this would work }\end{array}$ \\
\hline
\end{tabular}

\begin{tabular}{lll}
\hline Blinding of clinicians & Unclear risk & Comment: No statement made \\
\hline $\begin{array}{l}\text { Blinding of outcome as- } \\
\text { sessment (detection bias) }\end{array}$ & Unclear risk & Comment: No statement made \\
All outcomes & \\
\hline
\end{tabular}

\begin{tabular}{|c|c|c|}
\hline $\begin{array}{l}\text { Incomplete outcome data } \\
\text { (attrition bias) } \\
\text { All outcomes }\end{array}$ & Unclear risk & $\begin{array}{l}\text { Quote: "all analyses were carried out on the intent-to-treat population". } \\
\text { Comment: The study had dropouts and the method of imputation was not de- } \\
\text { scribed. Also, although numbers of dropout and reasons for dropout were re- } \\
\text { ported, we rated this as unclear, as the numbers of dropouts were high and } \\
\text { not quite balanced. For bupropion } 10 / 33 \text { dropped out, for placebo } 8 / 33 \text {. Addi- } \\
\text { tionally, participants who could not tolerate a dose of at least } 200 \mathrm{mg} / \mathrm{day} \text { of } \\
\text { bupropion were discontinued }\end{array}$ \\
\hline
\end{tabular}

\begin{tabular}{|c|c|c|}
\hline $\begin{array}{l}\text { Selective reporting (re- } \\
\text { porting bias) }\end{array}$ & Unclear risk & $\begin{array}{l}\text { Comment: There was insufficient information to make a judgement as we } \\
\text { could not locate the protocol }\end{array}$ \\
\hline
\end{tabular}

Reimherr 2005

\begin{tabular}{ll}
\hline Methods & RCT with parallel groups, 1 site \\
\hline
\end{tabular}

Participants

Participants: Adults with a diagnosis of ADHD

Setting: Recruited from clinic participants, referrals, and a limited amount of public solicitations

Study date: Not reported

Type of ADHD: Not reported

Comorbid psychiatric disorders: None

Number randomised: 59 (bupropion 35; placebo 24)

Sex: $73 \%$ male

Mean (SD) age: 34.4 (13.4) years

Race: Not reported

Employment status: Not reported

Prior ADHD treatment (\% yes): Not reported

Prior treatment with stimulants (\% yes): Not reported

Interventions

6 weeks of sustained-release bupropion versus placebo

Dose bupropion: Up to $400 \mathrm{mg} /$ day (2 pills daily if $>200 \mathrm{mg}$ )

Adjunctive treatment: Unclear whether participants received adjunctive psychological interventions 
Reimherr 2005 (Continued)

Outcomes

1. Achievement of significant clinical improvement (\% of participants achieving a significant improvement)

2. ADHD severity score

3. Clinical Global Impression - Improvement (\% of participants achieving a score of 1 or 2 at study conclusion)

4. Global functioning score at study conclusion

5. Anxiety symptoms

6. Number of participants withdrawn due to any adverse events

7. Retention (\% of participants who completed the study)

Study funded by industry Yes (GlaxoSmithKline Inc.)

\begin{tabular}{ll}
\hline Country & USA \\
\hline Inclusion criteria & Inclusion criteria \\
1. At least 18 years \\
2. Meet DSM-IV criteria and Wender Utah criteria \\
3. Have minimum score of 15 on Wender-Reimherr Adult Attention Deficit Disorder Scale (WRAADDS) \\
4. At least moderate impairment on Weissman Social Adjustment Scale (WSAS)
\end{tabular}

\section{Exclusion criteria}

1. People with bipolar and depressive mood disorders

2. People with signs and symptoms of schizophrenic spectrum disorders, borderline personality disorder, and antisocial personality disorder

Notes Unclear whether compliance was measured

\section{Risk of bias}

Bias Authors' judgement Support for judgement

Random sequence genera- Unclear risk Comment: No statement made

tion (selection bias)

Allocation concealment $\quad$ Unclear risk $\quad$ Comment: No statement made
(selection bias)

\begin{tabular}{|c|c|c|}
\hline $\begin{array}{l}\text { Blinding of participants } \\
\text { and personnel (perfor- } \\
\text { mance bias) }\end{array}$ & Unclear risk & $\begin{array}{l}\text { Quote: "double-dummy-study" } \\
\text { Comment: No details were reported }\end{array}$ \\
\hline
\end{tabular}

\begin{tabular}{lll}
\hline Blinding of clinicians & Unclear risk & Comment: No statement made \\
\hline $\begin{array}{l}\text { Blinding of outcome as- } \\
\text { sessment (detection bias) }\end{array}$ & Unclear risk & Comment: No statement made \\
All outcomes & \\
\hline
\end{tabular}

\begin{tabular}{|c|c|c|}
\hline $\begin{array}{l}\text { Incomplete outcome data } \\
\text { (attrition bias) }\end{array}$ & High risk & $\begin{array}{l}\text { Quote: "all patients with at least one outcome measure during the dou- } \\
\text { ble-blind period were included". }\end{array}$ \\
\hline
\end{tabular}

All outcomes

Comment: 12 participants did not provide outcome data. The paper lacks details to determine whether there are any differences between groups regarding cause of dropout 
Reimherr 2005 (Continued)

Selective reporting (re- Unclear risk Quote: "there were no significant adverse events and medication was well tolporting bias)

erated".

Comment: No clear data on adverse effects

Wilens 2001

\begin{tabular}{|c|c|}
\hline Methods & RCT with parallel groups, 1 site \\
\hline \multirow[t]{18}{*}{ Participants } & Participants: Adult outpatients with ADHD \\
\hline & Setting: Recruited from advertisements and referrals to a psychopharmacology clinic \\
\hline & Study date: Not reported \\
\hline & Type of ADHD (not reported separately for the two groups) \\
\hline & 1. $58 \%$ inattentive subtype $(n=23)$ \\
\hline & 2. $35 \%$ combined $(n=14)$ \\
\hline & 3. $8 \%$ hyperactive/impulsive subtype $(n=3)$ \\
\hline & Comorbid psychiatric disorders \\
\hline & 1. $19 \%$ major depression ( $n=7$; bupropion 6 , placebo 1 ) \\
\hline & 2. $8 \%$ at least 2 anxiety disorders ( $n=3$; bupropion 1 , placebo 2 ) \\
\hline & 3. $49 \%$ any comorbid disorder ( $n=18$; bupropion 11 , placebo 7 ) (all current conditions) \\
\hline & Number randomised: 40 (bupropion 21; placebo 19) \\
\hline & Sex: $55 \%$ male \\
\hline & Mean (SD) age: $38.3(11.1)$ years \\
\hline & Race: Not reported \\
\hline & Employment status: Not reported \\
\hline & Prior ADHD treatment (\% yes): Not reported \\
\hline & Prior treatment with stimulants (\% yes): Not reported \\
\hline
\end{tabular}

Interventions

6 weeks of sustained-release bupropion versus placebo

Dose bupropion: Up to $400 \mathrm{mg} /$ day (2 times $200 \mathrm{mg} /$ day)

Adjunctive treatments: Unclear whether participants received adjunctive psychological interventions

Outcomes

1. Achievement of significant clinical improvement (\% of participants achieving a significant improvement)

2. ADHD severity score

3. Clinical Global Impression - Improvement (\% of participants achieving a score of 1 or 2 at study conclusion)

4. Depressive symptoms

5. Anxiety symptoms

6. Retention (\% of participants who completed the study)

7. Other outcomes: Number of participants that lowered their dose due to adverse effects, number of participants with at least 1 adverse effect 
Wilens 2001 (Continued)

Study funded by industry Yes (Glaxo Welcome Inc.)

\begin{tabular}{ll}
\hline Country & USA \\
\hline Inclusion criteria & Inclusion criteria \\
& $\begin{array}{l}\text { 1. Outpatient adults with ADHD } \\
\text { 2. Between } 20 \text { and } 59 \text { years of age }\end{array}$
\end{tabular}

\section{Exclusion criteria}

1. People with "clinically unstable psychiatric conditions" (e.g. bipolar disorder, drug or alcohol abuse/ dependence, current use of psychotropics or significant chronic medical conditions)

\begin{tabular}{lll}
\hline Notes & Compliance was measured using pill counting but no results were reported \\
\hline Risk of bias & \\
\hline Bias & Authors' judgement & Support for judgement \\
\hline $\begin{array}{l}\text { Random sequence genera- } \\
\text { tion (selection bias) }\end{array}$ & Unclear risk & Comment: No statement (“randomized” study) \\
\hline $\begin{array}{l}\text { Allocation concealment } \\
\text { (selection bias) }\end{array}$ & Unclear risk & Comment: No statement \\
\hline
\end{tabular}

Blinding of participants Low risk Quote: "weekly supplies of bupropion or placebo were dispensed by the pharand personnel (perfor- macy in identically appearing 100-mg capsules".

mance bias)

All outcomes

\begin{tabular}{lll}
\hline Blinding of clinicians & Unclear risk & Comment: No statement \\
\hline $\begin{array}{l}\text { Blinding of outcome as- } \\
\text { sessment (detection bias) } \\
\text { All outcomes }\end{array}$ & Unclear risk & Comment: No statement \\
\hline $\begin{array}{l}\text { Incomplete outcome data } \\
\text { (attrition bias) }\end{array}$ & High risk & $\begin{array}{l}\text { Quote: "40 were enrolled"; "we used the intent-to-treat method with the last } \\
\text { observation carried forward" }\end{array}$ \\
$\begin{array}{l}\text { All outcomes } \\
\text { Comment: Unclear how many participants were randomised. Data for some } \\
\text { variables were missing for up to 3 participants. 2 participants from the bupro- } \\
\text { pion group dropped out because of non-compliance }\end{array}$ \\
$\begin{array}{l}\text { Selective reporting (re- } \\
\text { porting bias) }\end{array}$ & Unclear risk & $\begin{array}{l}\text { Comment: Outcomes in the Methods section are reported in Results section, } \\
\text { but data on depression and anxiety are just reported as "no medication ef- } \\
\text { fects". We could not find a protocol for this study }\end{array}$ \\
\hline
\end{tabular}

Wilens 2005

\begin{tabular}{ll} 
Methods & RCT with parallel groups, 16 sites \\
\hline Participants & Participants: Adults with a diagnosis of ADHD \\
& Setting: Recruited from multi-centre outpatient clinics \\
& Study date: Not reported
\end{tabular}


Wilens 2005 (Continued)

\section{Type of ADHD}

1. Bupropion: $68 \%$ combined subtype $(n=55) ; 32 \%$ inattentive subtype $(n=16)$

2. Placebo: $58 \%$ combined subtype $(n=47) ; 42 \%$ inattentive subtype $(n=34)$

Comorbid psychiatric disorders: None

Number randomised: 162 (bupropion 81; placebo 81)

Sex: $60 \%$ male

Mean (SD) age: Bupropion 39.1 (10.3) years; placebo 41.4 (10.0) years

Race: $88 \%$ white, $4 \%$ American Hispanic, $1 \%$ Asian, $6 \%$ black, $1 \%$ other

Employment status: Not reported

Prior ADHD treatment (\% yes): Bupropion 47\%; placebo 39\%

Prior treatment with stimulants (\% yes): Bupropion 43\%; placebo $28 \%$

Interventions

8 weeks extended-release bupropion versus placebo

Dose bupropion: Up to $450 \mathrm{mg} /$ day

Adjunctive treatments: Unclear whether participants received adjunctive psychological interventions
Outcomes
1. Achievement of significant clinical improvement (\% of participants achieving a significant improve- ment)
2. ADHD severity score
3. Clinical Global Impression - Improvement (\% of participants achieving a score of 1 or 2 at study con- clusion)
4. Global functioning score at study conclusion
5. Depressive symptoms
6. Anxiety symptoms
7. Number of participants withdrawn due to any adverse events
8. Retention (\% of participants who completed the study)
9. Other outcomes: Number of participants with at least one adverse event

\begin{tabular}{ll}
\hline Study funded by industry & Yes (GlaxoSmithKline Inc.) \\
\hline Country & USA \\
\hline Inclusion criteria & Inclusion criteria \\
1. Between 18 and 60 years of age \\
2. Current diagnosis of ADHD as defined by the DSM-IV \\
3. Have met full DSM-IV criteria for a diagnosis of ADHD by age 7 with a chronic course of ADHD from \\
childhood to adulthood \\
4. Moderate-to-severe level of impairment due to symptoms of ADHD at the randomisation visit \\
5. Be in good general health based on physical and laboratory examinations and medical history \\
6. Premenopausal were required to use a reliable form of contraception
\end{tabular}

\section{Exclusion criteria}

1. People with a current diagnosis of major depressive disorder

2. People with a current or lifetime diagnosis of bipolar or psychotic disorders

3. People with a current primary diagnosis of panic disorder, obsessive-compulsive disorder, post-traumatic stress disorder or acute stress disorder 
Wilens 2005 (Continued)

4. People who met criteria for alcohol or substance abuse within the last year

Notes Compliance was assessed using pill counting. Compliance rates: Bupropion $98.9 \%$; placebo $99.8 \%$

\section{Risk of bias}

\begin{tabular}{|c|c|c|}
\hline Bias & Authors' judgement & Support for judgement \\
\hline $\begin{array}{l}\text { Random sequence genera- } \\
\text { tion (selection bias) }\end{array}$ & Unclear risk & Comment: No statement \\
\hline $\begin{array}{l}\text { Allocation concealment } \\
\text { (selection bias) }\end{array}$ & Unclear risk & Comment: No statement \\
\hline $\begin{array}{l}\text { Blinding of participants } \\
\text { and personnel (perfor- } \\
\text { mance bias) } \\
\text { All outcomes }\end{array}$ & Low risk & $\begin{array}{l}\text { Quote: "placebo tablets were identical in appearance to the active medica- } \\
\text { tion" }\end{array}$ \\
\hline Blinding of clinicians & Unclear risk & Comment: No statement \\
\hline $\begin{array}{l}\text { Blinding of outcome as- } \\
\text { sessment (detection bias) } \\
\text { All outcomes }\end{array}$ & Unclear risk & Comment: No statement \\
\hline $\begin{array}{l}\text { Incomplete outcome data } \\
\text { (attrition bias) } \\
\text { All outcomes }\end{array}$ & High risk & $\begin{array}{l}\text { Quote: "The intent-to-treat (ITT) population was comprised of all randomized } \\
\text { subjects who received at least } 1 \text { dose of investigational product and had inves- } \\
\text { tigator-rated ADHD Rating Scale assessment at randomization and on at least } \\
\text { one post-randomizatiob visit." } \\
\text { Comment: This suggests that only a subset of randomised participants were } \\
\text { analysed. } 16 \text { participants on bupropion and } 13 \text { on placebo withdrew. }\end{array}$ \\
\hline $\begin{array}{l}\text { Selective reporting (re- } \\
\text { porting bias) }\end{array}$ & Unclear risk & $\begin{array}{l}\text { Comment: The protocol also specifies that quality of life was measured (clini- } \\
\text { caltrials.gov/show/NCT00048360). However, this was a secondary outcome }\end{array}$ \\
\hline
\end{tabular}

ADHD: attention deficit hyperactivity disorder

DSM-IV: Diagnostic and Statistical Manual of Mental Disorders, Fourth Edition

ITT: intention-to-treat

LOCF: last observation carried forward

RCT: randomised controlled trial

SD: standard deviation

Characteristics of excluded studies [ordered by study ID]

\begin{tabular}{ll}
\hline Study & Reason for exclusion \\
\hline Clay 1988 & Not performed with adults \\
\hline
\end{tabular}

$\mathrm{RCT}$ : randomised controlled trial.

\section{DATA AND ANALYSES}




\section{Comparison 1. Bupropion versus placebo}

\begin{tabular}{|c|c|c|c|c|}
\hline Outcome or subgroup title & No. of studies & $\begin{array}{l}\text { No. of partici- } \\
\text { pants }\end{array}$ & Statistical method & Effect size \\
\hline 1 Severity of ADHD (at study completion) & 3 & 129 & $\begin{array}{l}\text { Std. Mean Difference (IV, } \\
\text { Fixed, } 95 \% \mathrm{CI} \text { ) }\end{array}$ & $\begin{array}{l}-0.50[-0.86 \\
-0.15]\end{array}$ \\
\hline $\begin{array}{l}2 \text { Achievement of significant clinical im- } \\
\text { provement (\% participants) }\end{array}$ & 4 & 315 & $\begin{array}{l}\text { Risk Ratio (M-H, Fixed, } \\
95 \% \mathrm{Cl})\end{array}$ & $1.50[1.13,1.99]$ \\
\hline $\begin{array}{l}3 \text { Clinical Global Impression (CGI) - Im- } \\
\text { provement scale (\% participants achieving } \\
\text { at least one or two on CGI) }\end{array}$ & 5 & 337 & $\begin{array}{l}\text { Risk Ratio (M-H, Fixed, } \\
95 \% \mathrm{Cl})\end{array}$ & $1.78[1.27,2.50]$ \\
\hline $\begin{array}{l}4 \text { Number of participants withdrawn due to } \\
\text { adverse events }\end{array}$ & 3 & 253 & $\begin{array}{l}\text { Risk Ratio (M-H, Fixed, } \\
95 \% \mathrm{Cl})\end{array}$ & $1.20[0.35,4.10]$ \\
\hline $\begin{array}{l}5 \text { Depressive symptoms (change from } \\
\text { baseline to study completion) }\end{array}$ & 2 & 184 & $\begin{array}{l}\text { Mean Difference (IV, } \\
\text { Fixed, } 95 \% \mathrm{Cl} \text { ) }\end{array}$ & $0.52[-0.46,1.51]$ \\
\hline $\begin{array}{l}6 \text { Anxiety symptoms (change from baseline } \\
\text { to study completion) }\end{array}$ & 2 & 184 & $\begin{array}{l}\text { Mean Difference (IV, } \\
\text { Fixed, } 95 \% \mathrm{CI} \text { ) }\end{array}$ & $0.36[-0.72,1.43]$ \\
\hline $\begin{array}{l}7 \text { Retention rate (number of patients com- } \\
\text { pleting study) }\end{array}$ & 5 & 352 & $\begin{array}{l}\text { Risk Ratio (M-H, Fixed, } \\
95 \% \mathrm{Cl})\end{array}$ & $0.96[0.87,1.06]$ \\
\hline $\begin{array}{l}8 \text { Number of participants that lowered } \\
\text { their dose due to adverse events }\end{array}$ & 2 & 104 & $\begin{array}{l}\text { Risk Ratio (M-H, Fixed, } \\
95 \% \mathrm{Cl})\end{array}$ & $1.86[0.57,6.10]$ \\
\hline $\begin{array}{l}9 \text { Number of participants with at least one } \\
\text { adverse event }\end{array}$ & 3 & 227 & $\begin{array}{l}\text { Risk Ratio (M-H, Fixed, } \\
95 \% \mathrm{Cl})\end{array}$ & $1.14[0.95,1.37]$ \\
\hline
\end{tabular}

Analysis 1.1. Comparison 1 Bupropion versus placebo, Outcome 1 Severity of ADHD (at study completion).

\begin{tabular}{|c|c|c|c|c|c|c|c|c|}
\hline \multirow{3}{*}{$\begin{array}{l}\text { Study or subgroup } \\
\text { Hamedi } 2014\end{array}$} & \multicolumn{2}{|c|}{ Bupropion } & \multicolumn{2}{|c|}{ Placebo } & \multirow{2}{*}{\multicolumn{2}{|c|}{$\begin{array}{c}\text { Std. Mean Difference } \\
\text { Fixed, } 95 \% \mathrm{Cl} \\
\end{array}$}} & \multirow{3}{*}{$\begin{array}{l}\text { Weight } \\
31.73 \%\end{array}$} & \multirow{3}{*}{$\begin{array}{c}\begin{array}{c}\text { Std. Mean Difference } \\
\text { Fixed, } \mathbf{9 5} \% \mathbf{~ C l}\end{array} \\
-0.81[-1.44,-0.18]\end{array}$} \\
\hline & \multirow{2}{*}{$\frac{\mathbf{N}}{21}$} & \multirow{2}{*}{$\frac{\text { Mean(SD) }}{23.7(15.3)}$} & \multirow{2}{*}{$\frac{\mathbf{N}}{21}$} & \multirow{2}{*}{$\frac{\operatorname{Mean}(\mathrm{SD})}{34.4(10.1)}$} & & & & \\
\hline & & & & & $\longrightarrow$ & & & \\
\hline Reimherr 2005 & 29 & $12.9(5.6)$ & 18 & $14.7(5.1)$ & 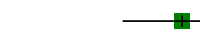 & - & $36.1 \%$ & $-0.33[-0.92,0.27]$ \\
\hline Wilens 2001 & 21 & $19.2(11)$ & 19 & $23.8(11.8)$ & $\longrightarrow$ & - & $32.17 \%$ & $-0.4[-1.02,0.23]$ \\
\hline 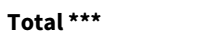 & 71 & & 58 & & & & $100 \%$ & $-0.5[-0.86,-0.15]$ \\
\hline \multicolumn{3}{|c|}{ Test for overall effect: $\mathrm{Z}=2.77(\mathrm{P}=0.01)$} & & & & & & \\
\hline & & & Favo & bupropion & -1 & 1 & Favours & ebo \\
\hline
\end{tabular}


Analysis 1.2. Comparison 1 Bupropion versus placebo, Outcome 2

Achievement of significant clinical improvement (\% participants).

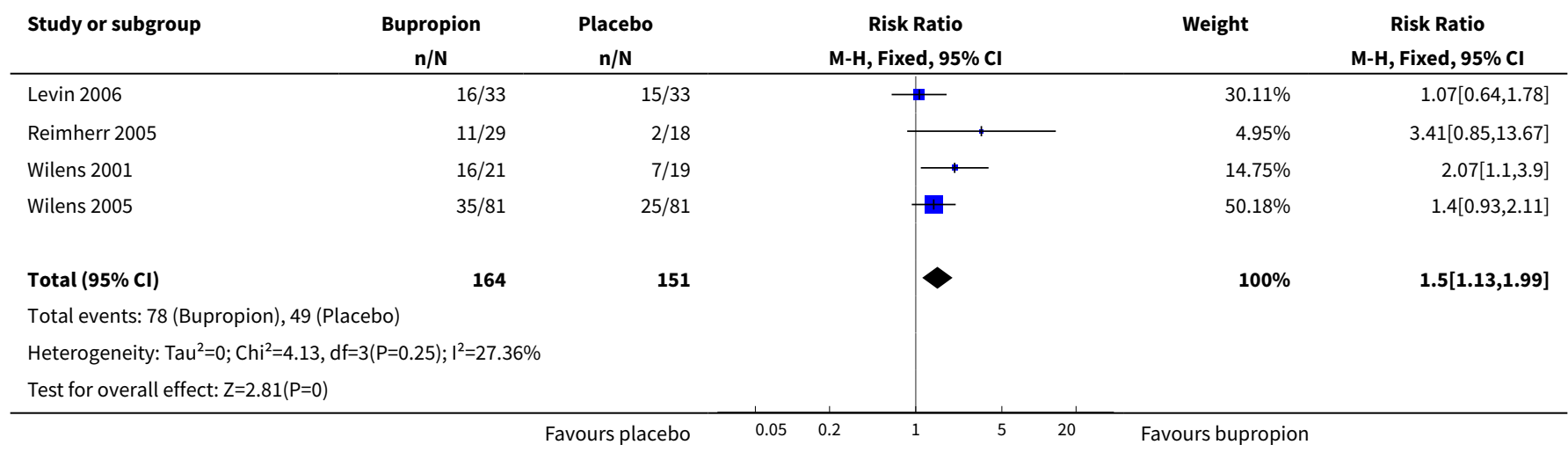

Analysis 1.3. Comparison 1 Bupropion versus placebo, Outcome 3 Clinical Global Impression (CGI) - Improvement scale (\% participants achieving at least one or two on CGI).

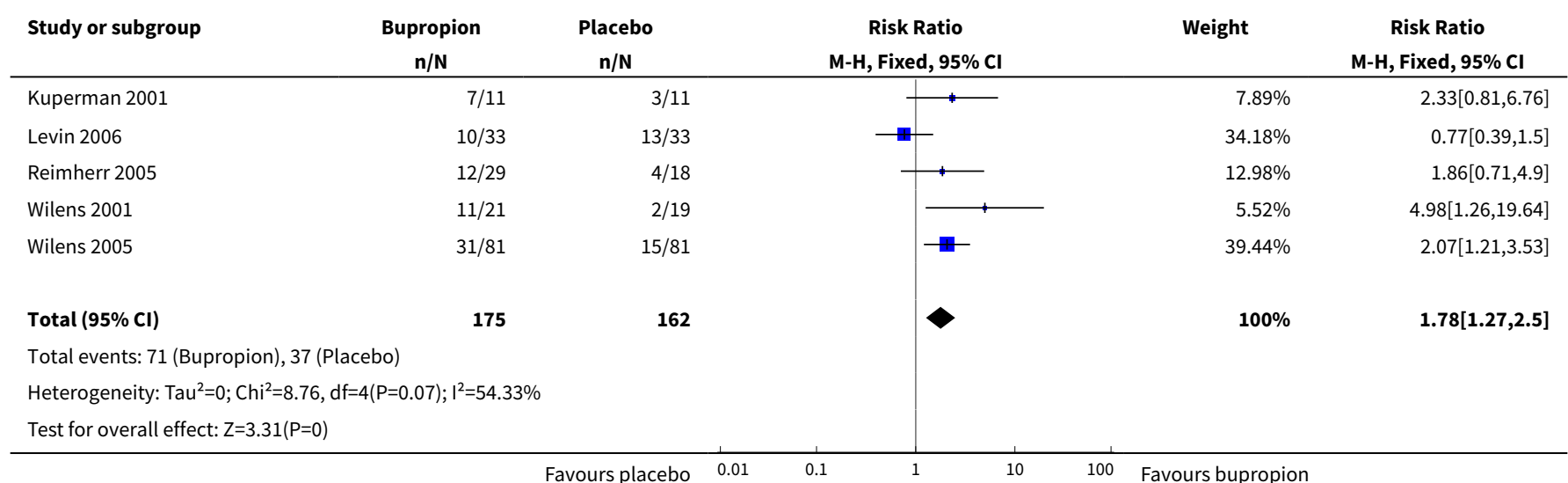

Analysis 1.4. Comparison 1 Bupropion versus placebo, Outcome 4 Number of participants withdrawn due to adverse events.

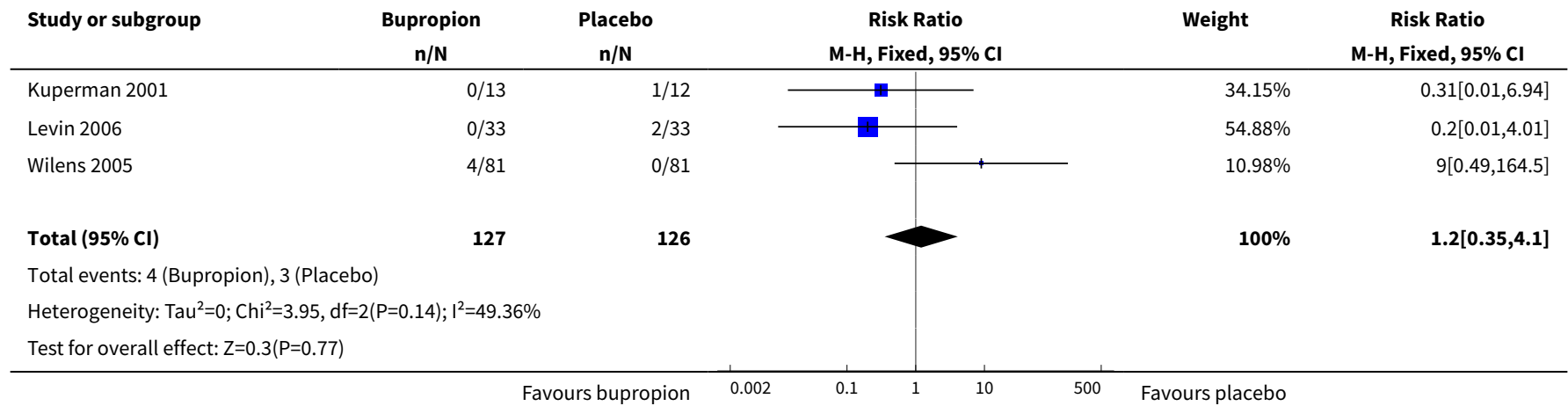


Analysis 1.5. Comparison 1 Bupropion versus placebo, Outcome 5

Depressive symptoms (change from baseline to study completion).

\begin{tabular}{|c|c|c|c|c|c|c|c|}
\hline \multirow[t]{2}{*}{ Study or subgroup } & \multicolumn{2}{|c|}{ Bupropion } & \multicolumn{2}{|c|}{ Placebo } & \multirow{2}{*}{$\begin{array}{c}\text { Mean Difference } \\
\text { Fixed, } 95 \% \mathrm{Cl} \\
\end{array}$} & \multirow[t]{2}{*}{ Weight } & \multirow{2}{*}{$\begin{array}{c}\text { Mean Difference } \\
\text { Fixed, } 95 \% \mathrm{Cl} \\
\end{array}$} \\
\hline & $\mathbf{N}$ & Mean(SD) & $\mathbf{N}$ & $\operatorname{Mean}(\mathrm{SD})$ & & & \\
\hline Kuperman 2001 & 11 & $-1.5(4.4)$ & 11 & $-2.9(3)$ & 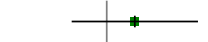 & $9.75 \%$ & $1.4[-1.75,4.55]$ \\
\hline Wilens 2005 & 81 & $0.3(3.1)$ & 81 & $-0.1(3.6)$ & & $90.25 \%$ & $0.43[-0.6,1.46]$ \\
\hline Total ${ }^{\star \star \star}$ & 92 & & 92 & & $>$ & $100 \%$ & $0.52[-0.46,1.51]$ \\
\hline \multicolumn{8}{|c|}{ Heterogeneity: Tau $^{2}=0 ; \mathrm{Chi}^{2}=0.33, \mathrm{df}=1(\mathrm{P}=0.57) ; I^{2}=0 \%$} \\
\hline Test for overall effect & & & & & & & \\
\hline
\end{tabular}

Analysis 1.6. Comparison 1 Bupropion versus placebo, Outcome 6 Anxiety symptoms (change from baseline to study completion).

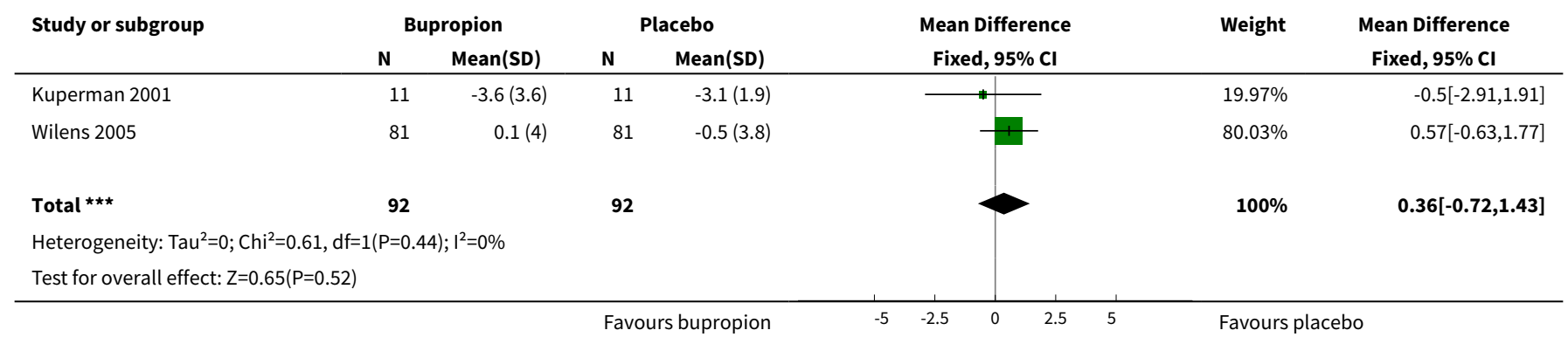

Analysis 1.7. Comparison 1 Bupropion versus placebo, Outcome 7 Retention rate (number of patients completing study).

\begin{tabular}{|c|c|c|c|c|c|}
\hline Study or subgroup & $\begin{array}{c}\text { Bupropion } \\
\mathrm{n} / \mathrm{N}\end{array}$ & $\begin{array}{c}\text { Placebo } \\
\mathrm{n} / \mathrm{N}\end{array}$ & $\begin{array}{c}\text { Risk Ratio } \\
\text { M-H, Fixed, } 95 \% \mathrm{Cl} \\
\end{array}$ & Weight & $\begin{array}{c}\text { Risk Ratio } \\
\text { M-H, Fixed, } 95 \% \mathrm{Cl} \\
\end{array}$ \\
\hline Wilens 2001 & $19 / 21$ & $19 / 19$ & + & $13.97 \%$ & $0.91[0.77,1.07]$ \\
\hline Levin 2006 & $23 / 33$ & $25 / 33$ & $\rightarrow$ & $17.1 \%$ & $0.92[0.68,1.24]$ \\
\hline Kuperman 2001 & $11 / 13$ & $11 / 12$ & $\rightarrow$ & $7.82 \%$ & $0.92[0.69,1.23]$ \\
\hline Wilens 2005 & $65 / 81$ & $68 / 81$ & \# & $46.5 \%$ & $0.96[0.83,1.1]$ \\
\hline Reimherr 2005 & 29/35 & $18 / 24$ & + & $14.6 \%$ & $1.1[0.84,1.46]$ \\
\hline Total $(95 \% \mathrm{Cl})$ & 183 & 169 & 1 & $100 \%$ & $0.96[0.87,1.06]$ \\
\hline \multicolumn{6}{|c|}{ Total events: 147 (Bupropion), 141 (Placebo) } \\
\hline \multicolumn{6}{|c|}{ Heterogeneity: $\mathrm{Tau}^{2}=0 ; \mathrm{Chi}^{2}=1.6, \mathrm{df}=4(\mathrm{P}=0.81) ; \mathrm{I}^{2}=0 \%$} \\
\hline Test for overall effect & & & & & \\
\hline
\end{tabular}


Analysis 1.8. Comparison 1 Bupropion versus placebo, Outcome 8 Number of participants that lowered their dose due to adverse events.

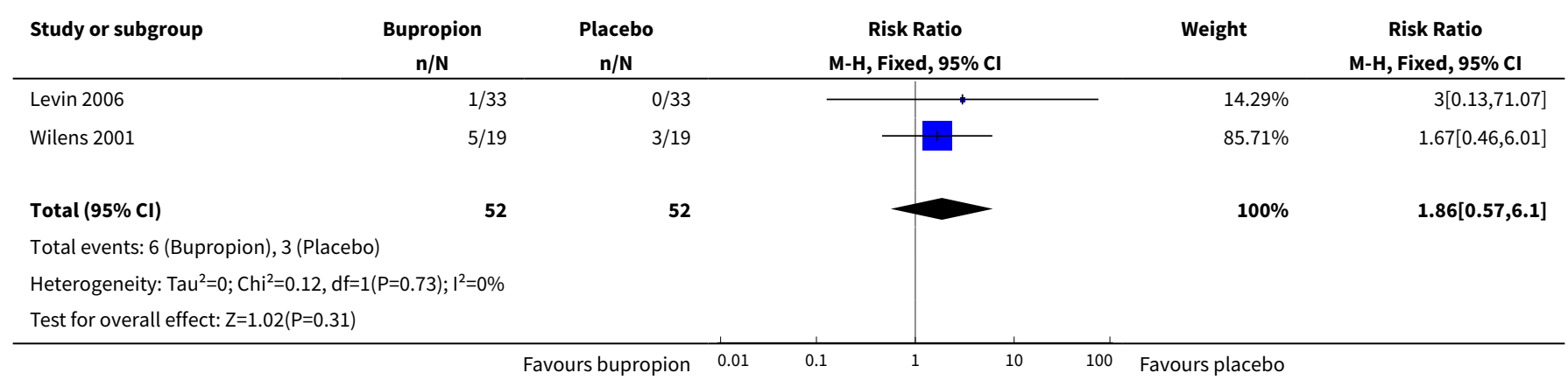

Analysis 1.9. Comparison 1 Bupropion versus placebo, Outcome 9 Number of participants with at least one adverse event.

\begin{tabular}{|c|c|c|c|c|c|}
\hline Study or subgroup & $\begin{array}{c}\text { Bupropion } \\
\mathrm{n} / \mathrm{N} \\
\end{array}$ & $\begin{array}{c}\text { Placebo } \\
\mathrm{n} / \mathrm{N}\end{array}$ & $\begin{array}{c}\text { Risk Ratio } \\
\text { M-H, Fixed, 95\% Cl }\end{array}$ & Weight & $\begin{array}{c}\text { Risk Ratio } \\
\text { M-H, Fixed, 95\% Cl }\end{array}$ \\
\hline Kuperman 2001 & $9 / 13$ & $8 / 12$ & $\longrightarrow$ & $11.58 \%$ & $1.04[0.61,1.78]$ \\
\hline Wilens 2001 & $14 / 21$ & $11 / 19$ & $\rightarrow$ & $16.07 \%$ & $1.15[0.71,1.88]$ \\
\hline Wilens 2005 & $60 / 81$ & $52 / 81$ & & $72.35 \%$ & $1.15[0.94,1.42]$ \\
\hline Total $(95 \% \mathrm{Cl})$ & 115 & 112 & $\vartheta$ & $100 \%$ & $1.14[0.95,1.37]$ \\
\hline \multicolumn{6}{|c|}{ Heterogeneity: $\mathrm{Tau}^{2}=0 ; \mathrm{Chi}^{2}=0.13, \mathrm{df}=2(\mathrm{P}=0.94) ; \mathrm{I}^{2}=0 \%$} \\
\hline Test for overall effect & & & & & \\
\hline
\end{tabular}

\section{Comparison 2. Bupropion versus placebo (sensitivity analyses)}

\begin{tabular}{|c|c|c|c|c|}
\hline Outcome or subgroup title & No. of studies & $\begin{array}{l}\text { No. of partici- } \\
\text { pants }\end{array}$ & Statistical method & Effect size \\
\hline $\begin{array}{l}1 \text { Severity of ADHD (at study completion) - clin- } \\
\text { ician rated }\end{array}$ & 2 & 87 & $\begin{array}{l}\text { Std. Mean Difference } \\
\text { (IV, Fixed, 95\% CI) }\end{array}$ & $-0.36[-0.79,0.07]$ \\
\hline $\begin{array}{l}2 \text { Severity if ADHD (at study completion) - stud- } \\
\text { ies that exclude psychiatric comorbidity }\end{array}$ & 2 & 89 & $\begin{array}{l}\text { Std. Mean Difference } \\
\text { (IV, Fixed, 95\% CI) }\end{array}$ & $\begin{array}{l}-0.55[-0.98 \\
-0.12]\end{array}$ \\
\hline $\begin{array}{l}3 \text { Achievement of significant clinical improve- } \\
\text { ment (\% participants) - studies that exclude } \\
\text { psychiatric comorbidity }\end{array}$ & 2 & 209 & $\begin{array}{l}\text { Risk Ratio }(\mathrm{M}-\mathrm{H} \text {, } \\
\text { Fixed, } 95 \% \mathrm{Cl})\end{array}$ & $1.58[1.06,2.35]$ \\
\hline $\begin{array}{l}4 \mathrm{CGI} \text { - Improvement (\% participants achiev- } \\
\text { ing at least one or two on CGI) - studies that ex- } \\
\text { clude psychiatric comorbidity }\end{array}$ & 3 & 231 & $\begin{array}{l}\text { Risk Ratio }(\mathrm{M}-\mathrm{H} \text {, } \\
\text { Fixed, } 95 \% \mathrm{Cl})\end{array}$ & $2.06[1.34,3.16]$ \\
\hline $\begin{array}{l}5 \text { Number of participants withdrawn due to ad- } \\
\text { verse events - studies that exclude psychiatric } \\
\text { comorbidity }\end{array}$ & 2 & 187 & $\begin{array}{l}\text { Risk Ratio }(\mathrm{M}-\mathrm{H} \text {, } \\
\text { Fixed, } 95 \% \mathrm{Cl})\end{array}$ & $2.42[0.49,12.01]$ \\
\hline
\end{tabular}


Analysis 2.1. Comparison 2 Bupropion versus placebo (sensitivity analyses), Outcome 1 Severity of ADHD (at study completion) - clinician rated.

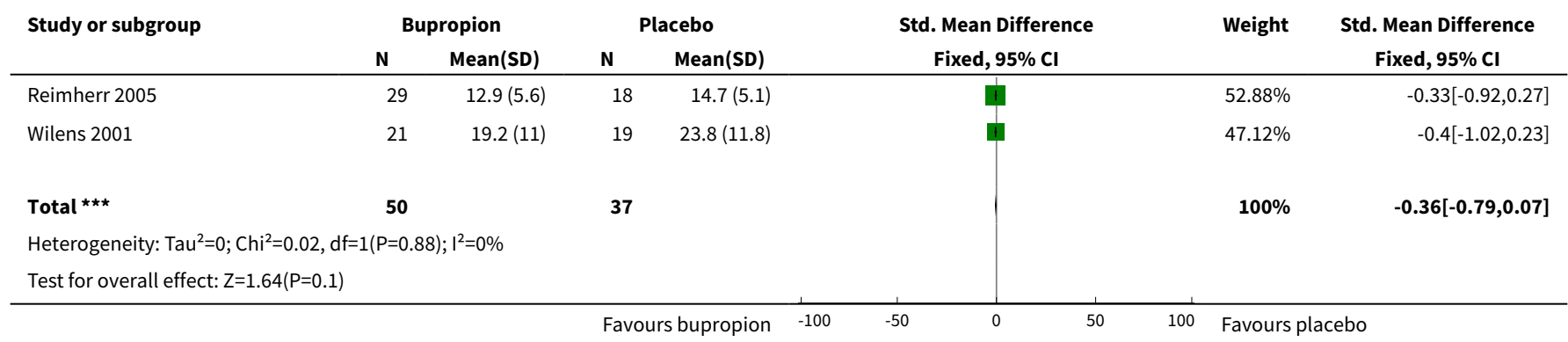

Analysis 2.2. Comparison 2 Bupropion versus placebo (sensitivity analyses), Outcome 2 Severity if ADHD (at study completion) - studies that exclude psychiatric comorbidity.

\begin{tabular}{|c|c|c|c|c|c|c|c|}
\hline \multirow{3}{*}{$\begin{array}{l}\text { Study or subgroup } \\
\text { Hamedi } 2014\end{array}$} & \multicolumn{2}{|c|}{ Bupropion } & \multicolumn{2}{|c|}{ Placebo } & \multirow{2}{*}{$\begin{array}{c}\text { Std. Mean Difference } \\
\text { Fixed, } 95 \% \mathrm{Cl}\end{array}$} & \multirow[t]{2}{*}{ Weight } & \multirow{2}{*}{$\begin{array}{c}\text { Std. Mean Difference } \\
\text { Fixed, } 95 \% \mathrm{Cl}\end{array}$} \\
\hline & $\mathbf{N}$ & $\operatorname{Mean}(\mathrm{SD})$ & $\mathbf{N}$ & Mean(SD) & & & \\
\hline & 21 & $23.7(15.3)$ & 21 & $34.4(10.1)$ & $\#$ & $46.78 \%$ & $-0.81[-1.44,-0.18]$ \\
\hline Reimherr 2005 & 29 & $12.9(5.6)$ & 18 & $14.7(5.1)$ & +1 & $53.22 \%$ & $-0.33[-0.92,0.27]$ \\
\hline 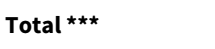 & 50 & & 39 & & 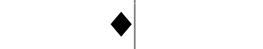 & $100 \%$ & $-0.55[-0.98,-0.12]$ \\
\hline \multicolumn{8}{|c|}{ Heterogeneity: Tau $^{2}=0 ; \mathrm{Chi}^{2}=1.2, \mathrm{df}=1(\mathrm{P}=0.27) ; \mathrm{I}^{2}=16.48 \%$} \\
\hline
\end{tabular}

\section{Analysis 2.3. Comparison 2 Bupropion versus placebo (sensitivity analyses), Outcome 3 Achievement} of significant clinical improvement (\% participants) - studies that exclude psychiatric comorbidity.

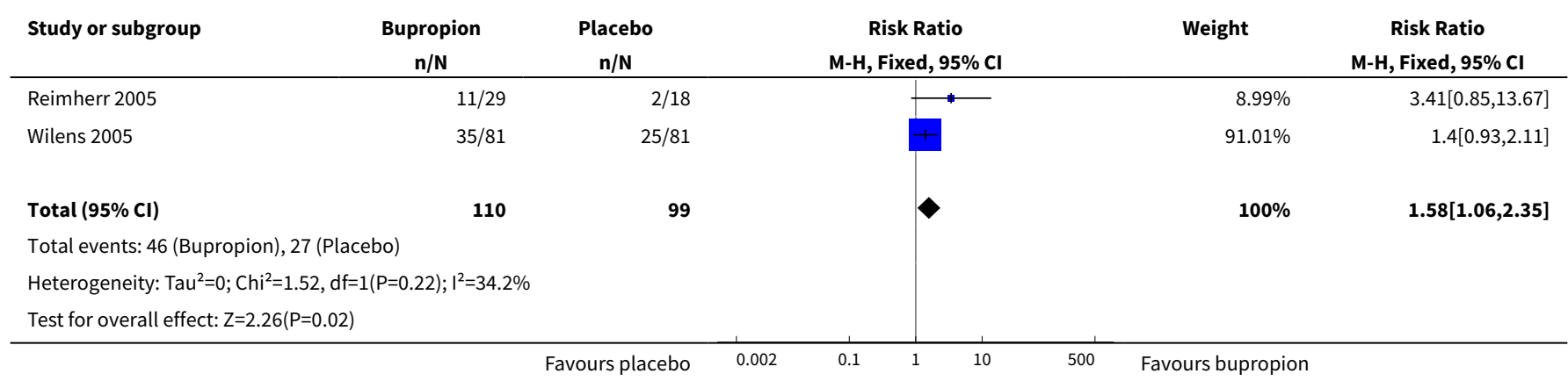


Analysis 2.4. Comparison 2 Bupropion versus placebo (sensitivity analyses), Outcome 4 CGI - Improvement (\% participants achieving at least one or two on CGI) - studies that exclude psychiatric comorbidity.

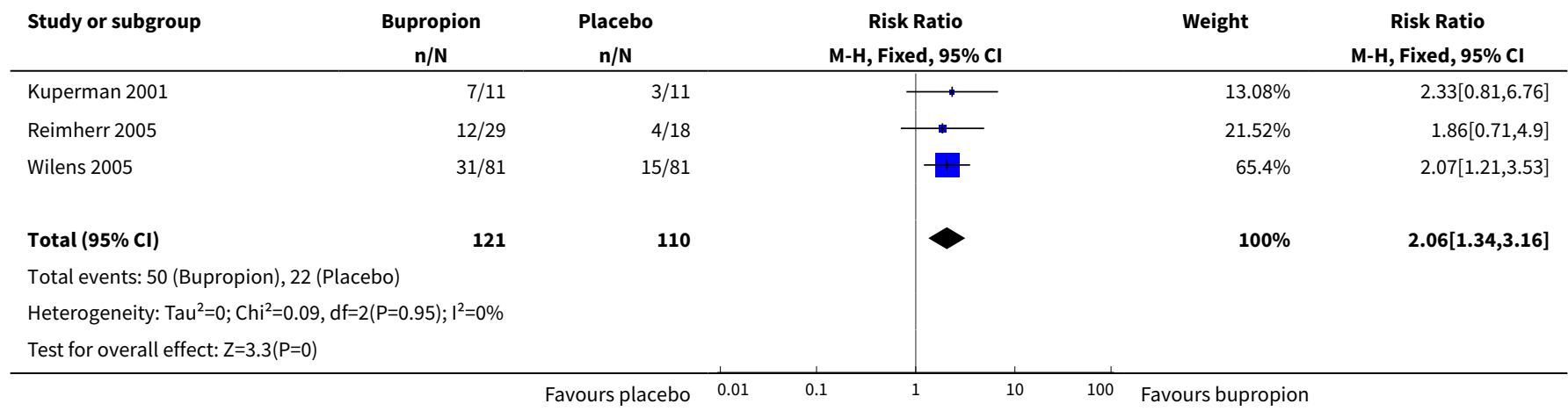

Analysis 2.5. Comparison 2 Bupropion versus placebo (sensitivity analyses), Outcome 5 Number of participants withdrawn due to adverse events - studies that exclude psychiatric comorbidity.

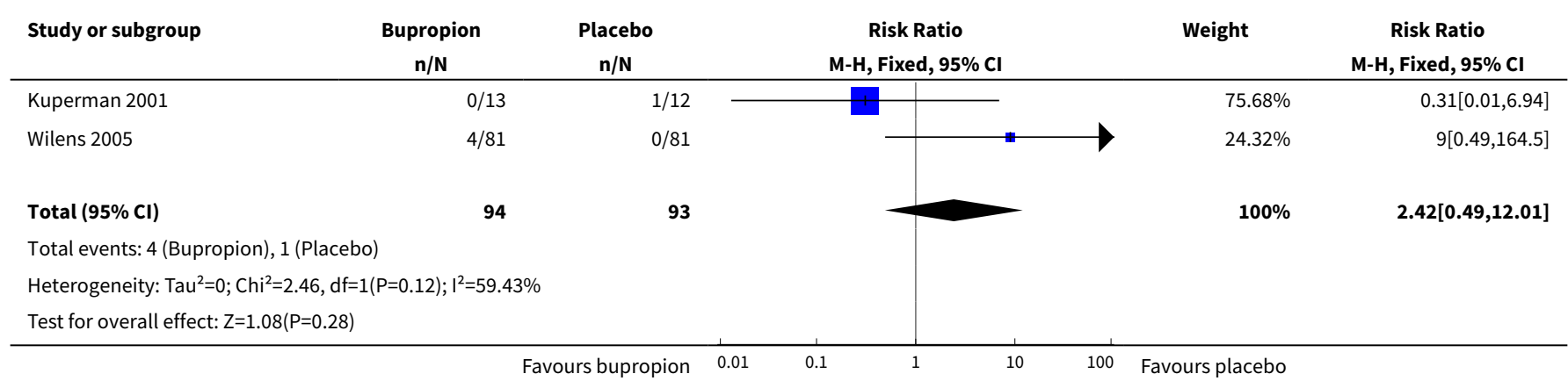

\section{ADDITIONAL TABLES}

Table 1. Methods archived for future updates of this review

\begin{tabular}{ll}
\hline Topic & Method \\
\hline Unit of analysis issues & $\begin{array}{l}\text { Cross-over trials } \\
\text { We will include cross-over trials. Given the risk of carry-over effects, we will use data from the first } \\
\text { period (before cross-over) only, and treat these as parallel-group trials. }\end{array}$ \\
\hline $\begin{array}{l}\text { Assessment of reporting bi- } \\
\text { ases }\end{array}$ & $\begin{array}{l}\text { We will produce funnel plots (estimated treatment effects against their standard error). We will test } \\
\text { funnel plot asymmetry when there are at least } 10 \text { studies included in the meta-analysis. Asymme- } \\
\text { try could be due to publication bias, but could also be due to a relationship between trial size and } \\
\text { effect size. In the event that we find a relationship, we will examine the clinical diversity of the stud- } \\
\text { ies, selection biases and poor methodological quality as alternative explanations to publication } \\
\text { bias. }\end{array}$
\end{tabular}

Subgroup analysis and inves- We will perform two subgroup analyses: tigation of heterogeneity

1. Type of drug release formulation: immediate release, sustained release and extended release.

2. Dose: above versus below median dose. 
Table 1. Methods archived for future updates of this review (Continued)

When there are more than 10 studies included in the analyses, we will investigate statistical heterogeneity using meta-regression (Deeks 2011).

Multiple time points

We will classify outcomes of all studies based on time of measurement from randomisation: acute (less than 24 hours), short-term (less than six weeks), medium-term (six weeks to six months), and long-term (more than six months). Within each time period, we will include the latest outcome in the meta-analysis.
We will conduct sensitivity analyses to determine whether findings are sensitive to restricting the analyses to studies judged to be at low risk of bias. In these analyses, we will restrict the analysis to the following:

1. Studies with low risk of selection bias (associated with sequence generation and allocation concealment).

2. Studies without financial support from the pharmaceutical industry.

3. Studies that used standardised instrument(s) to measure efficacy.

4. Studies without imputed data (see also 'Dealing with missing data').

Table 2. Results of individual studies

\begin{tabular}{|c|c|c|c|}
\hline Study ID & Outcome/scale & Results for bupropion & $\begin{array}{l}\text { Results for placebo ( } P \text { value for differ- } \\
\text { ence between groups) }\end{array}$ \\
\hline Kuperman 2001 & $\begin{array}{l}\text { Self-rated ADHD symp- } \\
\text { toms }\end{array}$ & -13.7 (SD 6.9) & $-12.4(S D 10.6)(P=0.69)$ \\
\hline Reimherr 2005 & Global level of functioning & $\begin{array}{l}\text { Mean final value at study comple- } \\
\text { tion } 57.5 \text { (SD 8.1) }\end{array}$ & $\begin{array}{l}\text { Mean final value at study completion } 56.2 \\
(S D \text { 3.6) }(P>0.05)\end{array}$ \\
\hline \multirow[t]{2}{*}{ Wilens 2005} & $\begin{array}{l}\text { ADHD Symptom Checklist } \\
\text { (DuPaul 1990) }\end{array}$ & $\begin{array}{l}\text { Mean difference from baseline } \\
-12.7\end{array}$ & Mean difference $-6.9(P<0.001)$ \\
\hline & Global level of functioning & $\begin{array}{l}\text { Mean change from baseline } 7.3 \\
\text { (SD 10.4) }\end{array}$ & $4.0(\mathrm{SD} 8.0)(P=0.035)$ \\
\hline
\end{tabular}

ADHD: attention deficit hyperactivity disorder

ID: identifier

SD: standard deviation.

Table 3. Results sensitivity analysis

\begin{tabular}{|c|c|c|c|c|}
\hline Outcome & Fixed-effect model & $\begin{array}{l}\text { Studies excluding psychiatric } \\
\text { comorbidity (fixed-effect mod- } \\
\text { el) }\end{array}$ & Random-effects model & $\begin{array}{l}\text { Studies using } \\
\text { clinician-rated } \\
\text { scales } \\
\text { (fixed-effect } \\
\text { model) }\end{array}$ \\
\hline $\begin{array}{l}\text { Severity of ADHD } \\
\text { symptoms }\end{array}$ & $\begin{array}{l}\text { SMD }-0.50(95 \% \mathrm{Cl}-0.86 \\
\text { to }-0.15), 129 \text { participants }\end{array}$ & $\begin{array}{l}\text { SMD }-0.55(95 \% \mathrm{Cl}-0.98 \text { to }-0.12) \text {, } \\
89 \text { participants }\end{array}$ & $\begin{array}{l}\text { SMD }-0.50(95 \% \mathrm{Cl}-0.86 \\
\text { to }-0.15), 129 \text { participants }\end{array}$ & $\begin{array}{l}\text { SMD }-0.36(95 \% \\
\mathrm{Cl}-0.79 \text { to } 0.07), \\
87 \text { participants }\end{array}$ \\
\hline $\begin{array}{l}\text { Proportion with } \\
\text { significant clini- } \\
\text { cal improvement }\end{array}$ & $\begin{array}{l}\mathrm{RR} 1.50 \text { ( } 95 \% \mathrm{Cl} 1.13 \text { to } \\
1.99), 315 \text { participants }\end{array}$ & $\begin{array}{l}\text { RR } 1.58 \text { ( } 95 \% \mathrm{Cl} 1.06 \text { to } 2.35), 209 \\
\text { participants }\end{array}$ & $\begin{array}{l}\text { RR } 1.48 \text { ( } 95 \% \mathrm{Cl} 1.05 \text { to } \\
2.11), 315 \text { participants }\end{array}$ & $\mathrm{N} / \mathrm{A}$ \\
\hline
\end{tabular}


Table 3. Results sensitivity analysis (Continued)

\begin{tabular}{|c|c|c|c|c|}
\hline $\begin{array}{l}\text { Proportion with } \\
\text { at least } 1 \text { or } 2 \text { on } \\
\text { CGI }\end{array}$ & $\begin{array}{l}\text { RR } 1.78 \text { (95\% CI } 1.27 \text { to } \\
2.50), 337 \text { participants }\end{array}$ & $\begin{array}{l}\text { RR } 2.06 \text { (95\% Cl } 1.34 \text { to } 3.16), 231 \\
\text { participants }\end{array}$ & $\begin{array}{l}\text { RR } 1.79 \text { (95\% CI } 1.02 \text { to } \\
3.14), 337 \text { participants }\end{array}$ & $\mathrm{N} / \mathrm{A}$ \\
\hline $\begin{array}{l}\text { Adverse events: } \\
\text { number of pa- } \\
\text { tients withdrawn }\end{array}$ & $\begin{array}{l}\text { RR } 1.20 \text { (95\% Cl } 0.35 \text { to } \\
4.10), 253 \text { participants }\end{array}$ & $\begin{array}{l}\mathrm{RR} 2.42 \text { ( } 95 \% \mathrm{Cl} 0.49 \text { to } 12.01) \text {, } \\
187 \text { participants }\end{array}$ & $\begin{array}{l}\text { RR } 0.85 \text { ( } 95 \% \mathrm{Cl} 0.07 \text { to } \\
9.77), 253 \text { participants }\end{array}$ & $\mathrm{N} / \mathrm{A}$ \\
\hline
\end{tabular}

ADHD: attention deficit hyperactivity disorder

CGI: Clinical Global Impression scale

$\mathrm{Cl}$ : confidence interval

N/A: not applicable

RR: risk ratio

SMD: standardised mean difference

\section{A P P E N D I CES}

\section{Appendix 1. Search strategies up to February 2017}

Cochrane Central Register of Controlled Trials (CENTRAL) in the Cochrane Library, which includes the Cochrane Developmental, Psychosocial and Learning Problems Specialised Register

\#1MeSH descriptor Attention Deficit and Disruptive Behavior Disorders explode all trees

\#2"ADHD or "ADDH" or "ADHS" or "ad/hd"

\#3((attention* or behav*) NEAR/3 (defic* or dysfunc* or disorder $\left.{ }^{\star}\right)$ )

\#4((disrupt ${ }^{\star}$ NEAR/3 disorder ${ }^{\star}$ ) or (disrupt ${ }^{\star}$ NEAR/3 behav ${ }^{\star}$ ) or (defian* NEAR/3 disorder ${ }^{\star}$ ) or (defian* NEAR/3 behav*))

\#5(impulsiv ${ }^{\star}$ or inattentiv ${ }^{\star}$ or inattention ${ }^{\star}$ )

\#6MeSH descriptor Hyperkinesis, this term only

\#7hyperkine*

\#8(minimal NEAR/3 brain NEAR/3 (disorder* or dysfunct* or damage*))

\#9hyperactiv ${ }^{\star}$

\#10(\#1 OR \#2 OR \#3 OR \#4 OR \#5 OR \#6 OR \#7 OR \#8 OR \#9)

$\# 11 \mathrm{MeSH}$ descriptor Propiophenones, this term only

$\# 12 \mathrm{MeSH}$ descriptor Antidepressive Agents, this term only

\#13MeSH descriptor Antidepressive Agents, Second-Generation, this term only

$\# 14 \mathrm{MeSH}$ descriptor Bupropion, this term only

\#15bupropion*

\#16amfebutamone*

$\# 17 z y b a{ }^{*}$

\#18wellbutrin*

$\# 19$ wellbatrin*

\#20quomem*

\#21zyntabac*

\#22radafaxine*

\#23((new or second) NEXT generation NEAR/3 (anti NEXT depress* or antidepress $\left.{ }^{\star}\right)$ )

\#24((atypical or a NEXT typical) NEXT (anti NEXT depress* or antidepress $\left.{ }^{\star}\right)$ )

\#25(\#11 OR \#12 OR \#13 OR \#14 OR \#15 OR \#16 OR \#17 OR \#18 OR \#19 OR \#20 OR \#21 OR \#22 OR \#23 OR \#24)

\#26(\#10 AND \#25)

\section{MEDLINE Ovid}

1 "attention deficit and disruptive behavior disorders"/ or attention deficit disorder with hyperactivity/ or conduct disorder/

2 ADHD.tw.

3 ADDH.tw.

4 ADHS.tw.

5 "AD/HD".tw.

6 ((attention\$ or behav\$) adj3 (defic $\$$ or dysfunc\$ or disorder\$)).tw.

7 ((disrupt\$ adj3 disorder\$) or (disrupt\$ adj3 behav\$) or (defian\$ adj3 disorder\$) or (defian\$ adj3 behav\$)).tw.

8 (impulsiv\$ or inattentiv\$ or inattention\$).tw. 
9 hyperkinesis/

10 hyperkine\$.tw.

11 (minimal adj3 brain adj3 (disorder\$ or dysfunct\$ or damage\$)).tw.

12 hyperactiv $\$$.tw.

13 or/1-12

14 Bupropion\$.tw.

15 Propiophenones/

16 Antidepressive Agents/

17 Antidepressive Agents, Second-Generation/

18 Bupropion/

19 bupropion\$.tw.

20 amfebutamone\$.tw.

21 zyban\$.tw.

22 wellbutrin $\$$.tw.

23 wellbatrin $\$ . t w$.

24 quomem\$.tw.

25 zyntabac\$.tw.

26 radafaxine $\$ . t w$.

27 ((new or second) adj generation adj3 (anti-depress\$ or antidepress\$)).tw.

28 ((atypical or a-typical) adj (anti-depress\$ or antidepress\$)).tw.

29 or/14-28

30 exp Adult/

31 Male/

32 female/

33 (adult\$ or man or men or woman or women or female\$ or male\$).tw.

34 or/30-33

35 randomized controlled trial.pt.

36 controlled clinical trial.pt.

37 randomi\#ed.ab.

38 placebo\$.ab.

39 drug therapy.fs.

40 randomly.ab.

41 trial.ab.

42 groups.ab.

43 or/35-42

44 exp animals/ not humans.sh.

4543 not 44

4613 and 29 and 34 and 45

\section{MEDLINE Ovid In-Process \& Other Non-Indexed Citations}

1 ((attention\$ or behav\$) adj3 (defic $\$$ or dysfunc $\$$ or disorder $\$)$ ).tw.

2 ((disrupt\$ adj3 disorder\$) or (disrupt\$ adj3 behav\$) or (defian\$ adj3 disorder\$) or (defian\$ adj3 behav\$)).tw.

3 (impulsiv\$ or inattentiv\$ or inattention\$).tw.

4 hyperkine\$.tw.

5 (minimal adj3 brain adj3 (disorder\$ or dysfunct\$ or damage\$)).tw.

6 hyperactiv\$.tw.

7 ADHD.tw.

8 ADDH.tw.

9 ADHS.tw.

10 "AD/HD".tw.

11 conduct disorders.tw.

121 or 2 or 3 or 4 or 5 or 6 or 7 or 8 or 9 or 10 or 11

13 bupropion\$.tw.

14 ((new or second) adj generation adj3 (anti-depress\$ or antidepress\$)).tw.

15 ((atypical or a-typical) adj (anti-depress\$ or antidepress\$)).tw.

16 amfebutamone\$.tw.

17 zyban\$.tw.

18 wellbutrin $\$$.tw.

19 wellbatrin\$.tw.

20 quomem\$.tw.

21 zyntabac\$.tw. 
22 radafaxine\$.tw.

23 or/13-22

2412 and 23

25 (random\$ or trial\$ or control\$ or group\$ or placebo $\$$ or blind\$ or prospectiv\$ or longditud\$ or meta-analys\$ or systematic review).tw. 2624 and 25

\section{MEDLINE Ovid Epub Ahead of Print}

1 ((attention\$ or behav\$) adj3 (defic\$ or dysfunc\$ or disorder\$)).tw.

2 ((disrupt\$ adj3 disorder\$) or (disrupt\$ adj3 behav\$) or (defian\$ adj3 disorder\$) or (defian\$ adj3 behav\$)).tw.

3 (impulsiv\$ or inattentiv\$ or inattention\$).tw.

4 hyperkine\$.tw.

5 (minimal adj3 brain adj3 (disorder\$ or dysfunct\$ or damage\$)).tw.

6 hyperactiv\$.tw.

7 ADHD.tw.

8 ADDH.tw.

9 ADHS.tw.

10 "AD/HD".tw.

11 conduct disorder\$.tw.

121 or 2 or 3 or 4 or 5 or 6 or 7 or 8 or 9 or 10 or 11

13 bupropion\$.tw.

14 ((new or second) adj generation adj3 (anti-depress\$ or antidepress\$)).tw.

15 ((atypical or a-typical) adj (anti-depress $\$$ or antidepress $\$)$ ).tw.

16 amfebutamone\$.tw.

17 zyban\$.tw.

18 wellbutrin\$.tw.

19 wellbatrin $\$ . t w$.

20 quomem\$.tw.

21 zyntabac\$.tw.

22 radafaxine\$.tw.

23 or/13-22

2412 and 23

25 (random $\$$ or trial\$ or control\$ or group\$ or placebo $\$$ or blind $\$$ or prospectiv\$ or longditud\$ or meta-analys\$ or systematic review).tw. 2624 and 25

\section{Embase Ovid}

1 attention deficit disorder/

2 hyperactivity/

3 conduct disorder/

4 ADHD.tw.

5 ADDH.tw.

6 ADHS.tw.

7 "AD/HD".tw.

8 ((attention\$ or behav\$) adj3 (defic $\$$ or dysfunc $\$$ or disorder\$)).tw.

9 ((disrupt\$ adj3 disorder\$) or (disrupt\$ adj3 behav\$) or (defian\$ adj3 disorder\$) or (defian\$ adj3 behav\$)).tw.

10 (impulsiv\$ or inattentiv\$ or inattention\$).tw.

11 hyperkine\$.tw.

12 (minimal adj3 brain adj3 (disorder\$ or dysfunct\$ or damage\$)).tw.

13 hyperactiv\$.tw.

14 or/1-13

15 amfebutamone/

16 amfebutamone\$.tw.

17 bupropion\$.tw.

18 propiophenone derivative/

19 Propiophenones.tw.

20 zyban\$.tw.

21 wellbutrin $\$ . t w$.

22 wellbatrin $\$ . t w$.

23 quomem\$.tw.

24 zyntabac\$.tw.

25 radafaxine/

26 radafaxine\$.tw. 
27 antidepressant agent/

28 ((new or second) adj generation adj3 (anti-depress\$ or antidepress\$)).tw.

29 ((atypical or a-typical) adj (anti-depress\$ or antidepress\$)).tw.

30 or/15-29

31 adult/

32 male/

33 female/

34 (adult\$ or man or men or woman or women or female\$ or male\$).tw.

35 or/31-34

36 exp Clinical trial/

37 Randomized controlled trial/

38 Randomization/

39 Single blind procedure/

40 Double blind procedure/

41 Crossover procedure/

42 Placebo/

43 Randomi\#ed.tw.

44 RCT.tw.

45 (random\$ adj3 (allocat\$ or assign\$)).tw.

46 randomly.ab.

47 groups.ab.

48 trial.ab.

49 ((singl\$ or doubl\$ or trebl\$ or tripl\$) adj3 (blind\$ or mask\$)).tw.

50 Placebo\$.tw.

51 Prospective study/

52 (crossover or cross-over).tw.

53 prospective.tw.

54 or/36-53

5514 and 30 and 35 and 54

\section{PsycINFO Ovid}

1 exp attention deficit disorder with hyperactivity/

2 hyperkinesis/

3 conduct disorder/

4 ADHD.tw.

5 ADDH.tw.

6 ADHS.tw.

7 "AD/HD".tw.

8 ((attention\$ or behav\$) adj3 (defic\$ or dysfunc\$ or disorder\$)).tw.

9 ((disrupt\$ adj3 disorder\$) or (disrupt\$ adj3 behav\$) or (defian\$ adj3 disorder\$) or (defian\$ adj3 behav\$)).tw.

10 (impulsiv\$ or inattentiv\$ or inattention\$).tw.

11 hyperkine\$.tw.

12 hyperactiv\$.tw.

13 (minimal adj3 brain adj3 (disorder\$ or dysfunct\$ or damage\$)).tw.

14 or/1-13

15 bupropion/

16 bupropion\$.tw.

17 Propiophenones.tw.

18 zyban\$.tw.

19 quomem\$.tw.

20 wellbatrin\$.tw.

21 wellbutrin $\$ . t w$.

22 zyntabac\$.tw.

23 radafaxine\$.tw.

24 Antidepressant Drugs/

25 amfebutamone\$.tw.

26 ((new or second) adj generation adj3 (anti-depress\$ or antidepress\$)).tw.

27 ((atypical or a-typical) adj (anti-depress $\$$ or antidepress $\$)$ ).tw.

28 or $/ 15-27$

2914 and 28

30 clinical trials/ 
31 (randomis* or randomiz $^{\star}$ ).tw.

32 (random\$ adj3 (allocat\$ or assign\$)).tw.

33 ((clinic\$ or control\$) adj trial\$).tw.

34 ((singl\$ or doubl\$ or trebl\$ or tripl\$) adj3 (blind\$ or mask\$)).tw.

35 (crossover\$ or "cross over\$").tw.

36 random sampling/

37 Experiment Controls/

38 Placebo/

39 placebo\$.tw.

40 exp program evaluation/

41 treatment effectiveness evaluation/

42 ((effectiveness or evaluat\$) adj3 (stud\$ or research\$)).tw.

43 or $/ 30-42$

4414 and 28 and 43

\section{CINAHL Plus EBSCOhost (Cumulative Index to Nursing and Allied Health Literature)}

\section{S44 S29 and S43}

$\mathrm{S} 43 \mathrm{~S} 30$ or S31 or S32 or S33 or S34 or S35 or S36 or S37 or S38 or S39 or S40 or S41 or $\mathrm{S} 42$

S42 placebo*

S41 crossover* or "cross over"

S40 (MH "Crossover Design")

S39 $\left(\right.$ tripl $^{\star}$ N3 mask $\left.^{\star}\right)$ or (tripl ${ }^{\star}$ N3 blind $\left.{ }^{\star}\right)$

S38 (trebl* N3 mask*) or (trebl* N3 blind*)

S37 (doubl* N3 mask*) or (doubl* N3 blind*)

S36 (singl ${ }^{\star}$ N3 mask $\left.^{\star}\right)$ or (singl ${ }^{\star}$ N3 blind $\left.{ }^{\star}\right)$

S35 (clinic* N3 trial ${ }^{\star}$ ) or (control ${ }^{\star} \mathrm{N} 3$ trial $^{\star}$ )

S34 (random* N3 allocat ${ }^{\star}$ ) or (random* N3 assign*)

S33 randomis* or randomiz ${ }^{*}$

S32 (MH "Meta Analysis")

S31 (MH "Clinical Trials+")

$\mathrm{S} 30 \mathrm{MH}$ random assignment

S29 S13 and S28

$\mathrm{S} 28 \mathrm{~S} 14$ or $\mathrm{S} 15$ or $\mathrm{S} 16$ or $\mathrm{S} 17$ or $\mathrm{S} 18$ or $\mathrm{S} 19$ or S20 or S21 or S22 or S23 or S24 or S25 or S26 or S27

S27 ((atypical or a-typical) N1 (anti-depress* or antidepress $\left.{ }^{\star}\right)$ )

S26 ((new or second) N1 generation N3 (anti-depress ${ }^{\star}$ or antidepress $\left.{ }^{\star}\right)$ )

S25 (MH "Antidepressive Agents")

S24 (MH "Antidepressive Agents, Second Generation")

S23 radafaxine*

S22 zyntabac*

S21 quomem*

S20 wellbatrin*

S19 wellbutrin*

S18 zyban*

S17 amfebutamone*

S16 bupropion*

S15 Propiophenon*

S14 (MH "Bupropion")

$\mathrm{S} 13 \mathrm{~S} 1$ or $\mathrm{S} 2$ or $\mathrm{S} 3$ or $\mathrm{S} 4$ or $\mathrm{S} 5$ or $\mathrm{S} 6$ or $\mathrm{S} 7$ or $\mathrm{S} 8$ or $\mathrm{S} 9$ or $\mathrm{S} 10$ or $\mathrm{S} 11$ or $\mathrm{S} 12$

S12 hyperactiv*

S11 (minimal N3 brain N3 (disorder* or dysfunct* or damage $\left.^{\star}\right)$ )

S10 hyperkine*

S9 (MH "Hyperkinesis")

S8 (impulsiv* or inattentiv* or inattention*)

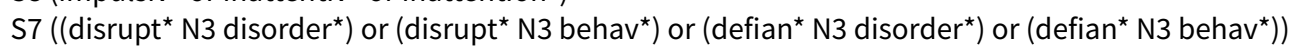

S6 ((attention* or behav $\left.{ }^{\star}\right)$ n3 (defic* or dysfunc ${ }^{\star}$ or disorder $\left.{ }^{\star}\right)$ )

S5 "AD/HD"

S4 ADHS

S3 ADDH

S2 ADHD

S1 (MH "Attention Deficit Hyperactivity Disorder") 
Science Citation Index - EXPANDED (SCI-EXPANDED); Social Sciences Citation Index (SSCI); Conference Proceedings Citation Index - Science (CPCI-S); Conference Proceedings Citation Index - Social Science \& Humanities (CPCI-SSH) Web of Science

12 \#11 AND \#10 AND \#9

DocType=All document types; Language=All languages; \#11 \#8 OR \#7 OR \#6

DocType=All document types; Language=All languages; \#10 \#5 OR \#4 OR \#3 OR \#2 OR \#1

DocType=All document types; Language=All languages;

\#9 TS=(random ${ }^{\star}$ or control ${ }^{\star}$ or trial ${ }^{\star}$ or groups or effectiveness or evaluation or placebo $\left.{ }^{\star}\right)$

DocType=All document types; Language=All languages;

\#8 TS=("second generation antidepressant*" or "second generation antidepressant*" or "new anti-depressant" or "new antidepressant")

DocType=All document types; Language=All languages;

\#7 TS=("atypical antidepressant*" or "a-typical antidepressant*" or "atypical anti-depressant*" or "a-typical anti-depressant*")

DocType=All document types; Language=All languages;

\#6 TS=(Bupropion ${ }^{\star}$ or amfebutamone* or zyban $^{\star}$ or wellbutrin* ${ }^{\star}$ or wellbatrin ${ }^{\star}$ or quomem ${ }^{\star}$ or zyntabac ${ }^{\star}$ or radafaxine $\left.{ }^{\star}\right)$

DocType=All document types; Language=All languages;

\#5 TS=("minimal brain disorder*")

DocType=All document types; Language=All languages;

\#4 TS= (impulsiv* or inattentiv* or inattention* or hyperactiv* or hyperkine*)

DocType=All document types; Language=All languages;

\#3 TS= ((disrupt ${ }^{\star}$ NEAR/3 disorder*) or (disrupt* NEAR/3 behav*) or (defian* NEAR/3 disorder $\left.{ }^{\star}\right)$ or (defian* NEAR/3 behav*))

DocType=All document types; Language=All languages;

\#2 TS= ((attention* or behav*) NEAR/3 (defic* or dysfunc ${ }^{\star}$ or disorder $\left.\left.{ }^{\star}\right)\right)$

DocType=All document types; Language=All languages;

\#1 TS=("ADHD" or "ADDH" or "ADHS" or "AD/HD")

DocType=All document types; Language=All languages

LILACS (Latin American and Caribbean Health Science Information database)

(bases.bireme.br)

Mh "attention deficit disorder with hyperactivity" or Mh "attention deficit hyperactivity disorder" [Words] or HYPERACTIV\$ OR HYPERKIN \$ OR IMPULSIV\$ OR INATTENT\$ OR HYPERKINE\$ OR ADHD OR ADDH OR ADHS OR "ad/HD" [Words] and Mh BUPROPION OR Tw bupropion \$ OR Tw amfebutamone\$ OR Tw zyban\$ or tw wellburin\$ or Tw wellbatrin\$ or Tw quomem\$ or Tw zyntabac OR Tw radafaxine\$ OR Mh Antidepressive Agents or Mh Antidepressive Agents, Second-Generation [Words]

\section{WorldCat}

(worldcat.org)

'kw:bupropion kw:adhd or hyperactiv*' > 'Thesis/dissertation'

metaRegister of Controlled Trials (mRCT)

(controlled-trials.com)

bupropion AND (ADHD OR hyperactiv*)

World Health Organization International Clinical Trials Registry Platform (WHO ICTRP)

(apps.who.int/trialsearch/Default.aspx)

(ADHD OR hyperactive OR "attention deficit") AND (bupropion)

\section{ClinicalTrials.gov}

(clinicaltrials.gov)

(ADHD OR hyperactive OR "attention deficit") AND (bupropion) | Adult

\section{Nederlands Trials Register}

(trialregister.nl/trialreg/index.asp)

ADHD AND bupropion 
Networked Digital Library of Theses and Dissertations (NDLTD)

(ndltd.org)

ADHD AND bupropion

DART Europe E-theses Portal

(dart-europe.eu/basic-search.php)

bupropion AND ADHD

Appendix 2. Data to be extracted from included studies

Study description and funding

1. Author.

2. Year of publication.

3. Country of study.

4. Authors affiliated with pharmaceutical industry (yes, no, unclear).

5. Study funded by industry (yes, no, unclear).

6. Study ID.

7. Source of data (report, correspondence with authors, individual participant data (IPD)).

ID: identifier.

\section{Methods}

1. Adequate sequence generation (yes, no, unclear).

2. Adequate allocation concealment (yes, no, unclear).

3. Adequate blinding of participants/clinicians/therapists/assessors (yes, no, unclear).

4. Incomplete outcome data (yes, no, unclear).

5. Selective outcome reporting (yes, no, unclear).

6. Design (cross-over/parallel groups; single/multi-site).

7. Were comorbid psychiatric disorders an exclusion criterion? (yes, no, unclear).

8. Duration of intervention (from randomisation to treatment completion).

9. Number of participants randomised.

10.Was an intention-to-treat (ITT) analysis performed? (yes, no, unclear).

\section{Participants}

1. Inclusion/exclusion criteria (NR).

2. Gender (\% male) (NR).

3. Age (mean, standard deviation (SD)) (NR).

4. Race (\% white) (NR).

5. Setting: primary care, specialised ADHD clinic (NR).

6. Employment status (\% unemployed/per group) (NR).

7. Prior ADHD treatment (yes/no), with psychostimulants (yes/no) (NR).

8. Type of ADHD (\% with inattentive subtype, $\%$ hyperactive/impulsive subtype, $\%$ combined subtype/per group) (NR).

9. Comorbid conditions (\% with comorbid psychiatric disorders/per group) (NR).

ADHD: attention deficit hyperactivity disorder.

NR: not reported.

\section{Intervention}

1. Number of participants randomised.

2. Number of participants analysed.

3. Type of bupropion (sustained release, extended release, regular).

4. Dose (mean, SD).

5. Was compliance assessed? (yes, no, unclear).

6. Was compliance adequate? (yes, no, unclear).

Bupropion for attention deficit hyperactivity disorder (ADHD) in adults (Review)

Copyright (c) 2017 The Cochrane Collaboration. Published by John Wiley \& Sons, Ltd. 
7. Were adjunctive psychological interventions, including coaching, provided? (yes, no, unclear).

SD: standard deviation.

\section{Control}

1. Number of participants randomised.

2. Number of participants analysed.

3. Type of treatment (placebo, no treatment, treatment as usual).

4. Description of treatment.

5. Were adjunctive psychological interventions, including coaching, provided? (yes, no, unclear).

\section{Outcomes}

1. Achievement of significant clinical improvement (\% of participants achieving a significant improvement).

2. Severity of ADHD score.

3. Clinical Global Impression (CGI) (\% participants achieving at least a CGI of one or two at study conclusion).

4. CGI - Improvement (\% of participants achieving a CGI - Improvement score of one or two at study conclusion).

5. Global functioning (mean, SD) score at study conclusion.

6. Depressive symptoms assessed by standardised instrument (mean, SD).

7. Anxiety symptoms assessed by standardised instrument (mean, SD).

8. Number of participants withdrawn due to adverse events (number of participants withdrawn due to any adverse event, \% participants withdrawn due to any somatic event, \% of participants withdrawn due to any psychiatric event).

9. Retention (\% of participants who completed the study).

10.Severity of side effects (mean SD score at study completion).

ADHD: attention deficit hyperactivity disorder.

SD: standard deviation.

\section{Results}

Number of participants allocated to each group.

Record the following for each outcome of interest.

1. Sample size.

2. Missing participants.

3. Summary data for each intervention group ( $2 \times 2$ table for dichotomous data; means and SDs for continuous data).

4. Subgroup analysis (type of drug release formulation (immediate, sustained release, extended release); dose: above versus below median dose).

SD: standard deviation.

\section{Miscellaneous}

1. Correspondence required.

Appendix 3. Search summary

\begin{tabular}{llll}
\hline Database & $\begin{array}{l}\text { Search } \\
\text { date }\end{array}$ & $\begin{array}{l}\text { Database date, } \\
\text { range or issue }\end{array}$ & $\begin{array}{l}\text { Number of } \\
\text { records }\end{array}$ \\
\hline $\begin{array}{l}\text { Cochrane Central Register of Con- } \\
\text { trolled Trials (CENTRAL) in the } \\
\text { Cochrane Library }\end{array}$ & 10 January 2012 & 2011 Issue 4 & 80 \\
\cline { 2 - 4 } & 26 September 2014 & 2014 Issue 8 (of 12) & 9 \\
\cline { 2 - 4 } & 10 November 2015 & 2015 Issue 10 (of 12) & 7 \\
\cline { 2 - 4 } & 20 February 2017 & 2017 Issue 1 January & 12 \\
\hline
\end{tabular}


(Continued)

MEDLINE Ovid

\begin{tabular}{llc}
09 January 2012 & 1948 to Dec Week 4 2011 & 388 \\
\hline 26 September 2014 & 1946 to Sept Week 3 2014 & 38 \\
\hline 10 November 2015 & 1946 to October Week 5 2015 & 36 \\
\hline 20 February 2017 & $\begin{array}{l}1946 \text { to February Week 5 } \\
2015\end{array}$ & 44
\end{tabular}

MEDLINE Ovid In-Process \& Other Non- $\quad 20$ February $2017 \quad$ February 17, 2017

Indexed Citations

\begin{tabular}{|c|c|c|c|}
\hline MEDLINE Ovid Epub Ahead of Print & 20 February 2017 & February 17, 2017 & 4 \\
\hline \multirow[t]{4}{*}{ Embase Ovid } & 09 January 2012 & 1980 to 2012 Week 01 & 581 \\
\hline & 26 September 2014 & 1980 to 2014 Week 38 & 169 \\
\hline & 10 November 2015 & 1980 to 2015 Week 45 & 75 \\
\hline & 20 February 2017 & 1980 to 2017 Week 08 & 146 \\
\hline \multirow[t]{4}{*}{ PsycINFO Ovid } & 09 January 2012 & 1806 to Jan Week 12012 & 104 \\
\hline & 26 September 2014 & 1806 to Sept Week 42014 & 1 \\
\hline & 10 November 2015 & 1806 to Nov Week 12015 & 10 \\
\hline & 20 February 2017 & $\begin{array}{l}1806 \text { to February Week } 2 \\
2017\end{array}$ & 9 \\
\hline \multirow{4}{*}{$\begin{array}{l}\text { CINAHL EBSCOhost (Cumulative index } \\
\text { to nursing and allied health literature) }\end{array}$} & 09 January 2012 & 1937 to current & 54 \\
\hline & 29 September 2014 & 1937 to current & 12 \\
\hline & 10 November 2015 & 1937 to current & 5 \\
\hline & 21 February 2017 & 1937 to current & 5 \\
\hline \multirow{4}{*}{$\begin{array}{l}\text { Science Citation Index - EXPANDED } \\
\text { Web of Science (SCI) }\end{array}$} & 09 January 2012 & 1970 to 6 January 2012 & 132 \\
\hline & 29 September 2014 & 1970 to 26 September 2014 & 27 \\
\hline & 11 November 2015 & 1970 to 10 November 2015 & 15 \\
\hline & 21 February 2017 & 1970 to 20 February 2017 & 13 \\
\hline \multirow{4}{*}{$\begin{array}{l}\text { Social Sciences Citation Index Web of } \\
\text { Science (SSCI) }\end{array}$} & 09 January 2012 & 1970 to 6 January 2012 & 102 \\
\hline & 29 September 2014 & 1970 to 26 September 2014 & 15 \\
\hline & 11 November 2015 & 1970 to 10 November 2015 & 11 \\
\hline & 21 February 2017 & 1970 to 20 February 2017 & 10 \\
\hline $\begin{array}{l}\text { Conference Proceedings Citation Index } \\
\text { - Science Web of Science (CPCI-S) }\end{array}$ & 09 January 2012 & 1990 to 6 January 2012 & 22 \\
\hline
\end{tabular}


(Continued)

\begin{tabular}{|c|c|c|c|}
\hline & 29 September 2014 & 1990 to 26 September 2014 & 1 \\
\hline & 11 November 2015 & 1990 to 10 November 2015 & 1 \\
\hline & 21 February 2017 & 1990 to 20 February 2017 & 0 \\
\hline Conference Proceedings Citation Index & 09 January 2012 & 1990 to 6 January 2012 & 11 \\
\hline Science (CPCI-SS\&H) & 29 September 2014 & 1990 to 26 September 2014 & 0 \\
\hline & 11 November 2015 & 1990 to 10 November 2015 & 0 \\
\hline & 21 February 2017 & 1990 to 20 February 2017 & 0 \\
\hline LILACS (Latin American and Caribbean & 10 January 2012 & - & 19 \\
\hline bases.bireme.br) & 29 September 2014 & - & 1 \\
\hline & 12 November 2015 & - & 0 \\
\hline & 21 February 2017 & - & 1 \\
\hline WorldCat (worldcat.org) & 10 January 2012 & - & 0 \\
\hline & 29 September 2014 & - & 0 \\
\hline & 12 November 2015 & - & 1 \\
\hline & 21 February 2017 & - & 0 \\
\hline metaRegister (mRCT; controlled-tri- & 10 January 2012 & - & 31 \\
\hline search in 2015 and 2017) & 02 October 2014 & - & 0 \\
\hline World Health Organization Interna- & 12 November 2015 & - & 10 \\
\hline $\begin{array}{l}\text { form (WHO ICTRP; apps.who.int/tri- } \\
\text { alsearch/Default.aspx) }\end{array}$ & 21 February 2017 & - & 0 \\
\hline ClinicalTrials.gov (clinicaltrials.gov) & 10 January 2012 & - & 7 \\
\hline & 02 October 2014 & - & 4 \\
\hline & 12 November 2015 & - & 6 \\
\hline & 21 February 2017 & - & 0 \\
\hline Netherlands Trials Register (trialregis- & 10 January 2012 & - & 0 \\
\hline & 02 October 2014 & - & 0 \\
\hline & 12 November 2015 & - & 0 \\
\hline & 21 February 2017 & - & 0 \\
\hline $\begin{array}{l}\text { Networked Digital Library of Theses } \\
\text { and Dissertations (NDLTD; ndltd.org) }\end{array}$ & 10 January 2012 & - & 0 \\
\hline
\end{tabular}




\begin{tabular}{|c|c|c|c|}
\hline & 02 October 2014 & - & 0 \\
\hline & 12 February 2015 & - & 1 \\
\hline & 21 February 2017 & - & 0 \\
\hline DART-Europe E-theses Portal (dart-eu- & 10 January 2012 & - & 0 \\
\hline & 02 October 2014 & - & 0 \\
\hline & 12 November 2015 & - & 0 \\
\hline & 21 February 2017 & - & 0 \\
\hline Total database records & & & 2235 \\
\hline
\end{tabular}

\section{CONTRIBUTIONS OF AUTHORS}

Wim Verbeeck: first review author, led all stages of the review and is the guarantor for the review. Geertruida E Bekkering: second review author, provided methodological and statistical support. Wim Van den Noortgate: third review author, contributed methodological and statistical support. Cornelis Kramers: fourth review author, contributed to the final draft of the manuscript.

\section{DECLARATIONS OF INTEREST}

Wim Verbeeck - none known.

Geertruida E Bekkering - none known.

Wim Van den Noortgate - none known.

Cornelis Kramers - none known.

\section{SOURCES OF SUPPORT}

\section{Internal sources}

- CEBAM, Cochrane Belgium, Leuven, Belgium.

Salary for Geertruida E Bekkering

- Department of Pharmacology and Toxicology, Radboud University Medical Centre, Nijmegen, Netherlands.

Salary for Cornelis Kramers

- Vincent van Gogh Institute for Psychiatry, Centre for Autism and ADHD, Venray, Netherlands.

Salary for Wim Verbeeck

- Faculty of Psychology and Educational Sciences, Katholieke Universiteit Leuven, Leuven, Belgium.

Salary for Wim Van den Noortgate

\section{External sources}

- None, Other.

\section{DIFFERENCES BETWEEN PROTOCOL AND REVIEW}

Please also see our protocol (Verbeeck 2011), and Table 1.

1. Methods. Data collection and analysis. 'Summary of findings' table. At the request of the editorial base, we added a new section on the "Summary of findings' table', beneath Data synthesis in the Methods section.

2. Methods. Data collection and analysis. Sensitivity analysis. We performed an additional post hoc sensitivity analysis in which we assessed the impact of choosing the fixed-effect model for our meta-analyses. By examining the results of both the fixed-effect and 
the random-effects models, we attempted to evaluate the impact of the clinical heterogeneity, and have more balanced weights for all trials in the meta-analysis.

3. Results. Effects of interventions. Other adverse effect outcomes. As adverse events were sparsely reported in the studies, we added post hoc analyses on the retention rate, the number of participants that lowered their dose due to adverse events, and the number of participants with at least one adverse event.

\section{NDEX TERMS}

\section{Medical Subject Headings (MeSH)}

Attention Deficit Disorder with Hyperactivity [ ${ }^{*}$ drug therapy]; Bupropion [administration \& dosage] [adverse effects] [*therapeutic use]; Central Nervous System Stimulants [administration \& dosage] [adverse effects] [^therapeutic use]; Delayed-Action Preparations; Off-Label Use; Patient Dropouts [statistics \& numerical data]; Randomized Controlled Trials as Topic; Severity of Illness Index; Treatment Outcome

\section{MeSH check words}

Adult; Female; Humans; Male 